University of South Florida

DIGITAL COMMONS

@ UNIVERSITY OF SOUTH FLORIDA
Digital Commons @ University of

South Florida

10-1-2002

\title{
APTS Needs Assessment for Sarasota County Area Transit
}

CUTR

Follow this and additional works at: https://digitalcommons.usf.edu/cutr_nctr

\section{Scholar Commons Citation}

CUTR, "APTS Needs Assessment for Sarasota County Area Transit" (2002). Research Reports. 218.

https://digitalcommons.usf.edu/cutr_nctr/218

This Technical Report is brought to you for free and open access by the National Center for Transit Research (NCTR) Archive (2000-2020) at Digital Commons @ University of South Florida. It has been accepted for inclusion in Research Reports by an authorized administrator of Digital Commons @ University of South Florida. For more information, please contact digitalcommons@usf.edu. 

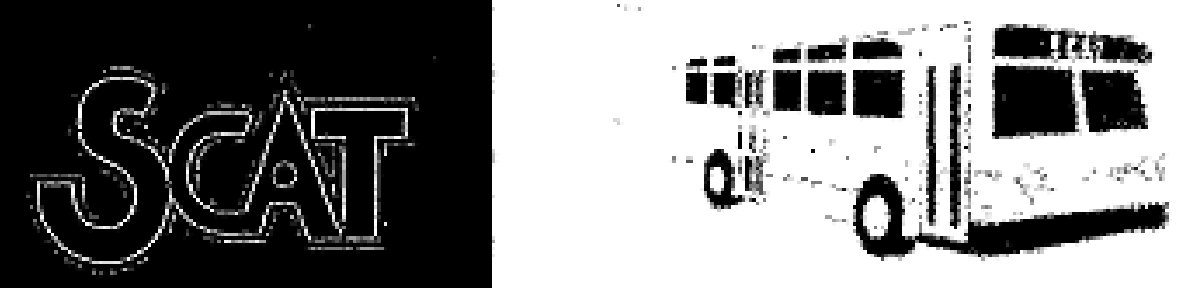

\section{APTS Needs Assessment for Sarasota County Area Transit} Sinal Repow

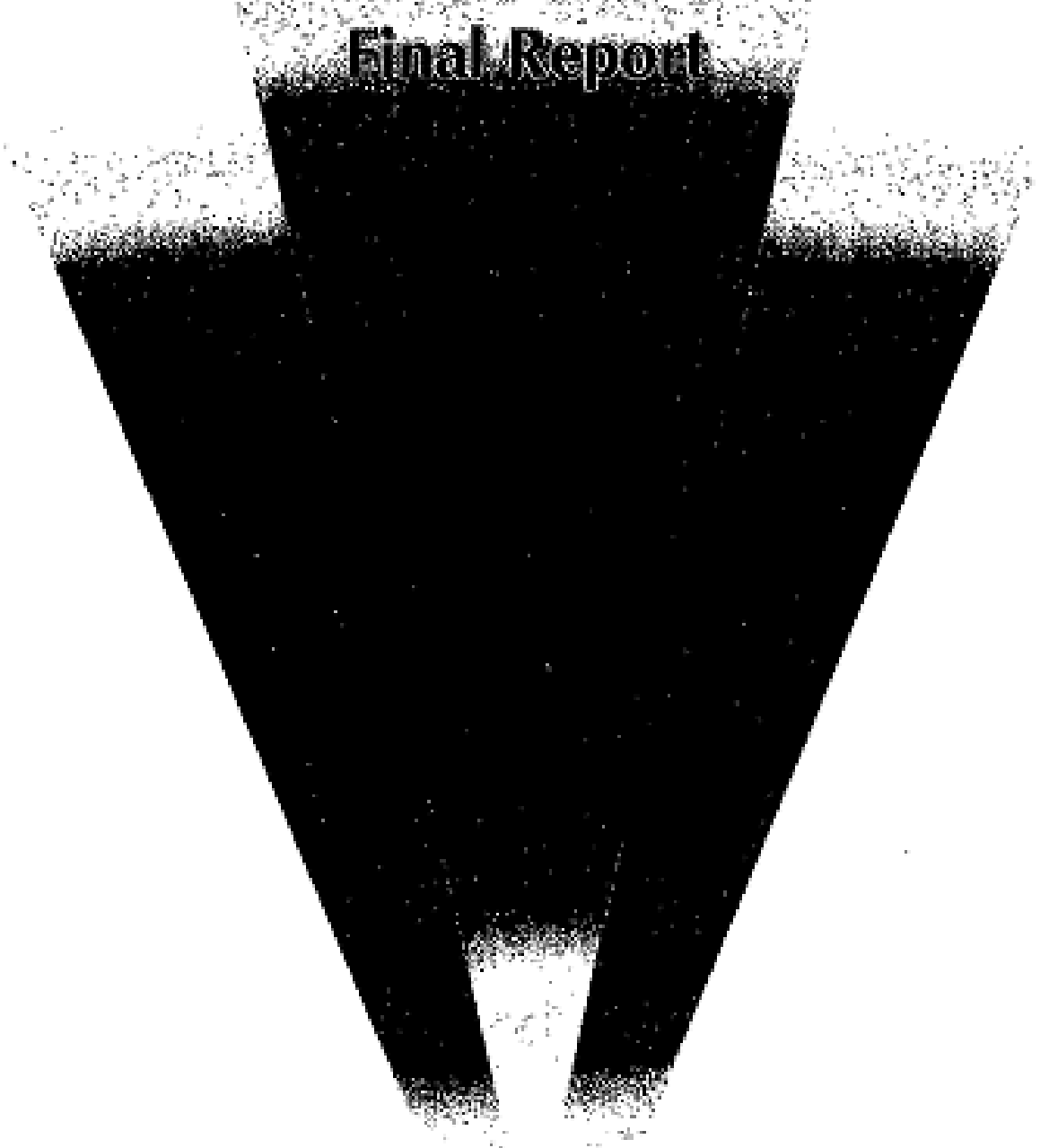

October 2002
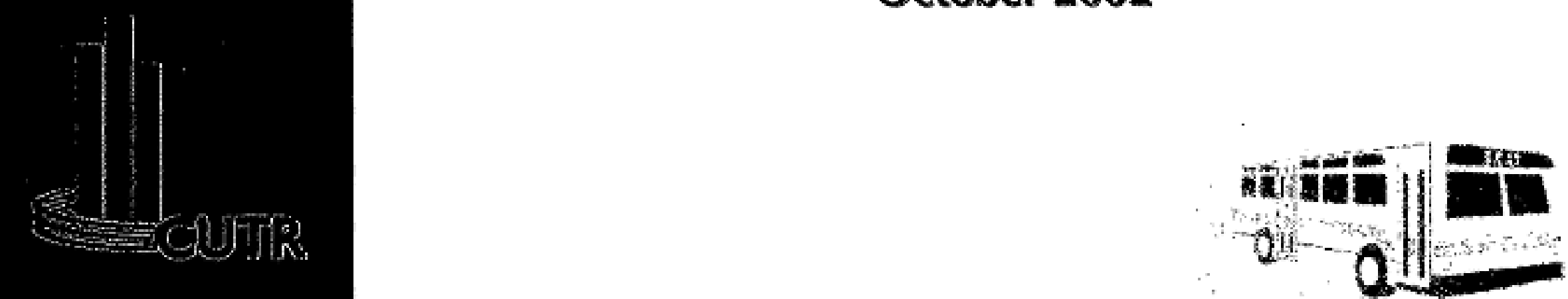


\title{
APTS Needs Assessment for Sarasota County Area Transit
}

\author{
Final Report
}

Prepared for

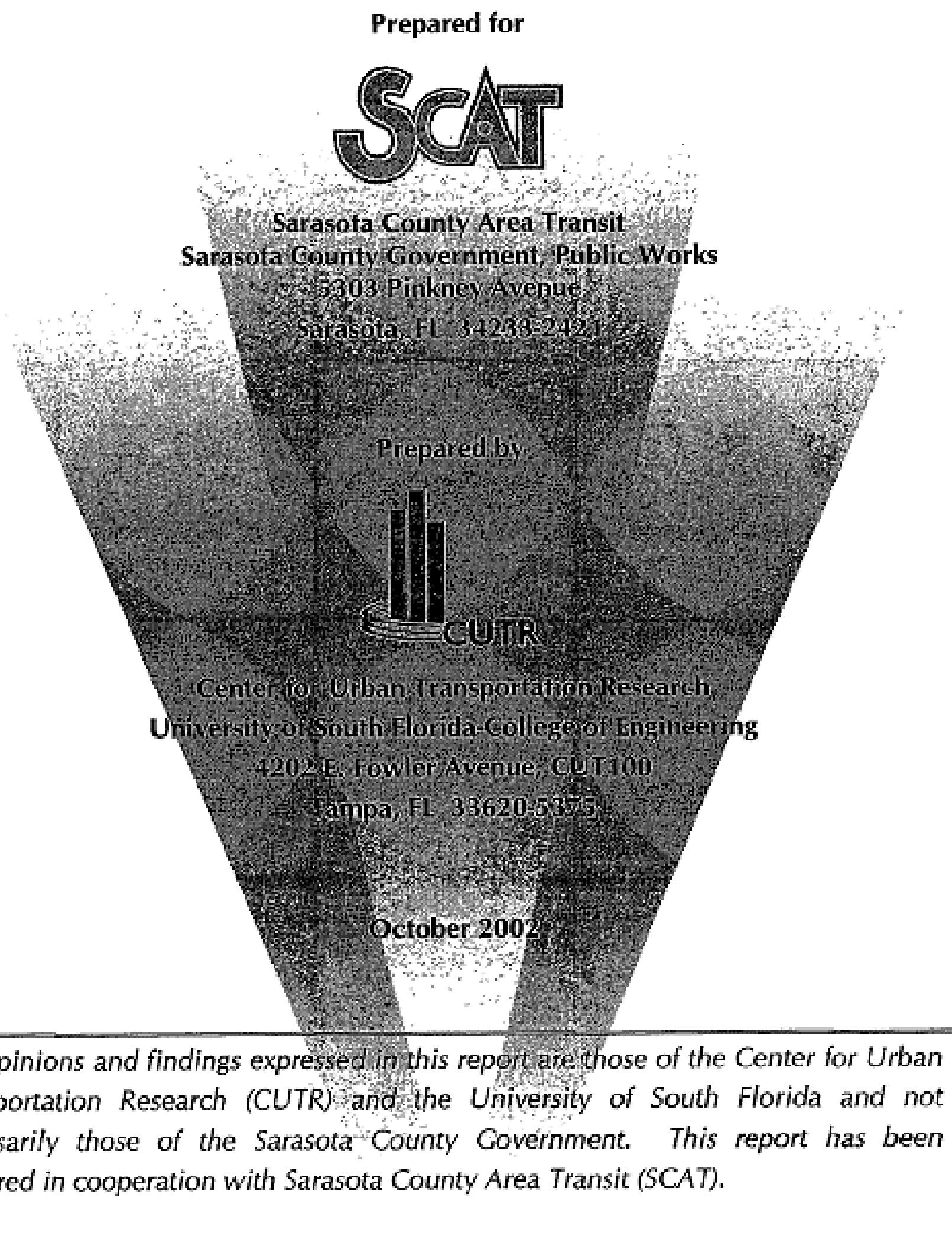

The opinions and findings expressed in this report are those of the Center for Urban Transportation Research (CUTR) and the University of South Florida and not necessarily those of the Sarasota County Government. This report has been prepared in cooperation with Sarasota County Area Transit (SCAT). 


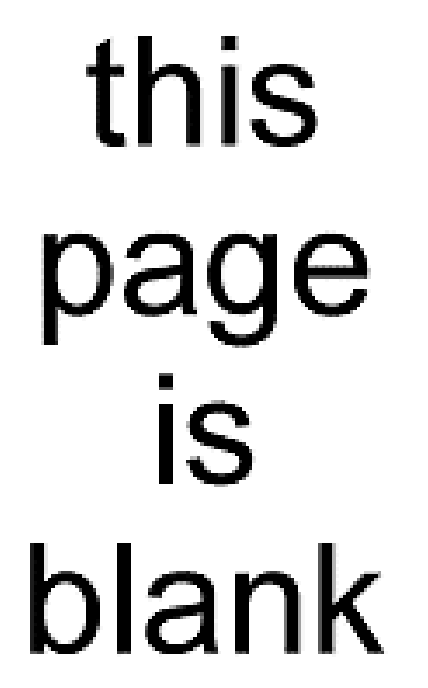




\section{TABLE OF CONTENTS}

List of Acronyms

Executive Summary . .66

\subsection{Introduction}

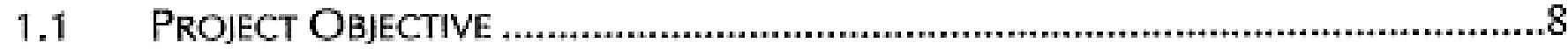

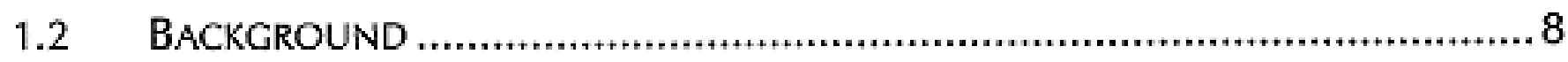

2.0 APTS/ITS Goals and Objectives ...........................................9

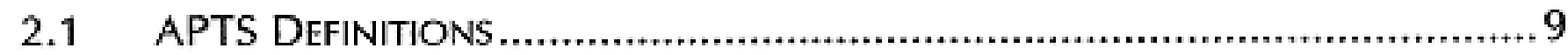

2.2 CURRENT APTS INDUSTRY DEVELOPMENT …......................................... 17

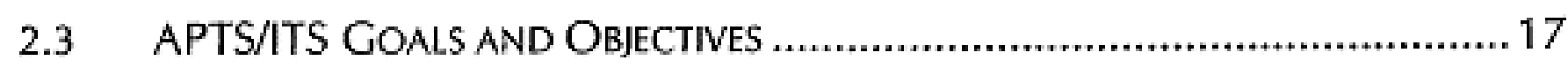

2.4 NATIONAL ITS PROGRAM GOALS ....................................................... 18

2.5 FLORIDA'S ITS STRATEGIC PLAN FINAL REPORT ...................................... 19

3.0 SCAT Agency Profile............................................................. 23

3.1 Sarasota County TRANSIT Related GoAls and OBjeCtives ................... 23

3.2 SCAT GOALS/OBJECTIVES ............................................................ 25

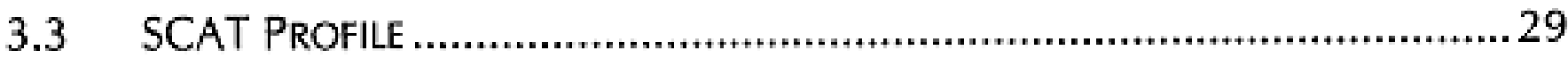

3.4 ISSUES AND TRENDS RELATING TO SCAT ............................................. 35

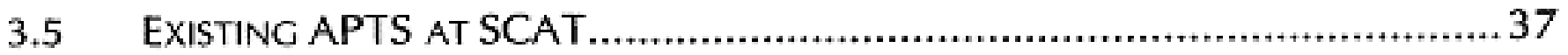

4.0 Needs Analyses.....................................................................38

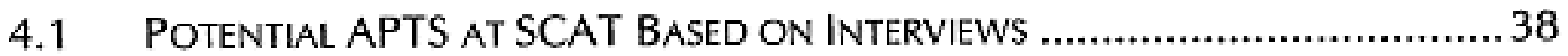

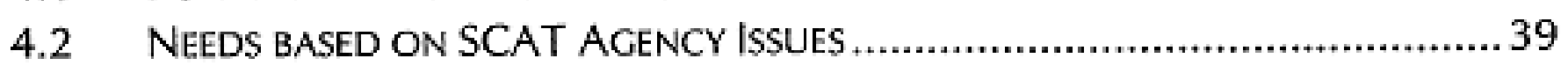

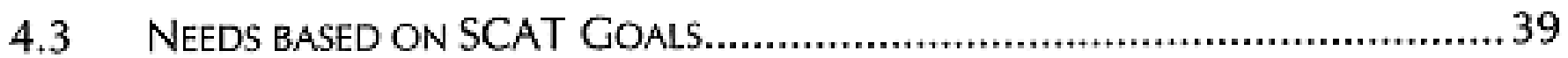

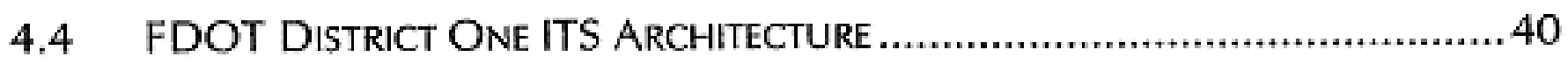

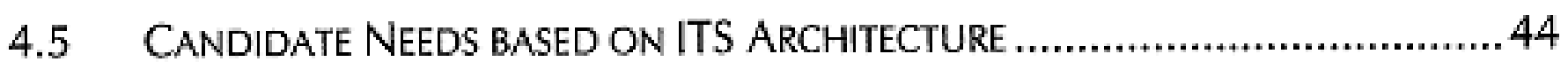

4.6 PRIORITIZED SUMMARY OF NEEDS .................................................. 45 


\section{TABLE OF CONTENTS (cont'd)}

5.0 Profile of Technologies

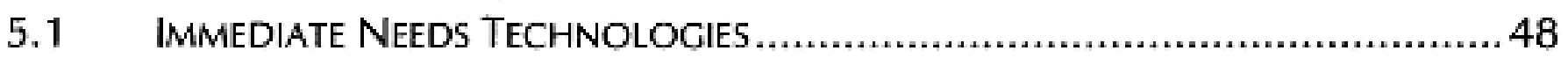

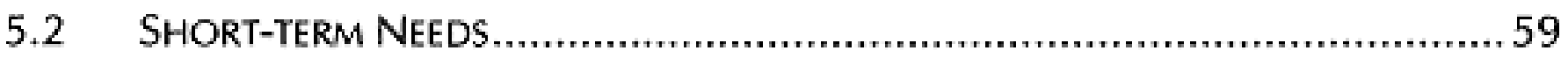

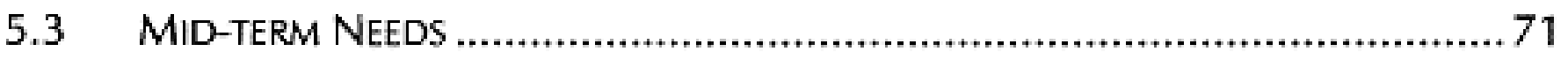

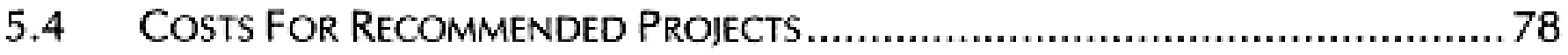

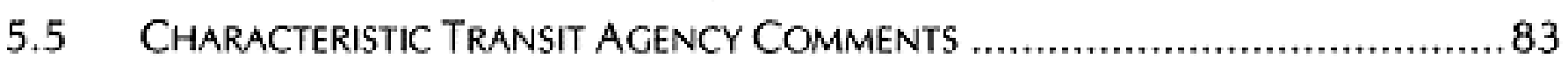

6.0 Peer System Experiences.......................................................... 89

7.0 APTS Recommendations for SCAT ........................................ 98

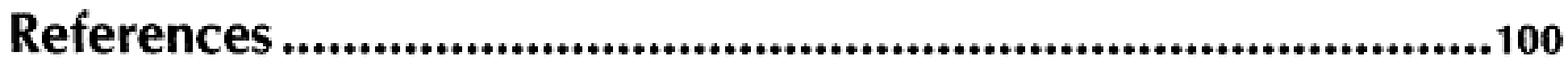

Appendix A (Detailed Cost Spreadsheets) ...................................A-1 


\section{LIST OF TABLES}

TABLE 1: STEP (SCAT) GOALS AND OBJECTIVES ..................................................... 25

TABLE 2: SCAT FIXED ROUTE SERVICES .................................................................. 32

TABLE 3: SARASOTA TROLLEYS ......................................................................... 33

TABLE 4: SCAT FARE POLICY ................................................................................ 34

TABle 5: SCAT TRANSit Performance Measures From FY 1999 to FY 2000................. 35

TABLE 6: EXISTING APTS AT SCAT .......................................................................... 37

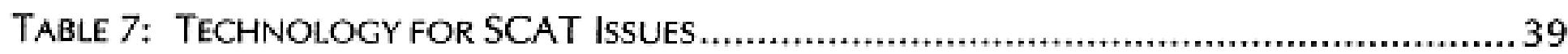

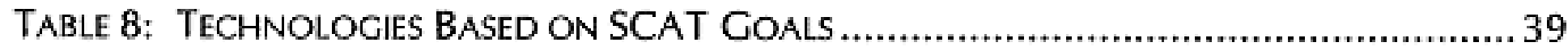

TABLE 9: PLANNED APTS FOR SCAT IN REGIONAL ARCHITECTURE .................................4 41

TABLE 10: APTS FOR SCAT ACCORDING TO REGIONAL ITS ARCHITECTURE $\ldots \ldots \ldots \ldots \ldots \ldots \ldots \ldots . . . . . . . .44$

TABLE 11: PRIORITIZED SUMMARY OF APTS TECHNOLOGIES ........................................... 45

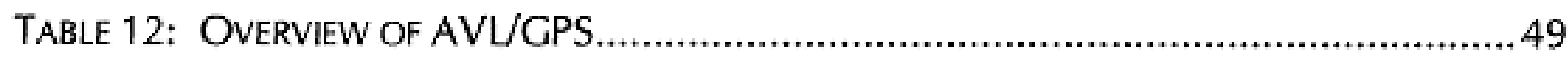

TABIE 13: FARE MEDIA AdVANTAGES AND DISADVANTAGES.......................................... 53

TABle 14: FINANCIAL. AdVANTAGE OF EleCtronIC FARE MEDIA $\ldots \ldots \ldots \ldots \ldots \ldots \ldots \ldots \ldots \ldots \ldots \ldots . \ldots \ldots$

TABLE 15: COST FOR AUTOMATIC VEHICLE LOCATION SYSTEM ........................................79

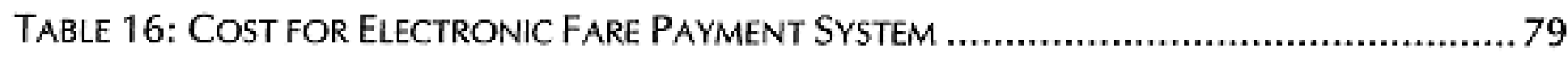

TABLE 17: COST FOR AUTOMATIC PASSENGER COUNTERS................................................ 80

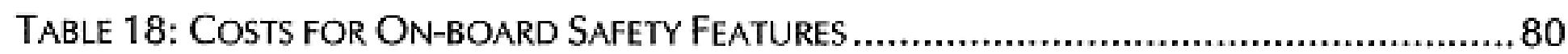

TABLE 19: COST FOR BUS SIGNAL PRIORITY .............................................................. 81

TABLE 20: COST FOR ADVANCED TRAVELER INFORMATION SYSTEMS (VMS AND

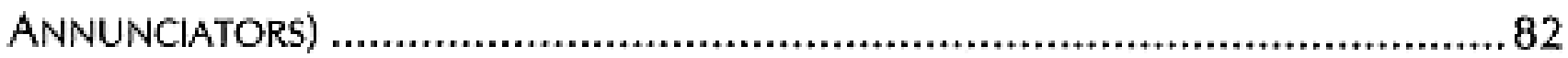

TABLE 21: COST FOR ADVANCED TRAVELER INFORMATION SYSTEM (WEBSITE) .....................8 82

TABLE 22: COST FOR ADVANCED TRAVELER INFORMATION SYSTEM (IVR) ...........................83

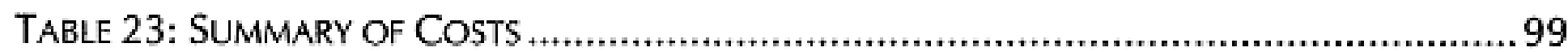




\section{LIST OF FIGURES}

Figure 1: COMPONENTS OF TRANSIT MANAGEMENT SYSTEMS........................................ 13

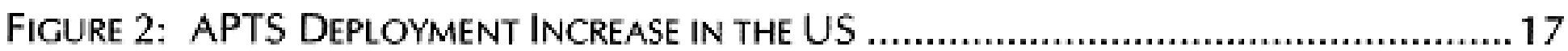

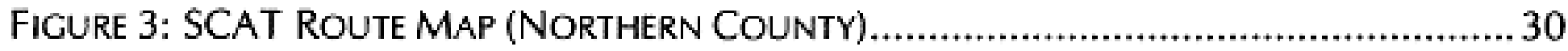

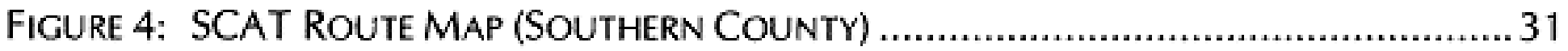




\section{LIST OF ACRONYMS}

ADA

APC

APTS

ATIS

AVL

BSP

CAD

CDPD

CMS

COTS

CSR/IVR

CVO

DGPS

EEPROM

EFP

FDOT

FMS

FTA

GIS

GPS

GUI

HOV

IC

ITS

IVI

LRTP

MDT

MPO

NIA

ROM

SCAT

SCAT Plus

SIP

TCP

TIS

TMC

TMS
Americans with Disabilities Act

Automated Passenger Counters

Advanced Public Transportation Systems

Advanced Traveler Information Systems

Automatic Vehicle Location

Bus Signal Priority

Computer Aided Dispatch

Cellular Digital Packet Data

Congestion Management Systems

Cost of the Self

Customer Speech Recognition/Interactive Voice Response

Commercial Vehicle Operations

Differential Global Positioning System

Electronically Erasable Programmable Memory

Electronic Fare Payment

Florida Department Of Transportation

Fleet Management Systems

Federal Transit Administration

Geographical Information Systems

Global Positioning System

Graphical User Interface

High Occupancy Vehicle

Integrated Circuit

Intelligent Transportation System

Intelligent Vehicle Initiative

Long Range Transportation Plan

Mobility Data Terminals

Metropolitan Planning Organization

National ITS Architecture

Read-Only Memory

Sarasota County Area Transit

SCAT's Paratransit Division

State Implementation Plans

Transfer Connection Protection

Traveler Information Systems

Transportation Management Centers

Transit Management Systems 


\section{EXECUTIVE SUMMARY}

The APTS Needs Assessment for SCAT was initiated by Sarasota County Government. Advanced Public Transportation Systems (APTS) needed to improve the efficiency and effectiveness of Sarasota County Area Transit (SCAT) in areas such as Advanced Traveler Information Systems (ATIS), Transit Management Systems, Electronic Fare Payment (EFP) Systems, and Transportation Demand Management (TDM) were assessed. The major objectives of this study were to identify existing and planned APTS for SCAT, identify and prioritize technologies that address SCAT needs, and calculate costs associated to implement these technologies.

This study examined emerging technologies in APTS and SCAT trends and issues to provide more efficient, effective and safe solutions to current SCAT challenges. To establish APTS needs for SCAT, current APTS industry trends, APTS goals and objectives, SCAT goals, and existing APTS at SCAT were considered. Existing APTS at SCAT includes transit operations software and a Countywide Communication System in the area of Transit Management Systems (TMS). There is also a partially functioning EFP system with magnetic fare media.

Interviews with SCAT employees showed that an AVL/GPS system is highly desirable. Staff also indicated a fully working EFP system would solve many of the current problems with cash and the existing fare boxes. Annunciators on buses and real-time information for passengers were also identified as key requirements for SCAT passengers.

SCAT management prioritized the APTS technologies into immediate, short-term and mid-term needs. An Automatic Vehicle Location/Monitoring (AVL/AVM) system with Mobile Data Terminals (MDT) and advanced vehicle and control center communication systems is the most immediate need (1-2 years). Smart card fare media and electronic vending outlets are upgrades for the system within 1-2 years were also identified. Automated Passenger Counters (APC), on board safety features and an update to the existing communication system is recommended for the vehicles within 1-5 years. An itinerary planning systems and real-time information systems with an updated website are also needed in the short term. Bus signal priority on congested corridors is also a needed development in the short term. Transit accessibility systems are needed in the mid-term (510 years). A vehicle component monitoring (to gauge engine temperature, oil pressure conditions etc.) system for each vehicle is suggested as a mid-term need.

Costs and staffing requirements were calculated for projects intended to serve the immediate and short-term needs. Capital costs for immediate needs are a little over $\$ 2.4$ million and costs for short-term needs are nearly $\$ 3.6$ million and the operating expenses per year for immediate needs and short-term needs are nearly $\$ 0.73$ million and 1 million respectively. 


\subsection{INTRODUCTION}

\subsection{Project Objectives}

The purpose of this study is to assess the intelligent Transportation Systems (ITS) needed to improve the efficiency and effectiveness of Sarasota County Area Transit (SCAT) in areas such as fleet operations and convenience to passengers. This study attempts to identify and address area needs and objectives for Advanced Public Transportation Systems (APTS) and corresponding APTS enhancements including phasing, capital costing, annual operating costs, staffing requirements and general conformity to National and State ITS Architectures. Major objectives of this study are to:

$>$ Identify existing and planned APTS projects for SCAT.

$>$ Assess and prioritize needs for SCAT and passengers.

$>$ Identify technologies that address SCAT needs and determine their proven capabilities and interoperability with Sarasota County's ITS Plan and emerging statewide ITS Architecture.

$>$ Develop a phasing plan for APTS technologies that need to be deployed in the short term (1-5 years), mid term ( $5-10$ years) and long term (10-20 years).

$>$ Provide a detailed description of all the technologies, capital costs, staffing needs, and maintenance and operations costs.

This study is designed to document APTS needs assessment for SCAT and will address all the major objectives mentioned above. This Final Report was prepared summarizing all findings and recommendations from the two technical memorandums previously submitted to SCAT.

\subsection{BACKGROUND}

The APTS Needs Assessment for SCAT was initiated by Sarasota County Government in response to the numerous funding requests by Sarasota County agencies for APTS services and technologies. However, in order to be compatible and interoperable with Sarasota County's ITS infrastructure and emerging statewide ITS Architecture, SCAT requested a review all previous APTS related projects and asked for recommendations of APTS technologies based on area needs. Sarasota County's transit system is managed by the Transit Services (a part of Public Works Business Center ) located at 5303 Pinkney Avenue in the County of Sarasota. The SCAT service area includes 45 fixed route vehicles and 31 demand responsive vehicles. 


\subsection{APTS/ITS GOALLS ȦND OBJECTIVES}

\subsection{APTS DEFINITIONS}

APTS applies state-of-the-art and emerging technologies to provide more efficient, effective and safe solutions to current transit problems. For the purpose of this report APTS and Transit ITS will be used interchangeably. Transit ITS is organized in parallel with the U.S. DOT's National ITS Program in the following areas (1):

\footnotetext{
Metropolitan

$>$ Transit Intelligent Vehicle Initiative (IVI)

$>$ Rural
}

The Metropolitan component of Transit ITS focuses on urban and suburban transportation in the following areas:

- Advanced Traveler Information Systems

- Transit Management Systems

- Electronic Fare Payment Systems

- Transportation Demand Management

\section{Advanced Traveler Information Systems}

The Advanced Traveler Information Systems (ATIS) provide travelers with real-time transit and traffic information. With the data from other ITS systems, the ATIS is able to provide travelers with pertinent information about the transportation system - when the next bus or train will arrive, the actual travel time from point $A$ to point $B$, and how many parking spaces are left at the park and ride lot. This information is disseminated to travelers through telephones, television monitors, cable and interactive television, radio, electronic signs, kiosks, personal computers, handheld electronic device, pagers, and the Internet (6).

\section{Target Objectives}

$>$ Increased transit ridership and revenues

$>$ Improved transit service and visibility within the community

$>$ Increased customer convenience

$>$ Enhanced compliance with the ADA

Traveler Information systems are broadly categorized into the following four major groups: 
Pre-Trip Information Systems - This system provides travelers with pertinent information before they begin their trip. In general, most information consists of transit routes, schedules, fares, etc. Traditional pre-trip information systems use automated telephone tree systems or human operators to assist travelers, but some newer systems use computers, the Internet, and personal digital assistants, to provide the same information more efficiently.

In Terminal and Wayside Information Systems - This system provides travelers with arrival and departure information, schedule updates, transfer information via electronic signs, kiosks, and television monitors. In Terminal and Wayside Information Systems are still in their infancy because systems are expensive to deploy.

In-Vehicle Information Systems - This system is similar to In-Terminal and Wayside Information Systems except information is provided inside transit vehicles via small electronic displays and annunciators. In rail vehicles, annunciators are frequently used to announce the next stop.

Dynamic Ride Sharing Systems - This system automates the arrangement of carpools by using advanced computer and telephone technologies. Drivers and riders call a central clearinghouse where a computer searches a database and finds the best available match for riders and ride seekers. If satisfactory, arrangements are made by direct contact between both parties and a carpool is formed.

\section{Benefits of Advanced Traveler Information Systems}

When ATIS are combined with computer and communications technologies, they provide vehicle information to travelers at home, at work, on the roadside or at bus and rail transit stations. The information allows travelers to choose the most efficient and convenient modes of travel. Travelers can access real-time schedules and congestion information through telephones, cable television, dynamic message signs, kiosks or the Internet. The result is greater convenience for routine or occasional travelers in using and choosing transit.

\section{Transit Management Systems}

The Transit Management Systems (TMS) consists of fleet management systems and operational software/computer aided dispatch. 


\section{Target Objectives}

$>$ Improved operating efficiency

$>$ Improved transit service and schedule adherence

$>$ Increased transit safety and security

$>$ Improved transit information

$>$ Increased compliance with the ADA

TMS focus on improving transit operations, schedule adherence, and safety by deploying the following technologies:

Automatic Vehicle Location (AVL) Systems - This system is a computer based vehicle tracking system that uses electronic tags and a GPS positioning system, sign post and odometer, deadreckoning, or combination-to monitor vehicle locations in real-time. In the United States, transit authorities use AVL systems extensively. Currently, there are at least 58 AVL systems in operation, under installation, or planned. Over the past four years, AVL system usage has increased by more than 200 percent and many more AVL systems are being planned.

Automated Passenger Counters (APC) - APC automate the data collection of passenger boarding's and alighting by time and location. Data are used in planning, operating, and scheduling activities; in National Transit Database reporting, and as input for traveler information systems.

Transit Operations Software - When linked with AVL systems, transit operations software can provide real-time dispatching, faster responses to service disruptions, and coordination between transit service, such as a fixed-route bus and demand responsive transit vehicle. In para-transit operations, transit operations software is especially useful in scheduling and dispatching. Computer aided dispatch (CAD), combined with some form of AVL, is the most popular form of transit operations software. An important component of CAD is the development of Transfer Connection Protection (TCP) software, which allows bus operators to inform passengers whether they will be able to make a transfer to a connecting bus given current schedule adherence.

Geographical Information Systems (GIS) - GIS uses an electronic map and relational databases to visualize and analyze relationships between non-related data. In transit, GIS is used to display and analyze bus routes, facilities, shelters, emergency call locations, trip planning route choices, ontime performance data, and origin and destination of ridesharing and para-transit customers.

Mobility Manager - This is a mechanism that integrates and coordinates transportation services offered by multiple providers (1). It helps service providers reduce redundant billing and collection procedures and provides more coordinated service. 
Mobile Data Terminals (MDT) - This is a type of AVL system that can be used both in fixed route and para-transit operations to dispatch messages (passenger pick-up and drop-off addresses and instructions), record and temporarily store certain types of information about passenger pick-up and drop-off times, and collect statistical and performance data on services.

Vehicle Component Monitoring - (e.g. engine temperature, oil pressure conditions) - This is a type of specific technology included in an AVL system. It is used to monitor and transmit vehicle mechanical information to dispatch such as engine temperature, oil pressure conditions.

Transit Signal Priority Systems - Transit Signal Priority is a strategy by which a particular set of vehicles is given preference at traffic signals, either anytime they arrive at an intersection or only under certain conditions. (e.g., on-time status, amount of traffic at opposing approaches etc.) Although a transit vehicle does not warrant the urgency as emergency vehicles, there are benefits to giving a bus priority at traffic signals under certain conditions.

On-board Safety Features - These include features such as silent alarms for drivers and on-board cameras to provide security and safety for personal and passengers. One recent technology addition is a Global Positioning System (GPS) Vehicle Monitoring System. This provides a wealth of information relating to the vehicles' activities with a data recorder and event monitor. Similar to a "flight data recorder" the System records date, time, location, speed, and direction of travel at user selectable intervals.

\section{Transit Management Systems Benefits}

Figure 1 illustrates components of TMS. Some benefits of TMS not previously mentioned include:

Increased efficiency, reduced operating costs, and improved services through more precise adherence to schedules.

$>$ Increased ridership as customers are able to better depend on transit through more efficient planning, scheduling and operations.

$>$ Regular transmission of location and schedule status information to dispatch centers.

$>$ Capability to monitor, supervise and control operations with real-time data in ways that were previously impossible.

$>$ Use information from AVL/CAD software packages for other purposes such as customer information, planning and scheduling.

$>$ Reduction of dispatchers' workload because TCP software relies on data rather than voice communication. Therefore, the dispatchers no longer have to be directly involved in the transfer decision-making process freeing up radio system capacity. 


\section{Figure 1: Components of Transit Management Systems}

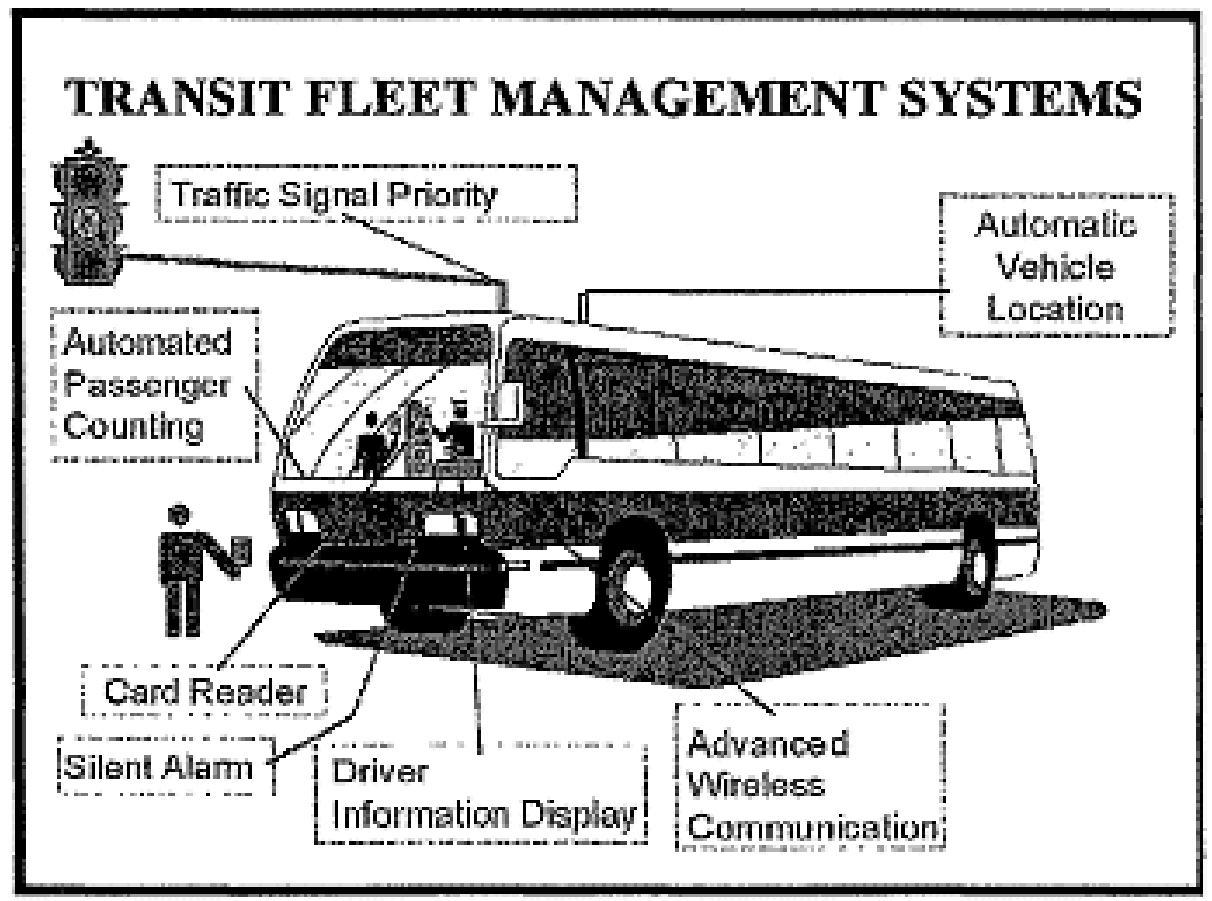

\section{Electronic Fare Payment Systems}

Electronic Fare Payment (EFP) systems use electronic communication, data processing, and data storage techniques to automate manual fare collection processes. Electronic fare media are capable of storing information in a read and/or write format. For customers transit becomes easier to use, because exact change is not necessary, and only a single fare card is needed to use the system.

\section{Target Objectives}

$\$$ Increased customer convenience

$>$ Expanded and more flexible fare structures

$>$ Expanded base for transit revenue

$>$ Reduced fare collection and processing costs

$>$ Improved security of transit revenues

The following are some examples of EFP systems:

Magnetic Stripe Cards - Magnetic stripes can be imprinted on cards made of heavy paper, thin plastic, or heavier plastic such as that used for standard credit and ATM cards. A number of transit authorities use read-only magnetic stripe passes for buses and subways. High coercivity magnetic media have been adopted by severaltransit systems to hinder the efforts of counterfeiters.

Contact Smart Cards - Integrated Circuit (IC) smart cards each contain a microcomputer in addition to electronically erasable programmable memory (EEPROM) and read-only memory (ROM). The EEPROM can be used to store information on the cash content of the card (use history, 
and other data subject to change). ROM is used for storing the microprocessor's operating program, as well as card identification data. The microcomputer is used to verify a user's positive identification number for some transactions, guard against tampering, and providing for data encryption, for security or privacy, if necessary.

Proximity Smart Cards - Proximity cards can be used for identification purposes. In this application, proximity ID cards simply identify their presence in the vicinity of a card-reading unit. They also share similarities with non-rewritable magnetic stripe cards such as ATM or credit cards. They could be used as bus and subway passes; however, they are not being used for that application anywhere in North America. They are being used for keyless entry systems, personnel identification, and inventory security in stores. In transit fare applications, they provide the operational capabilities for time-based and distance-based fare structure, inter-modal and interoperator transfers, and ancillary use as an "electronic coin purse" for small non-transit purchases, with sophisticated security capabilities.

Capacitively Coupled Cards - Capacitive coupling requires cards to each have two or more areas of metal foil covered by very thin layers of plastic insulator that are intimately positioned adjacent to similar areas in the read-write unit, thus creating capacitors that couple the circuits in the readwrite unit and card. Both power and signals can be sent via this coupling. Capacitive coupling eliminates direct physical metal-to-metal contacts that can wear and corrode, thus increasing lifetime and reliability. Although competing with proximity cards and contact cards in other markets, capacitively coupled cards have yet to be used in the transit market.

\section{Electronic Fare Payment Systems Benefits}

$>$ EFP systems make fare payment more convenient for travelers and revenue collection less costly for transit providers.

$>$ When combined with electronic communications systems, data processing computers and data storage systems EFP systems more efficiently collect fares.

$>$ Cards can be used for regional travel on buses and rail and in controlled parking facilities.

$>$ These systems can also be used to report real-time travel demand for better planning and scheduling of services.

$>$ EFP systems speeds up the passenger boarding process, thereby shaving travel time and increasing productivity.

\section{Transportation Demand Management}

Transportation Demand Management (TDM) refers to a set of techniques and programs employed to reduce automobile (single occupant vehicle) travel demand and redistribute that demand in higher occupancy vehicles (including transit), alternative modes, space and time. The techniques 
and programs utilize advanced technologies to monitor capacity and manage the system in realtime, as well as provide information and incentives for travelers to find alternative solutions to traveling alone. An example is the use of High Occupancy Vehicle (HOV) lanes on freeways in which cars with two or more passengers can drive. The objective of such a program is to encourage carpooling on congested highways.

\section{$\underline{\text { Target Objectives }}$}

$>$ Reduce the amount of automobile travel on the roadways

Facilitate and increase the use of public transportation

$>$ Provide advanced vanpooling and carpooling commuter services

$>$ Apply congestion pricing programs

$>$ Manage parking and apply demand pricing

TDM strategies that utilize ITS technologies include:

Dynamic Ridesharing - Dynamic ridesharing (also called real-time ridesharing) is a form of carpooling that provides rides for single, one-way trips rather than for trips made on a regular basis. Dynamic ridesharing can be either a program organized and run by an official agency or a system informally operated by participants. The emphasis is on organized programs because only these use ITS technologies for matching riders with drivers.

Automated Service Coordination - Automated service coordination can be defined as multiple transportation operators in a region that provide coordinated service with the assistance of APTS technologies. By coordinating the services of multiple transportation operators in a region, the connectivity of public transportation services can be greatly improved for persons who would have to travel on more than one transportation agency's vehicles. This will produce the opportunity for attracting more trips to public transportation.

Transportation Management Centers - Transportation Management Centers (TMCs) are state-ofthe-art facilities in which transportation professionals can monitor, manage or control transit and/or traffic operations. The use of ITS technologies and services provides real-time management of public transit and/or traffic resources and capacity.

\section{Transit Intelligent Vehicle Initiative (IVI)}

The Transit IVI seeks to develop technologies that help prevent crashes. Advanced safety and information systems are applied to help drivers operate transit vehicles more safely and effectively. The current focus of Transit IVI is to test these technologies on buses and para-transit vehicles. Rail vehicles will be considered in the future. According to the Federal Transit Administration (FTA), the 
five most frequent crash types (comprising approximately 87 percent of all crashes involving buses) are: 1) lane changes and merges; 2) rear-end collisions; 3) intersection collisions; 4) backing up collisions; and 5) buses running into parked cars. Based on this information, Transit IVI technologies are being tested to reduce these types of crashes.

Lane Change And Merge Collision Avoidance - Systems provide various levels of support for detecting and warning drivers of vehicles and objects in adjacent lanes. More recent systems introduce capabilities that will provide merge advice and/or warnings of vehicles in adjacent lanes, whose positions and relative velocity make the planned lane change unsafe. Those capabilities could include speed and steering control intervention for enhanced collision avoidance.

Forward Collision Avoidance - This feature senses the presence and speed of vehicles and objects in the vehicle's lane of travel and provide warnings and limited control of the vehicle speed (coasting or downshifting) to minimize risk of collisions with vehicles and objects in front of the vehicle.

Rear Impact Collision Mitigation - The two basic concepts proposed for this application is the following: transit bus-based systems to warn following driver(s) of potential collision (e.g., visual warning display on rear of bus); and impact injury and damage mitigation.

Tight Maneuvering/Precision Docking - This application positions the bus with precision relative to the curb or loading platform. Drivers can maneuver the bus into the loading area and sensors determine the lateral distance to the curb, front and rear, and the longitudinal distance to the end of the loading area. Drivers can override the system at any time by operating brakes or steering, and monitor the situation and take emergency action if necessary (for example, if a pedestrian steps in front of the bus).

\section{Transit IVI Benefits}

The primary benefit to be derived by transit agencies is improved safety. An analysis on the benefits of Transit IVI based on projected reductions of transit vehicle accidents and the resultant savings in the form of avoided losses in transit accident fatalities, injuries and property damage was performed. This analysis projected that the total benefits, over the next ten years, for Transit IVI technology deployments would range from $\$ 498.0$ million to as high as $\$ 1.2$ billion (1).

\section{Target Objectives}

$>$ Increased safety of transit passengers

Reduced costs of transit vehicle maintenance and repairs

$>$ Enhanced compliance with the ADA 


\subsection{CuRrent APTS INDUSTRY DeVelopment}

There has been a significant increase in the development and implementation of APTS applications in the United States over the past few years, as shown in Figure 2. Since 1996, the number of deployments of APTS technologies has increased by over $70 \%$. The largest increases have been seen in the deployments of fleet management systems, electronic fare payment systems, and advanced traveler information systems.

Today, APTS technologies are deployed (or are being planned for deployment) within 192 fixed route bus systems, 153 demand responsive transit systems, 11 heavy rail, 12 light rail, and 13 commuter rail systems. Transit Intelligent Vehicle Initiative (IVI) technologies are currently being researched and initial deployments in vehicle collision warning systems are being developed, tested and evaluated.

Figure 2: APTS Deployment Increase in the US

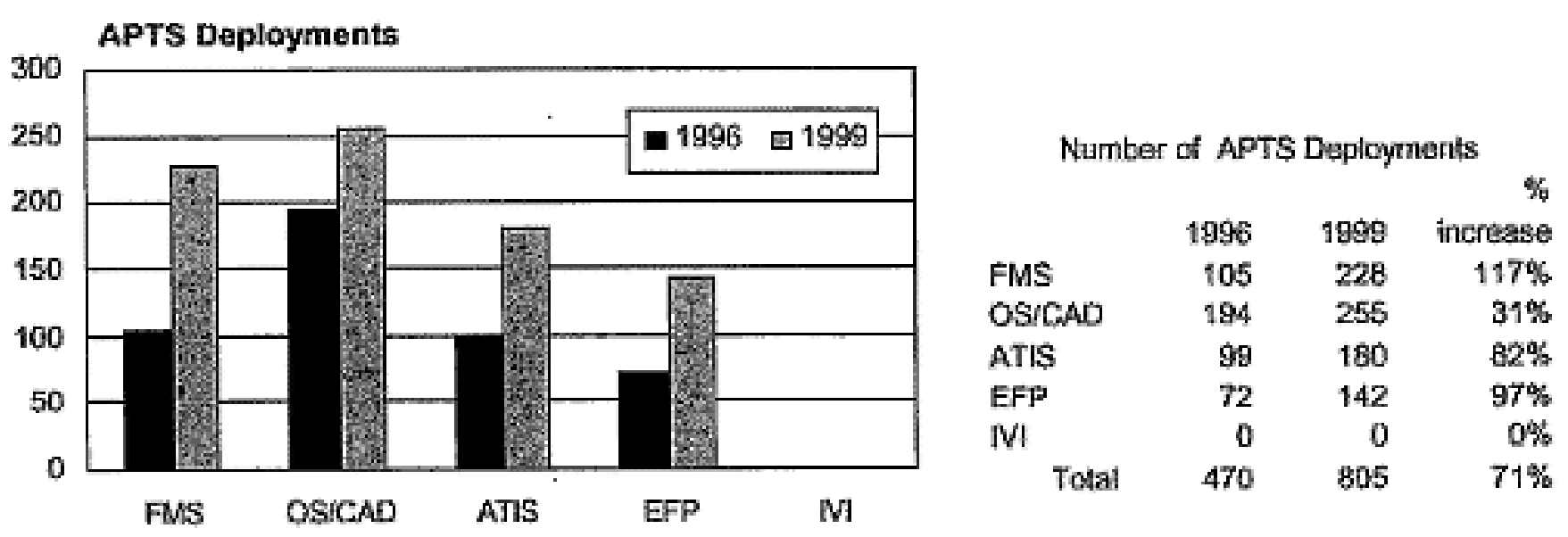

Source: Advanced Public Transportation Systems; The State of the Art Update 2000, USDOT/FTA, December

\begin{tabular}{|ll|}
\hline \multicolumn{1}{|c|}{ Legend } & \\
FMS - Fleet Management Systems & CAD - Computer-Aided Dispatch \\
ATIS - Advanced Traveler Information Systems & EFP - Electronic Fare Payment \\
VI - Intelligent Vehicle in itiative & \\
\hline
\end{tabular}

\subsection{APTS/ITS GoALS AND OBJECtIVES}

Typical transit agency objectives related to APTS/ITS include (1):

$>$ Improved dispatching operations and scheduling

$>$ Reduce the cost per passenger trip

$>$ Provide better passenger information and on-time performance

$>$ Promote open, interoperable systems in ITS 
Enhance the amount and quality of the data available for planning and analysis

$>$ Improve safety and security for transit operators and consumers

A discussion of these objectives is provided below.

\section{Improving Dispatching Operations}

Receiving and displaying accurate vehicle locations should enhance the operations of the fleet. Dispatchers will have the ability to track a vehicle, compare its location to a prescribed route and time point, and advise an operator of late or early running on a route. On the basis of this information, the operator can make necessary run adjustments. In addition to the field supervisors and the vehicle operators knowing that a vehicle is running off schedule, the dispatchers have the ability to see the extent of the problem and how it may impact other routes or blocks.

\section{Reducing the Cost per Passenger Trip}

APTS technologies will reduce operating costs by providing greater control and accountability of fleet and resource management. A growing interest has been savings in moving passengers from para-transit service to fixed-route service, which is less expensive on a per-ride basis and can accommodate additional trips at little or no cost.

\section{Providing Better Passenger Information}

This can easily be done through an on-line customer information system that would provide the real-time location of vehicles and information about all types of transportation and trip itinerary planning using off-the-shelf technology.

\section{Promoting Open, Interoperable Systems in APTS}

The USDOT is increasingly requiring that ITS implementations use open system architecture to encourage innovation and interoperability. Issues still remain. For example, to compare the scheduled versus real-time location of vehicles, a typical system would require an interface between the scheduling software and AVL. This is usually made available for an additional charge.

\section{Improving Safety and Security for Transit Operators and Consumers}

Finally, improved safety and security for transit operators and customers is one of the primary objectives of all public transportation agencies. The ability of AVL to pinpoint the location of any vehicle in their fleet provides an additional security feature that will make operations safer.

\subsection{National ITS Program Goals}

The ITS Program identifies five goal areas that ITS projects should address (2):

$>$ Safety, measured through a reduction in crash rates 
Mobility, measured through a reduction iǹ deláy and travel time variability, as well as an improvement in customer satisfaction

$>$ Efficiency, measured through increases in throughput or effective capacity, as well as congestion relief

$>$ Productivity, measured through cost savings

$>$ Energy and environment, measured through reductions in emissions and energy consumption

\subsection{Florida's its Strategic Plan Final Report}

The purpose of the ITS Strategic Plan is to guide the Florida Department of Transportation (FDOT), Florida Metropolitan Planning Organizations (MPOs) and local governments in the planning, programming and implementation of integrated multi-modal ITS elements to maximize the safety and efficiency of Florida's transportation system. This ITS Strategic Plan includes the FDOT's statewide vision for ITS, as well as a set of guiding principles to assist in the long-range planning and project development needed to achieve that vision. An ITS Business Plan is included that details the recommended steps for the FDOT's ITS program development and deployment over the next five years.

\section{Goals from the Florida ITS Strategic Plan include:}

\section{Goal 1: Safe Transportation for Residents, Visitors And Commerce} ITS Objectives

$>$ Minimize response time for incidents and accidents (incident management programs)

$>$ Reduce commercial vehicle safety violations (commercial vehicle operations (CVO) safety programs)

$>$ Reduce weather-related traffic incidents (road-weather information systems)

$>$ Minimize grade crossing accidents (highway-rail interface safety systems)

$>$ Improve emergency management communications (coordination of communication frequencies and real-time traveler information systems for evacuation and major route closings, re-routings or restrictions)

$>$ Improve security for highway and transit users (surveillance cameras, call boxes and emergency services support)

$>$ Improve the security, safety and convenience of pedestrians and bicyclists (improved interfaces at pedestrian crossings, signalized intersections, kiosks and surveillance systems)

\section{Goal 2: Protection Of The Public's Investment In Transportation} ITS Objectives

$>$ Reduced vehicular delay from incidents (incident response programs) 
$>$ Improved peak period flow and throughput (traffic control systems and operations)

$>$ Reduce the cost of commercial vehicle fleet operations (CVO and intermodal systems)

$>$ Assist in providing safe and efficient maintenance of traffic during project construction (work zone monitoring systems, real-time traveler information systems)

\section{Goal 3: A Statewide Interconnected Transportation System That Enhances Florida's Economic Competitiveness \\ ITS Objectives \\ $>$ Reduce cost and delay of intermodal connections (CVO and information systems) \\ $>$ Minimize shipping and delivery delays to improve freight operations (real-time system management programs) \\ $>$ Improved predictability of travel and delivery times (incident management systems) \\ Improve efficiency of fleet operations (CVO information systems) \\ $>$ Improve tourist access and convenience (special traveler information systems) \\ $>$ Increase employment (new ITS industry in Florida)}

Goal 4: Travel Choices to Ensure Mobility, Sustain the Quality of the Environment, Preserve Community Values and Reduce Energy Consumption

ITS Objectives

$>$ Improve mobility and choices for highway and transit users (ATISs for conditions and modal/route options)

$>$ Improve tourist access (specialized traveler information systems)

$>$ Reduce the need to travel (communications infrastructure to support telecommuting, teleconferencing, teleshopping, etc.)

$>$ Reduce energy use and environmental degradation (ITS systems management to reduce vehicle trips and vehicle miles of travel)

$>$ Improve service for special traveler needs (smart cards, computer aided dispatch (CAD) and AVL systems to enable true demand-responsive transit systems)

$>$ Improve multi-modal travel (smart cards, traveler information and transit management systems to reduce transit travel times)

$>$ Reduce energy use and delay associated with major incidents (ITS systems management and route diversion)

$>$ Improve efficiency of toll operations (electronic toll collection systems)

$>$ Enhance and support ride-sharing opportunities (high occupancy vehicle/high occupancy toll systems)

Recommended actions defined in the FDOT's ITS Business Plan include steps in several major areas. These are described in the following paragraphs. 


\section{Planning and Development}

$>$ Undertake strategic deployment-clarify ITS project priorities; develop a cost-effective incremental approach to deployment, consider both short- and long-term elements.

$>$ Provide a common framework for the planning, deployment and integration of systems through ITS architecture and standards consistency-develop regional applications of the National ITS Architecture (NIA), maximize the use of common architecture and standards; provide for a migration plan for older (legacy) systems to meet ITS standards and architecture consistency; establish a statewide ITS infrastructure through the use of statewide and national standards and architecture.

$>$ Promote institutional and inter-jurisdictional cooperation and coordination in the planning, deployment, operations, management and maintenance of ITS infrastructure-include ITS in all regional and statewide processes for transportation infrastructure planning, development and maintenance, emergency operations planning and management, and system operations and management; optimize cooperation and coordination among key stakeholders, both "vertical" (FDOT, local government, MPOs) and "horizontal" (transit and toll authorities, police, fire, emergency management services (EMS), etc.)

$>$ Provide service on a regional, integrated and interoperable basis-provide seamless service through the integration of traffic operations and transit services across jurisdictional lines.

$>$ Integrate ITS planning and ITS-related operations planning with statewide, metropolitan, authority and local government planning processes; incorporate ITS plans with Long Range Transportation Plans (LRTPs) and with State Implementation Plans (SIPs), Transportation Improvement Program (TIPs), Congestion Management Systems (CMSs), Transportation System Management (TSM) activities, etc.

$>$ Support concurrency/growth management program-use ITS as means of both monitoring and supporting program objectives; maximize the use of ITS-developed data as a resource for other planning needs.

$>$ Emphasize intermodal/multi-modal orientation to enhance both passenger and freight connections and transfers at ports, airports and via all applicable modes.

$>$ Utilize proven cost-effective technologies to deliver new and enhanced services to travelers and system users; use total life-cycle cost analysis to select the appropriate ITS components and designs.

\section{Operations and Management}

$>$ Provide performance-driven service, provide real-time operations and management of all transportation systems to maximize system performance, safety and time reliability; use ITS data to make real-time traffic control decisions and to evaluate transportation system performance.

$>$ Adapt system operations and management strategies to changing conditions-incorporate new and modify existing service attributes based on performance evaluations. 
$>$ Provide emergency operations support-ensure traveler information systems and traffic management systems are capable of supporting hurricane and other emergency evacuation procedures.

Actively pursue inter-agency operations and management agreements-agreements for the operation, maintenance, staffing, data-sharing and management of ITS deployments.

\section{Finance}

$>$ Provide ITS funding for NIA-consistent projects-funding priorities should favor those ITS projects which are consistent with state and national ITS architecture and standards.

$>$ Leverage value of "conventional" capital investment in roadway and transit improvements through ITS features that improve operational efficiency.

$>$ Develop ITS funding strategies-pursue development of specific funding strategies for ITS deployment in the MPOs, TIPs and FDOT's Work Program. Such strategies should include funding for long-term operations and management.

$>$ Capitalize on private sector resources-access technology, capital and entrepreneurship through public-private partnerships and private sector information service providers (ISPs); coordinate electronic payment services, such as smart card technology, with private sector financial institutions; maximize customer-responsive commercial opportunities (with revenue potential); capitalize on innovative finance for both capital and operations funding through the use of privatization, commercialization and cost-sharing; support private sector initiatives for personal safety and mobility (e.g., May Day systems, on-board navigation, etc.).

\section{Public Awareness/Involvement}

$>$ Include education, training and outreach for policy makers, general public and technical staff.

$>$ Respond to special user needs-provide for the mobility and safety needs of commuters, tourists, goods movement, pedestrians, bicyclists, older road users and mature drivers.

$>$ Identify and support ITS advocates/champions-seek out and promote ITS champions in local government, public agencies, academia and the private sector, including the general public.

\section{Research \& Development}

$>$ Support continued research and operational testing-provide a systematic research program to evaluate emerging technologies, new systems, markets and planning methods. 


\subsection{SCAT AGENCY PROFILE}

\subsection{Sarasota County Transit Related Goals And Objectives}

The transit related goals and objectives of Sarasota County are as follows (3):

\section{GOAL 1}

It shall be the goal of Sarasota County to develop and maintain a safe, convenient, efficient transportation system which: recognizes present need; reflects the Future Land Use Plan and the plans of adjacent jurisdictions; provides for an affordable balance of alternative transportation modes; provides for safe, efficient inter modal transportation linkages; and respects the integrity of environmentally sensitive areas.

\section{Traffic Circulation Sub-Element}

\section{Objective 1.1}

Development of a future thoroughfare system, consistent with the adopted Future Thoroughfare Plan and Maps, proposed population densities, housing and employment patterns, and land uses, shall be based on the Future Land Use Plan and coordinated with the plans of adjacent jurisdictions.

\section{Objective 1.2}

Sarasota County shall provide for the protection and acquisition of existing and future rights-of-way including mass transit rights-of-way and exclusive mass transit corridors.

\section{Objective 1.3}

Sarasota County shall provide for a safe, convenient and energy efficient multi-modal transportation system.

\section{Objective 1.4}

The Transportation plan shall enable County residents the opportunity to live and travel utilizing an integrated, inter modal transportation system.

\section{Objective 1.5}

All traffic circulation plans and programs, as well as aviation, port and rail plans and programs, shall be coordinated with the plans and programs of the State, the Region, the local Metropolitan Planning Organization and other local jurisdictions. 


\section{Objective 1.6}

Existing neighborhood environments, their cohesion, and integrity, shall be specifically considered in the development of the Year 2020 Future Thoroughfare Plan, and in individual roadway projects.

\section{Objective 1.7}

Consider the aesthetics of roadway corridors in the development roadway projects.

\section{Public Transit Sub-Element - Sarasota County Area Transit (SCAT)}

\section{GOAL 2}

It shall be the goal of Sarasota County to provide public transit services within a framework of available finances, which provide a safe, convenient and economically efficient alternative transportation for current and potential users.

\section{Objective 2.1}

To provide by the year 2005 public transit service levels, as measured by vehicle hour, that at minimum match the percentage of growth in county population from January 1995 to January 2005 and that at a minimum approximate the level of service found in other counties with similar population.

\section{Objective 2.1}

To maintain a formal method of evaluating route performance.

\section{GOAL 3}

To provide and enhance public transit services consistent with: the identified needs of the County's population, the constraints of the road network, and the prevailing urban land use patterns of the County. To coordinate public services with affected County departments, State programs and initiatives, State and Metropolitan planning activities and local jurisdictions in a manner that provides a stable and effective public transit service in Sarasota County.

\section{Objective 3.1}

To continue and improve coordination of public transportation service to both the general public and the special needs of the transportation disadvantaged with adjacent communities, the Community Transportation Coordinator, the Sarasota County Transportation Disadvantaged Coordinating Board, other transportation providers, the Florida Department of Transportation and the Sarasota-Manatee Metropolitan Planning Organization. 


\section{Objective 3.2}

To coordinate land use planning and land development based upon existing major trip generators or attractors, safe and convenient transit terminals with the provision of public transit services.

\section{Objective 3.3}

To investigate and consider implementing alternative programs to fund public transit.

\section{Port and Rail Sub-Element}

\section{GOAL 9}

It shall be the Goal of Sarasota County to develop and maintain an environmentally sensitive transportation system, which provides safe, convenient, and efficient travel through an affordable balance through the development of alternative transportation modes, the coordination with desired land use practices, and the coordination with adjacent communities.

\section{Objective 9.1}

To continue through the year 2020, to rely upon existing regional ports to serve the needs of Sarasota County residents.

\section{Objective 9.2}

To encourage the use of rail lines as an alternative means of transporting passengers and freight.

\subsection{SCAT GoALS/ObJectives}

The Sarasota Transportation Enhancement Plan (STEP) advisory committee, comprising representatives of public and private organizations of Sarasota County, is a future oriented committee established to enhance mobility for individuals within the community. SCAT has decided to adopt STEP goals. STEP goals and objectives are outlined in Table 1.

\section{Table 1: STEP (SCAT) Goals and Objectives}

\begin{tabular}{|c|c|}
\hline Goal 1 & $\begin{array}{l}\text { Increase community awareness of transportation alternatives in relation to the stated need for a } \\
\text { balanced multi-modal transportation system. }\end{array}$ \\
\hline Goal 2 & $\begin{array}{l}\text { Conduct educational outreach activities related to transportation issues } \\
\text { - Implement a media campaign to reinforce outreach activities } \\
\text { Distribute periodic publications, such as newsletters and press releases, that reinforce } \\
\text { educational outreach campaign }\end{array}$ \\
\hline Recommend public policies that support a balanced multi-modal transportation system. \\
\hline $\begin{array}{l}\text { Inform decision-makers, community leaders, and the public about transportation needs } \\
\text { and issues. } \\
\text { Assist decision-makers in developing policies that promote multi-modal, sustainable } \\
\text { transportation solutions }\end{array}$ \\
\hline
\end{tabular}




\begin{tabular}{|c|c|}
\hline Goal 3 & $\begin{array}{l}\text { Address the mobility needs of the underserved populations and recommend solutions to meet } \\
\text { those needs }\end{array}$ \\
\hline & $\begin{array}{l}\text { - Identify underserved populations in Sarasota County, including children, elderly, and } \\
\text { other special needs groups. } \\
\text { - Identify opportunities and initiatives, designed to meet the mobility needs of underserved } \\
\text { populations by maximizing use of existing transportation resources. } \\
\text { - Identify methods to improve the existing transportation system to increase its use by } \\
\text { underserved populations. } \\
\text { Develop new transportation programs as needed to help meet the mobility needs of } \\
\text { underserved populations }\end{array}$ \\
\hline \multirow[t]{2}{*}{ Goal 4} & $\begin{array}{l}\text { Create an integrated, countywide, multi-modal transportation system that provides links to the } \\
\text { larger metropolitan community. }\end{array}$ \\
\hline & $\begin{array}{l}\text { - Develop a plan to create a multi-modal transportation system that links together to } \\
\text { provide a fluid transportation system benefiting the entire community. } \\
\text { - Promote the development of a multi-modal transportation system that is coordinated by a } \\
\text { single agency/operation } \\
\text { - Promote the establishment of a centralized information and referral center to provide trip } \\
\text { planning assistance to agencies, organizations, and members of the general public } \\
\text { - Develop an Intelligent Transportation System (ITS) plan that reviews technology } \\
\text { applications necessary to facilitate the implementation of an integrated, countywide } \\
\text { multi-modal transportation system. } \\
\text { - Implement adopted ITS plan for Sarasota County }\end{array}$ \\
\hline \multirow[t]{2}{*}{ GOAL 5} & $\begin{array}{l}\text { To promote future-oriented transit designs coordinated with the local environment, land uses, } \\
\text { and surface transportation systems. }\end{array}$ \\
\hline & $\begin{array}{l}\text { - Identify alternatives to the personal automobile that enhance mobility in concert with the } \\
\text { preservation of the natural environment within Sarasota County } \\
\text { - Advocate for infrastructure that facilitates transit use and non-motorized modes of } \\
\text { transportation (bicycles, walking) such as sidewalk, curb cuts, and bike lanes and } \\
\text { shoulders. } \\
\text { - Improve passenger comfort associated with transit use by installing, benches, shelters, } \\
\text { and other amenities at bus stops and transfer centers. } \\
\text { Collaborate with local municipalities and neighboring counties to develop intra-city and } \\
\text { regional transportation alternatives consistent with stated community goals and values. }\end{array}$ \\
\hline \multirow[t]{2}{*}{ GOAL 6} & To secure funding sources dedicated to the enhancement of mobility within the community. \\
\hline & $\begin{array}{l}\text { - Secure a long-term funding source dedicated to the enhancement of mobility within the } \\
\text { community. } \\
\text { - Promote increased local financial support for transportation services designed to improve } \\
\text { mobility for underserved populations. } \\
\text { - Identify opportunities to establish innovative public/private partnerships in the creation of } \\
\text { an integrated countywide, multi-modal transportation system. }\end{array}$ \\
\hline
\end{tabular}

The following are proposed goals for SCAT in the Sarasota Transportation Enhancement Plan (3).

\section{GOAL 1}

To increase community awareness of transportation alternatives, in relation to the stated need for a balanced multi-modal transportation system. 


\section{Objective 1.1}

This goal focuses on the importance of community awareness regarding the need for a balanced, multi-modal transportation system in Sarasota County. The policy objectives associated with this goal address activities designed to increase community awareness of the transportation issues outlined in the STEP. These activities include educational outreach activities, the implementation of a media campaign to reinforce outreach efforts, and the regular distribution of publications such as newsletters and press release to supplement community outreach activities.

\section{GOAL 2}

To recommend public policies that supports a balanced multi-modal transportation system.

\section{Objective 2.1}

This goal recognizes the importance of translating community awareness into public policies that provide support and implementation infrastructure for the development of a balanced multi-modal transportation network in Sarasota County. The objectives associated with this goal extend educational outreach activities to decision-makers and community leaders, as well as the public. Another major component of this goal is to provide assistance to decision-makers in the development of policies that promote and support multi-modal, sustainable transportation solutions.

\section{GOAL 3}

To address the mobility needs of the underserved populations and recommend solutions to meet those needs

\section{Objective 3.1}

In the development of a balanced multi-modal transportation system that attempts to meet both individuals and community mobility needs, it is necessary to identify and address the mobility needs of underserved populations. This goal and its associated objectives seek to fill this gap by promoting activities designed to identify underserved populations. In addition, the objectives of this goal also stress the importance of increasing opportunities for underserved population to use existing transportation programs and systems for their mobility needs. Finally, this goal also calls for the development of new transportation programs specifically designed to address mobility needs of underserved populations that cannot be met by existing transportation programs.

\section{GOAL 4}

To create an integrated, countywide, multi-modal transportation system that provides links to the larger metropolitan community. 


\section{Objectives 4.1}

This goal builds on the efforts outlined in the previous goal by providing implementable activities designed to provide the foundation for an integrated, countywide multi-modal transportation system. The objectives developed to accomplish this goal call for the development of a plan for development of a comprehensive mobility network that is coordinated by a single agency/operation. An important component in the concept of a comprehensive mobility network is a centralized information and referral center that provides trip-planning assistance. This goal also calls for the development of an ITS plan for the review and application of technologies necessary for the creation of an integrated, countywide, multi-modal transportation system.

\section{GOAL 5}

To promote future-oriented transit designs coordinated with the local environment, land uses, and surface transportation systems.

\section{Objective 5.1}

This goal acknowledges the importance of preserving the natural environment in Sarasota County. Towards this end, these goals and objectives focus on the provision of infrastructure and amenities that will facilitate greater use of environment friendly transportation alternatives to the personal vehicle. Infrastructure that encourages use of transit and non-motorized forms of transport include sidewalk, curb cuts, and bike lanes and shoulders. The objectives also call for the installation of passenger amenities at bus stops and transfer centers to increase passenger comfort, such as benches, shelters, passenger information, and telephones. Finally, the objectives associated with this goal advocate collaboration with local municipalities and neighboring counties in the development of transportation alternatives that are consistent with community goals and values.

\section{GOAL 6}

To secure funding sources dedicated to the enhancement of mobility within the community.

\section{Objective 6.1}

This goal focuses most importantly on the long-term financial feasibility of the comprehensive mobility network envisioned in STEP. Towards this end, the objectives of this goal seek to secure a funding source dedicated to the enhancement of mobility in the community. In addition, the objectives call for increased local financial support for transportation services designed to improve mobility for underserved populations. Finally, the importance of innovative public/private partnerships is highlighted in relation to the funding and implementation of an integrated countywide, multi-modal transportation system. 


\subsection{SCAT PROFILE}

\section{Overview}

The Sarasota County Transportation Authority functionally operates as Transit Services within the Public works Business center of Sarasota County Government. The transit system is informally known as the Sarasota County Area Transit (SCAT) bus system (3). Their mission statement is to provide quality, reliable, cost effective public transportation services for the benefit of residents and visitors of Sarasota County to ensure personal mobility and enhance their quality of life (4). The total fleet size is 45 buses all of which are wheelchair lift equipped. SCAT operates Monday through Saturday, approximately 6:00am to 7:00 pm. There is also an express bus route in service during morning and evening commuter rush hours Monday thru Friday. Complementary paratransit service is provided through SCAT + Plus (formerly, Senior Friendship Center) for those who cannot use SCAT buses to make their trips. SCAT routes operate Countywide from SarasotaBradenton Airport in the north to North Port and Englewood in the south, a distance of 40 miles. Figures 4 and 5 illustrate SCAT's route in both northern and southern Sarasota County respectively (4). More than 94 percent of Sarasota County's population is now within $1 / 2$ mile of a SCAT bus route.

\section{Organizational Chart}

There are currently twenty-eight positions available in the transit division of SCAT (5). A couple of these positions have require more than one employee, like the operation supervisor position which requires seven employees, and the bus operators position which requires seventy-nine employees. Almost all the positions are currently filled with the exception of a few, which include Administrative Assistant II, Equipment Technician, and Customer Service Representative positions. The hierarchy flows from the General Transit Manager to the Administrative Coordinator and the Administrative Assistant III. The division is then broken down into three major parts, namely the transit operations department, finance department, and the equipment operations department. 
Figure 3: SCAT Route Map (Northern County)

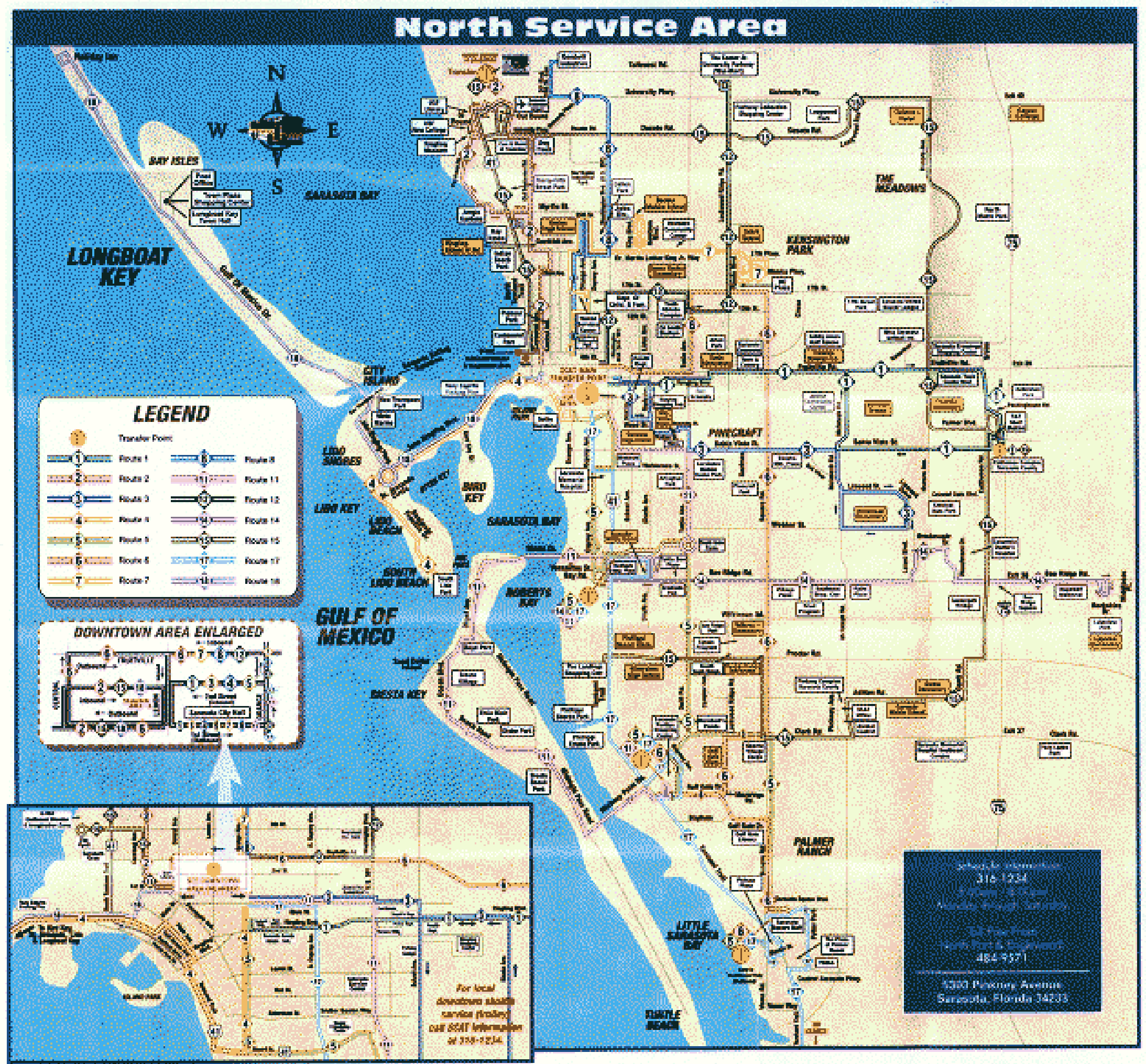


Figure 4: SCAT Route Map (Southern County)

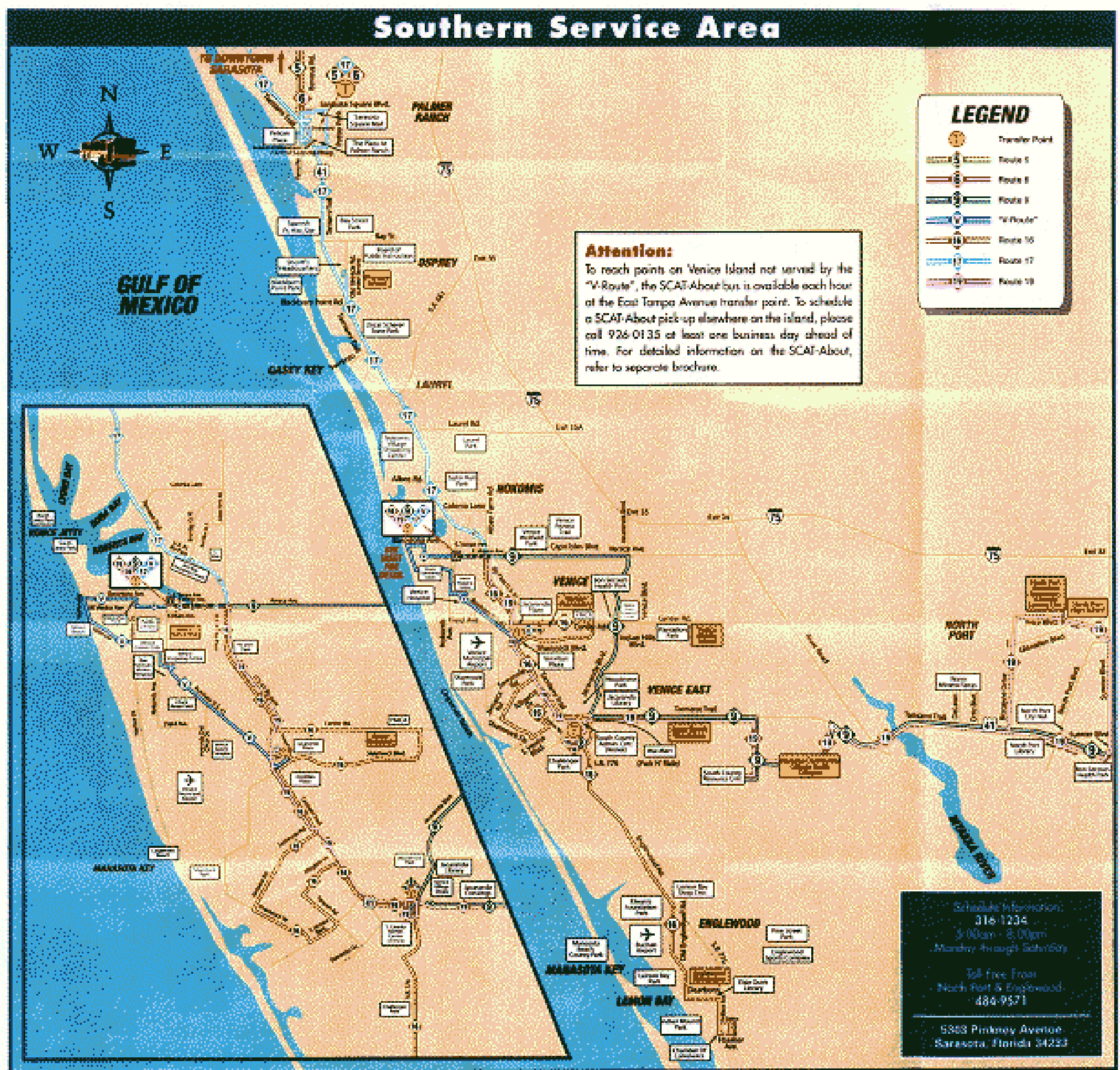




\section{SCAT Services}

The following services are currently being offered by SCAT (4):

\section{Fixed Route}

SCAT's fixed route provides service along the following routes.

Table 2: SCAT Fixed Route Services

\begin{tabular}{|l|l|}
\hline Route No. & Service Area \\
\hline 1 & Fruitville Road \\
\hline 2 & Art School \\
\hline 3 & Pine Craft \\
\hline 4 & Lido \\
\hline 5 & Osprey-Swift \\
\hline 6 & Beneva \\
\hline 7 & Newtown NE Plaza \\
\hline 8 & Newton 301 \\
\hline 9 & North Port \\
\hline 10 & No route Currently Assigned \\
\hline 11 & Siesta Key \\
\hline 12 & North Lockwood \\
\hline 14 & Bee Ridge \\
\hline 15 & Airport/Cattlemen \\
\hline 16 & Englewood \\
\hline 17 & Trail \\
\hline 18 & Longboat \\
\hline 19 & Price BLVD \\
\hline
\end{tabular}

\section{Express}

The SCAT Express provides service along the express routes nine and sixteen, which runs via Ringling Boulevard, Cattlemen Road, 1-75 and Jacaranda Boulevard. 


\section{Sarasota Trolleys}

The Sarasota trolleys allow customers to enjoy the view of downtown Sarasota, while conveniently and comfortably riding to their destination via one of the SCAT's trolley car reproductions. The trolley buses are air-conditioned and equipped to transport up to two wheelchair riders. Table 3 shows the types of trolleys offered during the week.

Table 3: Sarasota Trolleys

\begin{tabular}{|l|l|}
\hline Route & Sarasota Trolleys \\
\hline Monday - Friday & Downtown Loop \\
\hline Saturday & Downtown Loop \\
\hline Monday - Saturday & Scenic Loop \\
\hline
\end{tabular}

\section{V-Route}

The V-Route is a traditional fixed-bus, public transportation service. It services specified streets throughout Venice Island from East Tampa Avenue to Publix on U.S Business 41 and to Jacaranda Plaza Monday through Saturday from 6:00am to 6:35pm.

\section{SCAT-About}

The SCAT-About service is designed as an alternative to the "V-route" and provides service to the entire Island of Venice (except Caspersen Beach) Monday through Saturday from 6:00am to $7: 00 \mathrm{pm}^{\prime \prime}$. Reservations for this service are guaranteed if made at least 24 hours in advance or prior to $2.00 \mathrm{pm}$ the day before a scheduled trip.

\section{SCAT + Plus}

The SCAT + Plus service is comprised of two programs, namely:

\section{Transportation Disadvantaged}

SCAT + Plus provides specialized door-to-door transportation for those individuals who, because of a disability, age or any other reason are dependent on others and are physically unable to access the SCAT fixed-bus route system. On occasion private providers contracted with SCAT + Plus will be used when necessary

\section{Medicaid Bus Pass Program}

Sarasota County Area Transit offers individuals meeting the criteria under the Medicaid Program a special Medicaid bus pass. For a minimum cost of $\$ 2.00$ per month the Medicaid bus pass allows unlimited trips on the SCAT fixed bus route system.

ADA Bus Pass Program

This program offers free monthly passes for silver card clients who voluntarily refrain from using the SCAT + Plus system. Silver card clients are eligible for door-to-door fixed-route transit services. 


\section{Fare Policy}

Table 4 is a summary of the fare policy of SCAT (4).

Table 4: SCAT Fare Policy

\begin{tabular}{|l|l|}
\hline Service Provided & Full Fare \\
\hline Basic Fixed-route Bus Fare & $\$ 0.50$ \\
\hline SCAT Express & $\$ 1.00$ \\
\hline V-Route & $\$ 0.50$ \\
\hline SCAT-About & $\$ 1.00$ \\
\hline Sarasota Trolley Main Street & $\$ 0.25$ \\
\hline Sarasota Trolley Scenic & $\$ 1.00$ \\
\hline Disabled and Senior Citizens Fixed-route Bus Fare & $\$ 0.25$ \\
\hline Transportation Disadvantaged Bus Fare & $\$ 2.00$ \\
\hline Americans with Disabilities Bus Fare & $\$ 1.00$ \\
\hline Medicaid Monthly Bus Pass & $\$ 2.00$ \\
\hline Monthly Unlimited Use Passport & $\$ 30.00$ \\
\hline 20 Ride bus punch card & $\$ 10.00$ \\
\hline ADA Bus Pass & FREE \\
\hline
\end{tabular}

Discounted monthly bus passport and 20 ride bus punch cards are also available for frequent rides who are senior citizens, disabled or on Medicare. Discounted monthly bus passports are $\$ 15$, while discounted 20 ride bus punch cards are $\$ 5$. Up to two children age 5 years or younger may ride the bus free with each paying passenger. 


\section{Performance Measures}

Table 5 shows the changes in various performance measures from FY 1999 to FY 2000 (5).

Table 5: SCAT Transit Performance Measures from FY 1999 to FY 2000

\begin{tabular}{|l|l|l|l|}
\hline General Performance Indicators & FY 98/99 & FY 99/2000 & Percent Change \\
\hline Service Area Population & 272,00 & 278,800 & $2.5 \%$ \\
\hline Passenger Trips & $1,607,504$ & $1,620,586$ & $0.8 \%$ \\
\hline Passenger Miles & $9,279,654$ & $10,366,340$ & $11,7 \%$ \\
\hline Route Miles & 394.4 & 394.4 & $0.0 \%$ \\
\hline Total Operating Expense & $\$ 4,465,765$ & $\$ 4,966,701$ & $11.2 \%$ \\
\hline Operating Revenue & $\$ 1,162,470$ & $\$ 1,096,567$ & $-5.7 \%$ \\
\hline Effectiveness Measures & & & \\
\hline Vehicle Miles Per Capita & 5.94 & 6.29 & $6.1 \%$ \\
\hline Passenger Trips per Capita & 5.91 & 5.81 & $-1.6 \%$ \\
\hline Average Age of Fleet (years) & 5.82 & 6.82 & $17.2 \%$ \\
\hline Revenue Miles Between Accidents & 167,492 & 96,184 & $-42.6 \%$ \\
\hline Efficiency Measures & & & 1,103 \\
\hline Operating Expense Per Capita & $\$ 16.80$ & $\$ 17.81$ & $8.5 \%$ \\
\hline Operating Expense Per Passenger Trip & $\$ 2.78$ & $\$ 3.06$ & $10.3 \%$ \\
\hline Revenue Hours Per Employee & 1,206 & $9.3 \%$ \\
\hline
\end{tabular}

\subsection{Issues AND TRENDS RELATING to SCAT}

Based on the profile, performance measures and extensive communication with staff and management the following issues and trends were identified for SCAT.

Increase frequencies on fixed-route system - SCAT is looking at changing the majority of one-hour frequencies to half an hour, either system-wide or on the best performing routes.

Marketing - SCAT is planning on expanding and refining marketing to improve image, gain ridership, and widen the potential customer base by targeting various socio-economic groups, such as the youth market. 
Business-to-business relationships - Establishing or improving advertising on buses and schedules, and joint promotional activities.

Transit information - Planning on providing real-time schedule information via telephone, kiosk and/or computer.

Fleet management - Updating existing communications system, implementing GIS, AVL/GPS, and APCs.

Establishing park-and-ride lots - Working with the MPO and the FDOT, potential park-and-ride lots have been suggested in conjunction with new express services.

Implement paratransit feeder service to the fixed-route system - Paratransit picks up passengers and takes them to bus stops. Sixty-four percent of respondents to a recent survey said they would consider using SCAT if SCAT + Plus delivered them to the SCAT bus stops.

Identify areas with potential for expansion of fixed-route services - Expand routes and obtain additional buses due to expanded coverage.

Establish alternative fare payment methods - A multi-modal voucher program for transportation and a SCAT "all-day fare pass" are options.

Enhance SCAT website - Provide real-time information.

Establishing a guaranteed ride home program - This is to be initiated as part of the new bi-county Commuter Assistance Program being administered by SCAT.

Establish Sunday service.

Increase span of service to $10: 30 \mathrm{PM}$

Bus operators cited the following areas for improvement - The night/evening service and increase of bus frequency were highest priorities. Then installing bus shelters, adding time to schedules, Sunday service and improved information. 


\subsection{ExISTING APTS AT SCAT}

Table 6 shows the extent of deployment of APTS at SCAT.

Table 6: Existing APTS At SCAT

\begin{tabular}{|c|c|c|}
\hline APTS Categories & Status & Details \\
\hline \multicolumn{3}{|l|}{ Transit Management Systems } \\
\hline Transit Operations Software & $\begin{array}{l}\text { Operational in } \\
\text { January } 2001\end{array}$ & $\begin{array}{l}\text { Installed Trapeze PASS for para-transit } \\
\text { scheduling. Will be installing Trapeze INFO to } \\
\text { assist in trip planning. Will install Trapeze FX- } \\
\text { LITE to assist in providing internal management } \\
\text { controls. }\end{array}$ \\
\hline Communication Systems & Operational & $\begin{array}{l}\text { Has } 7 \text { voice only talk groups (channels) with } \\
\text { County's } 800 \mathrm{MgHz} \text { radio. It is a Motorola } \\
\text { Astro Digital System } 3.01 \mathrm{MBE} \text {. }\end{array}$ \\
\hline \multicolumn{3}{|l|}{ Electronic Fare Payment Systems } \\
\hline Magnetic Fare Media & Not functioning & Installed Agent's Farebox in October 2000 \\
\hline Traveler Information Systems & None & \\
\hline Transit Intelligent Vehicle Initiative & None & \\
\hline
\end{tabular}




\subsection{NEEDS ANALYSES}

This section contains SCAT APTS needs analyses. Technologies that address SCAT needs and a determination of their proven capabilities and interoperability with Sarasota County's ITS Plan and emerging statewide ITS Architecture were identified. A detailed analyses of the technologies needed were assessed based on interviews with SCAT personal, agency issues and trends, SCAT goals and objectives, and regional ITS architecture. These technologies were ranked and prioritized by SCAT management.

\subsection{Potential APTS at SCAT Based ON INTERVIEWS}

Interviews with SCAT employees were conducted in October 2001 to determine the areas that can benefit from APTS and what technologies are most highly desired. SCAT para-transit staff, maintenance staff and a fixed-route driver were interviewed face-to-face. The following is a summary of needs expressed during the interviews (6):

$>$ GPS on buses was called the "best thing (we) can ever get" by one employee.

$>$ A staff member complained it was hard to adhere to schedules because of heavy congestion on some corridors. A well-designed BSP system might correct this problem.

$>$ A staff member expressed an interest in an automated telephone system that helps with dispatch calls and reduces instances of lost calls.

$>$ The maintenance division wanted automation for accountability of fuel usage. A staff member stated the inventory systems needed improvement.

$>$ One of the more commonly cited difficulties among many staff members was with the current fare box system. A state-of-the-art EFP system would solve the continuing problems with bills and coins being stuck in fare boxes.

$>$ The need to announce stops was a complaint by one of the staff members. If a driver is either running late or unable to make the announcements it increases the chances they may neglect to do so. This can lead to customer confusion and dissatisfaction. A PA system with an annunciator is an APTS solution for this problem.

$>$ An Automated Information System with an interactive web page is another key requirement stated by SCAT employees. Such a site would help further customer support and increase the customer base's ability to effectively and conveniently utilize the transit system. 


\subsection{Needs Based on SCAT Agency Issues}

Table 7 summarizes SCAT agency needs based on its current issues.

Table 7: Technology for SCAT Issues

\begin{tabular}{|l|l|}
\hline Agency Issues & Candidate APTS Technology \\
\hline $\begin{array}{l}\text { Widen the potential customer base to various socio- } \\
\text { economic groups such as youth markets }\end{array}$ & $\begin{array}{l}\text { Real-time information has the potential to improve } \\
\text { transit service and visibility within the community. }\end{array}$ \\
\hline Update existing communications & $\begin{array}{l}\text { Improve existing communication system to voice and } \\
\text { data. }\end{array}$ \\
\hline $\begin{array}{l}\text { Working with the MPO and FDOT to establish park- } \\
\text { and-ride lots }\end{array}$ & $\begin{array}{l}\text { Real-time information with TCP software at the park } \\
\text { and ride lots would make them more convenient for } \\
\text { users. }\end{array}$ \\
\hline $\begin{array}{l}\text { Implement paratransit feeder service to the fixed- } \\
\text { route system }\end{array}$ & $\begin{array}{l}\text { CAD software with TCP software will help } \\
\text { passengers make a transfer to a connecting bus and } \\
\text { current schedule adherence more reliable. }\end{array}$ \\
\hline Establish alternative fare payment methods & $\begin{array}{l}\text { A working EFP system with a multi-modal voucher } \\
\text { program for transportation and a SCAT "all-day fare } \\
\text { pass" are options. }\end{array}$ \\
\hline \begin{tabular}{l} 
Provide real-time information. \\
\hline Enhance SCAT website
\end{tabular} & $\begin{array}{l}\text { Dynamic ridesharing program would facilitate and } \\
\text { increase the use of SCAT. }\end{array}$ \\
\hline Establishing a guaranteed ride home program &
\end{tabular}

\subsection{NeEDs Based ON SCAT GoAls}

SCAT goals along with the technology that has the potential to address a particular goal are tabulated below.

Table 8: Technologies Based on SCAT Goals

\begin{tabular}{|l|l|}
\hline Goal & Candidate APTS Technology \\
\hline $\begin{array}{l}\text { Goal 1: Increase community awareness of } \\
\text { transportation alternatives in relation to the stated } \\
\text { need for a balanced multi-modal transportation } \\
\text { system. }\end{array}$ & $\begin{array}{l}\text { Traveler Information Systems - Real-time information } \\
\text { has the potential to improved transit service and } \\
\text { visibility within the community. }\end{array}$ \\
\hline $\begin{array}{l}\text { Goal 2: Recommend public policies that support a } \\
\text { balanced multi-modal transportation system. }\end{array}$ & $\begin{array}{l}\text { AVU/GPS with CAD/TCP and Traveler Information } \\
\text { Systems - Facilitates and increases the use of public } \\
\text { transportation. }\end{array}$ \\
\hline $\begin{array}{l}\text { Goal 3: Address the mobility needs of the } \\
\text { underserved populations and recommend solutions } \\
\text { to meet those needs. }\end{array}$ & $\begin{array}{l}\text { Annunciators on buses and Transit Accessibility } \\
\text { Systems - Increases compliance with the ADA and } \\
\text { improves transit service to the transportation } \\
\text { disadvantaged. }\end{array}$ \\
\hline $\begin{array}{l}\text { Goal 4: Create an integrated, countywide, multi- } \\
\text { modal transportation system that provides links to } \\
\text { the larger metropolitan community. }\end{array}$ & $\begin{array}{l}\text { AVLGPS, CAD/TCP, Traveler Information Systems } \\
\text { and EFP Systems - Facilitates and increases the use of } \\
\text { public transportation. }\end{array}$ \\
\hline
\end{tabular}




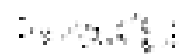

Goal 5: To promote future-oriented transit designs coordinated with the local environment, land uses, and surface transportation systems.

Goal 6: To secure funding sources dedicated to the enhancement of mobility within the community.
Transportation Demand Management combined with EFP Systems - increases customer convenience and reduces the amount of automobile travel on the roadways.

AVL/GPS, CAD/TCP, Traveler Information Systems and EFP Systems - Facilitates and increases the use of public transportation hence increasing mobility.

\subsection{FDOT District ONE ITS ARCHITECTURE}

Jaffe Engineering, along with Kimley-Horn \& Associates, Inc., developed the Florida Department of Transportation (FDOT) Statewide ITS Architecture based on the National ITS Architecture and the Florida ITS Strategic Plan. The architecture is defined by districts on their website, http://www.jeng.com/florida/Default.htm. Each District has its own architecture interconnect diagram that is based on the needs of the stakeholders and the local jurisdictions within that particular region of the state. SCAT falls within the jurisdiction of District One (7).

The District One ITS Architecture interconnects multiple organizations, within its boundaries. These organizations crisscross between counties, cities and MPOs. As with many of the defined state architectures, District One includes many customized market packages. Market packages are considered on ITS building blocks. The transit related market packages prioritized in the District One Architecture are summarized below and tabulated in Table 9:

Transit vehicle tracking - The transit vehicle tracking for Sarasota County (both transit and paratransit) currently has transit schedules and fare information accessible from web sites. In the future, transit passengers will make requests for service via these web sites. As a result, dispatch would need to be able to receive and process the request to the transit vehicles, which in turn would need to be able to accept the information. This would require transit vehicle location and schedule performance information. Related to transit vehicle tracking are transit traveler information services. These would entail enhancing the websites to provide detailed transit information and handle the requests.

Transit fixed route operations - These require interaction between traffic management, transit management, and the transit vehicle and driver. The technologies needed are traffic information for transit, driver availability, route assignment, vehicle schedule performance, and driver instructions. The various areas involved would all need to process and receive this information. Demand response for county paratransit requires the same types of hardware and information, with the difference of servicing requests for transit rather than schedules.

Transit security and maintenance - This currently has little APTS applications. Emergency notification is present on transit, however emergency data and acknowledgement is needed by the 
county emergency center, as well as SCAT's security. The vehicles also require emergency acknowledgement. In the field of maintenance, transit management and personnel require vehicle condition information, maintenance status, and work schedule. The transit vehicle should be able to transmit vehicle conditions via on-board maintenance.

Multi-modal coordination - In terms of signal priority requires significant APTS. Transit management needs vehicle schedule performance, while the vehicle itself must make the priority request. The traffic control equipment (operated by City of Sarasota) must then accept the request, followed by traffic management via the TMC processing and executing the request. The multimodal coordination as it relates to transit schedule coordination is also complex. TRMS is currently in place in Collier County, LeeTran, inter-city bus services, SCAT, and MCAT. To further the service options, transit multi-modal information is needed between LeeTran bus high-speed ferry system, Southwest Florida international airport, SCAT, MCAT, and Sarasota/Bradenton international airport.

Table 9: Planned APTS for SCAT in Regional Architecture

\begin{tabular}{|c|c|c|c|}
\hline $\begin{array}{l}\text { Type of Market } \\
\text { Package }\end{array}$ & Participating Area & Existing Flow & Planned/Future Flow \\
\hline \multirow[t]{3}{*}{$\begin{array}{l}\text { Transit Vehicle } \\
\text { Tracking (SCAT) }\end{array}$} & $\begin{array}{l}\text { - Information Service Provider } \\
\text { - Private sector traveler } \\
\text { information services } \\
\text { - Local agency web sites } \\
\end{array}$ & $\begin{array}{l}\text { Transit and fare } \\
\text { schedules }\end{array}$ & - Transit information request \\
\hline & $\begin{array}{l}\text { Transit Management (SCAT } \\
\text { Dispatch: Transit center } \\
\text { tracking and dispatch) }\end{array}$ & $\begin{array}{l}\text { Transit and fare } \\
\text { schedules }\end{array}$ & $\begin{array}{l}\text { - Transit information request } \\
\text { - Transit vehicle location data } \\
\text { - Transit vehicle schedule performance }\end{array}$ \\
\hline & $\begin{array}{l}\text { - Transit Vehicle (SCAT transit } \\
\text { vehicles: On-board trip } \\
\text { monitoring) } \\
\end{array}$ & & $\begin{array}{l}\text { - Transit vehicle location data } \\
\text { - Transit vehicle schedule performance }\end{array}$ \\
\hline \multirow[t]{3}{*}{$\begin{array}{l}\text { Transit Vehicle } \\
\text { Tracking (County } \\
\text { Paratransit } \\
\text { Systems) }\end{array}$} & $\begin{array}{l}\text { Information Service Provider } \\
\text { - Private sector traveler } \\
\text { iniormation services } \\
\text { - Local agency web sites }\end{array}$ & $\begin{array}{l}\text { Transit and fare } \\
\text { schedules }\end{array}$ & - Transit information request \\
\hline & $\begin{array}{l}\text { - Transit Management (County } \\
\text { paratransit systems: Transit } \\
\text { center tracking and dispatch) }\end{array}$ & $\begin{array}{l}\text { Transit and fare } \\
\text { schedules }\end{array}$ & $\begin{array}{l}\text { - Transit information request } \\
\text { - Transit vehicle location data } \\
\text { - Transit vehicle schedule performance }\end{array}$ \\
\hline & $\begin{array}{l}\text { Transit Vehicle (County } \\
\text { paratransit vehicles: On- } \\
\text { board trip monitoring) }\end{array}$ & & $\begin{array}{l}\text { - Transit vehicle location data } \\
\text { - Transit vehicle schedule performance }\end{array}$ \\
\hline $\begin{array}{l}\text { Transit Fixed- } \\
\text { Route Operations } \\
\text { (SCAT) }\end{array}$ & - Traffic Management & & - Traffic information for transit \\
\hline
\end{tabular}




\begin{tabular}{|c|c|c|c|}
\hline $\begin{array}{l}\text { Type of Market } \\
\text { Package }\end{array}$ & Participating Area & Existing Flow: & Planned/Future Flow \\
\hline & $\begin{array}{l}\text { - Transit Management (SCAT } \\
\text { Dispatch: } \\
\text { - Transit center fixed route } \\
\text { operations } \\
\text { - Transit garage operations } \\
\end{array}$ & & $\begin{array}{l}\text { - Traffic information for transit } \\
\text { - Transit driver availability } \\
\text { - } \text { Route assignment }\end{array}$ \\
\hline & - Transit Drivers & & $\begin{array}{l}\text { - Transit driver availability } \\
\text { - Route assignment }\end{array}$ \\
\hline & $\begin{array}{l}\text { Transit Vehicle (SCAT transit } \\
\text { vehicles: On-board fixed } \\
\text { route schedule management) }\end{array}$ & & $\begin{array}{l}\text { - Transit vehicle schedule performance } \\
\text { - Driver instructions }\end{array}$ \\
\hline \multirow[t]{2}{*}{$\begin{array}{l}\text { Demand } \\
\text { Response Transit } \\
\text { Operations } \\
\text { (County } \\
\text { Paratransit) }\end{array}$} & $\begin{array}{l}\text { - Transit Management (County } \\
\text { paratransit systems: } \\
\text { - Transit center Para transit } \\
\text { operations } \\
\text { - Transit garage operations } \\
\end{array}$ & & $\begin{array}{l}\text { - Transit driver availability } \\
\text { - Route assignment }\end{array}$ \\
\hline & - Transit Driver & & $\begin{array}{l}\text { - Transit driver availability } \\
\text { - Route assignment }\end{array}$ \\
\hline \multirow[t]{3}{*}{$\begin{array}{l}\text { Transit Security } \\
\text { (SCAT) }\end{array}$} & $\begin{array}{l}\text { - Emergency Management } \\
\text { (County Emergency } \\
\text { Communications Center) } \\
\end{array}$ & & $\begin{array}{l}\text { - Transit emergency data } \\
\text { - Transit emergency coordination data }\end{array}$ \\
\hline & $\begin{array}{l}\text { Transit Management (SCAT } \\
\text { Dispatch: Transit center } \\
\text { security) }\end{array}$ & $\begin{array}{l}\text { Emergency } \\
\text { notification }\end{array}$ & $\begin{array}{l}\text { - Transit emergency data } \\
\text { - Transit emergency coordination data } \\
\text { - Emergency acknowledgement }\end{array}$ \\
\hline & $\begin{array}{l}\text { - Transit Vehicle (SCAT transit } \\
\text { vehicles: On-board transit } \\
\text { security) }\end{array}$ & $\begin{array}{l}\text { Emergency } \\
\text { notification }\end{array}$ & - Emergency acknowledgement \\
\hline \multirow[t]{3}{*}{$\begin{array}{l}\text { Transit } \\
\text { Maintenance } \\
\text { (SCAT) }\end{array}$} & $\begin{array}{l}\text { Transit Management (SCAT } \\
\text { Dispatch: Transit garage } \\
\text { maintenance) }\end{array}$ & & $\begin{array}{l}\text { - Transit vehicle conditions } \\
\text { - Maintenance status } \\
\text { - Transit work schedule }\end{array}$ \\
\hline & $\begin{array}{l}\text { Transit Maintenance } \\
\text { Personnel }\end{array}$ & & $\begin{array}{l}\text { - Maintenance status } \\
\text { - Transit work schedule } \\
\end{array}$ \\
\hline & $\begin{array}{l}\text { - Transit Vehicle (SCAT transit } \\
\text { vehicles: On-board } \\
\text { maintenance) }\end{array}$ & & - Transit vehicle conditions \\
\hline \multirow{3}{*}{$\begin{array}{l}\text { Multi-Modal } \\
\text { Coordination - } \\
\text { Signal Priority } \\
\text { (SCAT) }\end{array}$} & $\begin{array}{l}\text { Transit Management (SCAT } \\
\text { Dispatch: Transit center } \\
\text { multi-modal coordination) }\end{array}$ & & - Transit vehicle schedule performance \\
\hline & $\begin{array}{l}\text { Transit Vehicle (SCAT transit } \\
\text { vehicles: On-board transit } \\
\text { signal priority) }\end{array}$ & & $\begin{array}{l}\text { - Transit vehicle schedule performance } \\
\text { - Local signal priority request }\end{array}$ \\
\hline & $\begin{array}{l}\text { Roadway (City of Sarasota } \\
\text { traífic control equipment and } \\
\text { Sarasota County traffic } \\
\text { control equipment: Roadside } \\
\text { signal priority) }\end{array}$ & & $\begin{array}{l}\text { - Local signal priority request } \\
\text { - Request for right of way }\end{array}$ \\
\hline
\end{tabular}




\begin{tabular}{|c|c|c|c|}
\hline $\begin{array}{l}\text { Type of Market } \\
\text { Package }\end{array}$ & Participating Area & Existing Flow & Planned/Future Flow \\
\hline & $\begin{array}{l}\text { Traffic Management (City of } \\
\text { Sarasota traffic signal control } \\
\text { system and Sarasota County } \\
\text { traffic signal control system; } \\
\text { TMC multi-modal } \\
\text { coordination) } \\
\end{array}$ & & - Request for right of way \\
\hline \multirow[t]{7}{*}{$\begin{array}{l}\text { Multi-Modal } \\
\text { Coordination - } \\
\text { Transit Schedule } \\
\text { Coordination }\end{array}$} & $\begin{array}{l}\text { Transit Management (Collier } \\
\text { County deviated fixed route } \\
\text { system: Transit center multi- } \\
\text { modal coordination) }\end{array}$ & $\begin{array}{l}\text { TRMS } \\
\text { coordination }\end{array}$ & \\
\hline & $\begin{array}{l}\text { Transit Management } \\
\text { (LeeTran fixed route transit } \\
\text { dispatch system: Transit } \\
\text { center multi-modal } \\
\text { coordination) } \\
\end{array}$ & $\begin{array}{l}\text { TRMS } \\
\text { coordination }\end{array}$ & - Transit multi-modal information \\
\hline & $\begin{array}{l}\text { Transit Management (Inter- } \\
\text { city bus service: Transit } \\
\text { center multi-modal } \\
\text { coordination) } \\
\end{array}$ & $\begin{array}{l}\text { TRMS } \\
\text { coordination }\end{array}$ & \\
\hline & $\begin{array}{l}\text { Multi-Modal Transportation } \\
\text { Service Provider (Buque bus } \\
\text { high speed ferry } \\
\text { system/LeeTran inter-modal } \\
\text { center/ Southwest Florida } \\
\text { international airport) } \\
\end{array}$ & & - Transit multi-modal information \\
\hline & $\begin{array}{l}\text { Transit Management (SCAT } \\
\text { dispatch: Transit center } \\
\text { multi-modal coordination) }\end{array}$ & $\begin{array}{l}\text { TRMS } \\
\text { coordination }\end{array}$ & - Transit multi-modal information \\
\hline & $\begin{array}{l}\text { Transit Management (MCAT } \\
\text { dispatch: Transit center } \\
\text { multi-modal coordination) }\end{array}$ & $\begin{array}{l}\text { TRMS } \\
\text { coordination }\end{array}$ & - Transit multi-modal information \\
\hline & $\begin{array}{l}\text { Multi-modal Transportation } \\
\text { Service Provider } \\
\text { (Sarasota/Bradenton } \\
\text { international airport) } \\
\end{array}$ & & - Transit multi-modal information \\
\hline \multirow{3}{*}{$\begin{array}{l}\text { Transit Traveler } \\
\text { Information } \\
\text { (SCAT) }\end{array}$} & $\begin{array}{l}\text { Information Service Provider } \\
\text { (Local agency web pages) }\end{array}$ & $\begin{array}{l}\text { Transit and fare } \\
\text { schedules }\end{array}$ & \\
\hline & $\begin{array}{l}\text { Transit Management (Scat } \\
\text { dispatch: Transit center } \\
\text { information service) }\end{array}$ & & $\begin{array}{l}\text { - Transit information request } \\
\text { - Transit and fare schedules }\end{array}$ \\
\hline & $\begin{array}{l}\text { - Information Service Provider } \\
\text { (Private sector traveler } \\
\text { information services) }\end{array}$ & & $\begin{array}{l}\text { - Transit information request } \\
\text { - Transit and fare schedules }\end{array}$ \\
\hline
\end{tabular}

Note: For detailed diagrams of the above market packages refer to http://www.jeng.com//florida/districts/D1/D1.htm 


\subsection{Candidate Needs Based On ITS ArChitecture}

Table 10 is based on the ITS market packages that have been suggested for SCAT. The candidate APTS technology group is suggested based on existing APTS at SCAT and the future architecture flows suggested in table 9 .

Table 10: APTS for SCAT According to Regional ITS Architecture

\begin{tabular}{|c|c|c|}
\hline $\begin{array}{c}\text { Transit Area / Technology } \\
\text { Category }\end{array}$ & Reason (Future Architecture Flow) & Candidate APTS Technology Group \\
\hline$\frac{\text { SCAT }}{\text { Traveler Information }}$ & $\begin{array}{l}\text { Transit information } \\
\text { - Transit schedules }\end{array}$ & $\begin{array}{l}\text { Real-time information } \\
\text { systems }{ }^{(1)} \\
\text { - Computer upgrade } \\
\text { - CAD } \\
\text { - } \text { systems and Itinerary planning } \\
\text { - }\end{array}$ \\
\hline$\frac{\text { SCAT }}{\text { Transit Management }}$ & $\begin{array}{l}\text { - Traffic information } \\
\text { - Vehicle location data } \\
\text { - Driver availability and instructions } \\
\text { - Vehicle schedule performance }\end{array}$ & $\begin{array}{l}\text { - Transit Operations Software } \\
\text { - Automatic Vehicle Location } \\
\text { - CAD and Itinerary planning } \\
\text { systems } \\
\text { - Computer upgrade }\end{array}$ \\
\hline$\frac{\text { SCAT }}{\text { Transit Management }}$ & $\begin{array}{l}\text { - Vehicle schedule performance } \\
\text { - } \quad \text { Local signal priority request } \\
\text { coordination }\end{array}$ & $\begin{array}{l}\text { - Transit Signal Priority (TSP) } \\
\text { - TSP Hardware } \\
\text { - } \text { Timing strategies } \\
\text { - } \\
\text { - Mobility Manager } \\
\end{array}$ \\
\hline$\frac{\text { SCAT }}{\text { Transit Management }}$ & $\begin{array}{l}\text { - Transit vehicle conditions } \\
\text { - Maintenance status } \\
\text { - Transit work schedule }\end{array}$ & $\begin{array}{l}\text { - Vehicle component } \\
\text { monitoring } \\
\text { - Engine temperature } \\
\text { - Oil pressure conditions } \\
\text { - On board computer } \\
\end{array}$ \\
\hline $\begin{array}{l}\text { SCAT } \\
\text { Transit Management }\end{array}$ & $\begin{array}{l}\text { - } \text { Transit emergency data } \\
\text { - Emergency coordination data } \\
\text { - Emergency acknowledgement }\end{array}$ & $\begin{array}{l}\text { - } \text { Communications upgrade } \\
\text { - } \mathrm{AVL}^{(2\rangle}\end{array}$ \\
\hline $\begin{array}{l}\text { SCAT Plus } \\
\text { Transit Management }\end{array}$ & $\begin{array}{l}\text { Transit driver availability } \\
\text { - Route assignment }\end{array}$ & $\begin{array}{l}\text { - Real-time information } \\
\text { systems }{ }^{(1)} \\
\text { - } \\
\text { - TVL }{ }^{(2)} \\
\text { - } \\
\text { CADsit Op and Itinerary planning } \\
\text { systems }\end{array}$ \\
\hline
\end{tabular}

Notes:

1. Real-time information systems include the following

Pre-trip Information Systems

In-terminal and Wayside Information Systems

In-vehicle Information System

2. AVL includes the following:

Tracking unit includes GPS antenna and cable

Mobile Data Terminal

Workstations 


\subsection{Prioritized Summary Of Needs}

Table 11 lists the prioritized summary of needs. The findings from staff interviews, SCAT goals, SCAT issues and the ITS Architecture for the region were presented to SCAT management. Based on the findings, management prioritized the APTS technologies as shown below. The ranking guidelines for the tables are as follows:
0 - Do not want to rank at this time
1 - Immediate Need (1-2 Years)
$>2$ - Short-term Need (1-5 Years)
$>3$ - Mid-term Need (5-10 Years)
> 4 - Long-term Need (10-20 Years)

Table 11: Prioritized Summary of APTS Technologies

\begin{tabular}{|l|l|c|l|}
\hline & Major APTS Categories & Rank & \multicolumn{1}{|c|}{ Comments } \\
\hline 1 & Transit Management Systems - improves service & & \\
\hline & . Automatic Vehicle Location (AVL) System - backbone of APTS & 1 & \\
\hline & . Automated Passenger Counters (APC) - improves transit info. & 2 & \\
\hline & . Transit Operations Software - improve operating efficiency & 1 & Fixed-route and paratransit \\
\hline & . Vehicle Component Monitoring - improve operating efficiency & 3 & \\
\hline & . On Board Safety Features - increase safety & 2 & \\
\hline & . Advanced Communication System - improve information & 2 & \\
\hline & . Bus Signal Priority - improves operating efficiency & $2 / 3$ & $\begin{array}{l}\text { (congested corridors 2; } \\
\text { non-congested corridors3) }\end{array}$ \\
\hline & & & \\
\hline II & Advanced Traveler Information Systems - increase reliability & & \\
\hline & . Itinerary Planning Systems - increase reliability & 2 & \\
\hline & . Real-time Information Systems - increase ridership & 2 & \\
\hline & . Transit Accessibility Systems - improve customer convenience & 3 & \\
\hline & . Website - improve customer convenience & 2 & \\
\hline & . CSR/IVR - Telephone System - improve customer convenience & 3 & \\
\hline & & & \\
\hline III & Electronic Fare Payment Systems - improve security of revenue & 1 & \\
\hline & & & \\
\hline
\end{tabular}




\begin{tabular}{|l|l|c|c|}
\hline IV & Transportation Demand Management - better management & 3 & \\
\hline & . Automated Service Coordination & 3 & \\
\hline & . Transportation Management Centers & 3 & \\
\hline & Manage park and ride lots & 3 & \\
\hline & & & \\
\hline V & Transit Intelligent Vehicle Initiative - increase safety & $3 / 2$ & (paratransit 2; fixed-route 3) \\
\hline
\end{tabular}

Notes: Text in italics denotes possibilities by that particular technology.

\section{Immediate Needs (1-2 Years)}

An Automatic Vehicle Location/Monitoring (AVUAVM) system (with Mobile Data Terminals (MDT) and advanced vehicle and control center communication systems) is the most immediate need (1-2 years). These technologies require a centralized operations control and dispatch center with schedule adherence monitoring abilities. A Computer Aided Dispatch (CAD) with Transfer Connection Protection (TCP) software assists real-time traffic information in addition to easing scheduling. AVL system and CAD would improve scheduling and dispatch. An existing electronic fare-box system that can use magnetic stripe fare media is awaiting modifications for implementation. Smart card fare media and electronic vending outlets are the anticipated upgrades for the electronic fare-box system within 1-2 years. This would eliminate any problems with the machines not accepting bills by using smart cards. Smart cards also help increase transit usability as people need not worry about always having money on hand. Transit operations software for both fixed route and paratransit services are needed to improve operating efficiency in the immediate future.

The following is a summary of immediate needs for SCAT:

$>$ Automatic Vehicle Location

Transit Operations Software

$>$ Electronic Fare Payment Systems

\section{Short-Term Needs (1-5 Years)}

Automated Passenger Counters (APC), On-Board Safety Features and an upgrade to the existing communication system are identified as short-term needs (1-5 years). An itinerary planning system and an updated Website (providing real-time bus information) are also needed in the short term. This enables transit customers to know exactly when the vehicle will arrive, even if it is running behind schedule. One of the rider's most frequently cited problems is not knowing when the bus will arrive. To help increase safety, Transit IVI for paratransit service is recommended within the next five years. It would also help assist in gathering data to better time the routes. Bus signal priority on congested corridors is also identified as a short term need. 
The following is summary of short-term needs for SCAT:

Automatic Passenger Counters

$>$ On-board Safety Components

Advanced Communication Systems

$>$ Bus Signal Priority

$>$ Itinerary Planning Systems

$>$ Real-time Information Systems

$>$ Website Design

\section{Mid-Term Needs (5-10 Years)}

Transit accessibility systems are needed in the mid-term (5-10 years). Transit accessibility systems use technology to help solve problems of transit access for persons with sensory and cognitive impairments. A vehicle component monitoring (to gauge engine temperature, oil pressure conditions etc.) system for each vehicle is suggested as a mid-term need. Transportation Demand Management (TDM) areas of automated service coordination, transportation management centers and managed park and ride lots are also needed within the next 5-10 years. Transit IVI technologies for fixed route buses are recommended within the next ten years.

The following is a summary of mid-term needs for SCAT:

Vehicle Component Monitoring

$>$ Transit Accessibility Systems

$>$ CSR/IVR - Telephone System

$>$ Transportation Demand Management

$>$ Automated Service Coordination

$>$ Parking Management

> Transit Intelligent Vehicle Initiative

\section{Long-Term Needs}

As the technologies are changing rapidly, there are currently no suggested long-term (beyond 10 years) needs for SCAT. 


\subsection{PROFILES OF TECHNOLOGIES}

\subsection{IMMediate NeEDS TeCHNOlOGies}

Technologies identified in the previous section based on SCAT immediate needs are outlined below. This section outlines their proven capabilities, state-of-the-art, and challenges to SCAT deployment for each of the prioritized technologies.

\section{AUTOMATIC VEHICLE LOCATION SySTEMS}

\section{Description}

AVL systems are computer-based vehicle tracking systems that use electronic tags and a positioning system-GPS, Sign Post and Odometer, Dead-Reckoning, or Combination to monitor vehicle locations in real-time. Vehicle location is determined by the AVL system and transmitted at regular intervals to the transit dispatch center (8). AVL is used for various purposes ranging from emergency location of vehicles, to fleet management and monitoring, and data collection. They normally come equipped with a mobile data terminal (MDT) for the driver to communicate with dispatch, and to get direct feedback on on-time status. In the case of paratransit, the mobile data terminal can give a driver his or her itinerary, including updates, such as cancellations, and sameday booked trips. The dispatch center usually contains one or more staffed dispatch stations. Each dispatcher usually has two screens, one with a computerized map showing the current locations and status of all vehicles in service (covered by the AVL), and one which can display a variety of information including communications with other drivers. Recent studies indicate that there are nearly 75 transit systems in the U.S and at least six Canadian transit authorities that have AVL systems operational, under installation, or under planned implementation (8).

An automated vehicle tracking system is made possible by navigational technologies such as GPS. The following table summarizes the function, benefits and disadvantages of the GPS component in an AVL system (8). 
Table 12: Overview of AVL/GPS

\begin{tabular}{|c|c|c|c|}
\hline Technology & How it Operates & Advantages & Disadvantages \\
\hline $\begin{array}{l}\text { Global } \\
\text { Positioning } \\
\text { System (and } \\
\text { Differential } \\
\text { GPS) }\end{array}$ & $\begin{array}{l}\text { A network of satellites in orbit } \\
\text { transmits signals to the } \\
\text { ground. Special receivers on } \\
\text { each vehicle read the signals } \\
\text { available to them and } \\
\text { triangulate to determine } \\
\text { location. } \\
\text { If the agency expects there to } \\
\text { be long periods between GPS } \\
\text { readings, sometimes } \\
\text { supplemented with odometer } \\
\text { readings or even more } \\
\text { extensive dead- reckoning. }\end{array}$ & $\begin{array}{l}\quad \text { Can be operated } \\
\text { anywhere. } \\
\text { GPS signals can } \\
\text { be received. } \\
>\text { Does not require } \\
\text { purchase, } \\
\text { installation, or } \\
\text { maintenance of } \\
\text { wayside } \\
\text { equipment. } \\
\text { Very accurate } \\
\text { (especially } \\
\text { differential GPS- } \\
\text { DGPS) }\end{array}$ & $\begin{array}{l}\text { Tall buildings, } \\
\text { tree cover, } \\
\text { tunnels, or } \\
\text { overpasses } \\
\text { can block } \\
\text { signals. }\end{array}$ \\
\hline
\end{tabular}

\section{State-of-the-Art}

The number of operational systems and the total number of agencies operating, installing, or planning AVL has increased many-fold in the last ten years (8). In 1991, it was identified that only four transit agencies had operational AVL systems in the United States, and only nine more were installing or planning AVL systems. By 1999, 61 agencies operated AVL systems, and another 93 were installing or planning such systems.

In addition to the increase in number of implementations, there also has been a great shift in the location technology used - away from signpost and odometer and towards GPS. Signpost and odometer systems drop from more than 40 percent of the total in the early nineties to less than ten percent in 1999. GPS/DGPS systems increase from 25-30 percent to about 70 percent over the same period (8). Further, given the AVL systems available to those agencies now out to bid, it is likely that a high percentage of the "unknown/other" will become GPS/DGPS systems. This trend is even more remarkable as GPS wasn't fully available until the early 1990 s when all of the satellites were placed into orbit.

\section{Challenges to SCAT Deployment}

There are several challenges to the procurement of AVL systems (8).

$>$ The first is their cost. Systems cost vary substantially, with a median of around $\$ 8,000$ per vehicle. 
Secondly, the customization of software required to successfully operate the AVL system at each location has been a problem and the major cause of implementation delays.

$>$ Finally acceptance of AVL systems by bus drivers and dispatchers used to the old manner of operations can be difficult. Many drivers are hesitant about a system that can track their bus's every move.

\section{TRANSIT OPERATIONS SOFTWARE}

Even though SCAT is currently deploying some aspects of transit operations software, the following technologies are featured for future consideration (8).

Transit operations software applications help transit agencies with:

$>$ Route planning

$>$ Driver scheduling

$>$ Vehicle assignments

CAD combined with some form of AVL is the most popular form of transit operations software. AVL/CAD gives transit properties real-time data capabilities in ways that were previously impossible such as:

$>$ Monitor

$>$ Supervise

$>$ Control operations

\section{Operations Software for Fixed-Route Bus Operations}

This is a major component of transit operations software. It involves the use of CAD systems application on fixed-route bus operations. Transit agencies use this software for bus service and operations planning. Customers benefit from better itinerary planning and transfer connections. A number of transit agencies and their vendors have implemented or are developing modules that will expand the capabilities of vehicle location and dispatch systems to provide data for other agency functions such passenger transfer management. Because a large portion of SCAT passengers use intra-agency transfers, these components would be very useful.

\section{Technology Description}

CAD fixed-route software falls into four primary categories, which are described in detail below:

$>$ Transfer connection protection software;

Expert systems for service restoration;

$>$ Itinerary planning systems; and

$>$ Service-planning applications 


\section{Transfer Connection Protection}

TCP software allows bus operators to inform on-board passengers whether they will be able to make a transfer to a connecting bus given current schedule adherence. The software reduces dispatchers' workload because connection protection software relies on data rather than voice communication. Therefore the dispatchers no longer have to be directly involved in the transfer decision-making process and radio system capacity is freed up. Although connection protection is still relatively new and the few real installations are for a single agency, the next logical step appears to be inter-agency and inter-modal connection protection. This would especially be useful to connect to the Manatee County Area Transit (MCAT) and late arriving transit buses at SCAT transfer points.

\section{Expert Systems for Service Restoration}

Expert systems are computer programs that process historical operating data and business rules to assist decision-makers in addressing operating problems. While expert systems and related software tools are already in use in other business environments, they are just beginning to be developed and deployed in the transit industry. Expert systems for SCAT can be used to resolve service disruptions including:

Dispatchers' real-world knowledge of bus operations;

$>$ Existing operating rules and procedures;

$>$ A historical database of responses to service disruptions; and

$>$ Real-time bus status information from an AVL/CAD system

\section{Itinerary Planning Systems}

Itinerary planning systems are another trend in transit software development. The function of an itinerary planning system is to determine the best way for a transit customer to travel from an origin to a destination. Itinerary planning systems are indirectly linked to CAD systems because they depend on the same static route schedule data.

The first automated itinerary planning systems ran on mainframe computers. Systems are now designed to run on networked PC servers and workstations that integrate itinerary planning, GIS, and off-the-shelf database software products. Access to many itinerary planning systems is available now on the Internet. These web applications have graphical user interfaces that allow customers to plan trips and tailor individual preferences themselves. The graphical nature of the web and the GIS software platforms used in itinerary planning software allow these systems to provide both textbased directions and detailed maps. The maps may show an overall transit itinerary, directions for making key transfers, and directions on how to access the transit system by walking from their origin. Some of the new itinerary planning applications integrate the schedules of multiple transit agencies, making the programming of such software extremely complex. Contributing to the 
complexity of development is that different agencies often use different scheduling programs. Further, different agencies change their schedules at different frequencies (e.g., one agency may change its schedules every three months, while another agency, every six months). The next phase in the development of itinerary planning system appears to be the incorporation of real-time information from AVL/CAD systems and incident reporting and management systems.

\section{Service Planning Applications}

Service planning applications are used to analyze the efficiency of fixed-route operations using data from AVLCAD systems. Service planning applications can perform the following functions:

$>$ Provide an average of running time between time points to determine which route segments are not performing to schedule, by how much, and why;

$>$ Calculate measures of headway and running time variability to determine where service and scheduling should be adjusted for efficiency and as a measure of customer service;

$>$ Develop new performance measures on an as-needed basis; and

$>$ Map the analysis for visual evaluation based on geographical referencing.

A key feature of all CAD systems is their ability to manage communications in concert with MDT, with some processing and control functions distributed to the MDT. The capability to maximize available radio frequency bandwidth is especially important considering that SCAT still faces limited wireless capacity.

\section{State-of-the-Art}

For the last five years the use of transit operations software has focused on increasing service reliability, improving customer service, improving safety, and increasing operational efficiency. To a large degree, agencies are still learning how to fully utilize these technologies and their capabilities. SCAT could use AVL/CAD to monitor on-time status of buses and track their actual location. Exception reporting, programmed into AVL/CAD systems, helps streamline this process. Dispatchers are able to more quickly spot operating problems and initiate service restoration. However, limitations still exist in how effectively dispatchers use these new sources of information. For example, even with good information, it is a difficult task to institute some service restoration strategies that involve more than a few buses or routes.

An important advance in CAD is the advent of fixed-route deviation software, which allows buses to deviate up to $3 / 4$ mile away from the standard route. This scheduling and dispatching application schedules route-deviation service from pre-defined patterns to accommodate passenger requests. How much a trip can deviate from its schedule is controlled by slack running time added at bus stops and by a defined perimeter of the service area. 
SCAT could find better uses of AVLCAD data in expert systems, itinerary planning software, and other systems that can effectively use real-time or historical information about operations.

\section{Challenges to SCAT Deployment}

The technical challenges related to software implementation include:

$>$ Because SCAT is currently deploying Trapeze transit operations software package, retrofitting future upgrades to Trapeze would need to be carefully considered.

$>$ The data structures of an AVLCAD server can be incompatible with that of SCAT agency scheduling system. This makes it difficult to match the protocols and formats of the two systems, a necessary precursor for CAD software to use schedule data in its adherence calculations.

$>$ SCAT agency schedule files may not contain certain pieces of information that are needed to integrate with CAD software. This can require SCAT to provide additional data to allow the software to function correctly. The additional information may concern such data points as the schedule details of deadhead trips, pull-ins, pull-outs, layovers times, or layover points.

> Vehicle location algorithms can be too sensitive. For example, a vehicle might be noted as offroute by merely pulling into a curbside bus bay to pick up passengers at a valid stop.

$>$ Some agencies have experienced difficulties in determining schedule adherence anomalies at terminals that have different arrival and departure locations, and the ends or beginnings of routes.

\section{Electronic Fare Payment Systems}

Each type of fare payment, electronic or not, has its advantages and disadvantages. Comparison of the advantages and disadvantages of magnetic stripe cards, smart cards, as well as other fare media commonly used by transit agencies, is shown in the table below (8).

Table 13: Fare Media Advantages and Disadvantages

\begin{tabular}{|l|l|}
\hline \multicolumn{1}{|c|}{ Advantages } & \multicolumn{1}{c|}{ Disadvantages } \\
\hline Cash and tokens & Cash and tokens \\
\hline Simplest form of payment & $>$ Most expensive form of payment to process \\
$>$ Most widely used & $>$ Highly susceptible to theft \\
$>$ Most widely available to & $>$ High exposure to fraud \\
customers & $>\begin{array}{l}\text { State-of-the-art cash and token collection equipment is } \\
\text { complex }\end{array}$ \\
\hline
\end{tabular}




\begin{tabular}{|c|c|}
\hline Advantages & Disadvantages \\
\hline $\begin{array}{l}\text { Paper passes and tickets } \\
\text { Inexpensive to purchase stock } \\
\text { Easily combined with other } \\
\text { payment technology, such as } \\
\text { magnetic stripe and optical } \\
\text { coating }\end{array}$ & $\begin{array}{l}\text { Paper passes and tickets: } \\
>\text { Susceptible to fraud } \\
>\text { Labor intensive } \\
>\text { Pre-printed stock needs to be treated like a currency }\end{array}$ \\
\hline $\begin{array}{l}\text { Magnetic stripe cards } \\
\text { Proven technology } \\
>\text { Inexpensive media } \\
>\text { Can be combined with printing } \\
>\text { Support a high number of uses }\end{array}$ & $\begin{array}{l}\text { Magnetic stripe cards } \\
>\text { Require complex equipment } \\
>\text { Maintenance intensive } \\
>\text { Susceptible to accidental erasure } \\
>\text { Have a large variance in reliability } \\
>\text { More susceptible to fraud than smart cards }\end{array}$ \\
\hline $\begin{array}{ll}\text { Smart cards } \\
>\text { Secure data transfer } \\
\text { Reduces passenger boarding } \\
\text { time and improves transit } \\
\text { schedule adherence } \\
>\text { No physical connection required } \\
\text { for contact less applications } \\
>\text { Larger memory capacity } \\
>\text { Can perform complex security } \\
\text { validation calculations } \\
\text { (microprocessor card) } \\
>\text { High reliability } \\
>\text { High resistance to fraud }\end{array}$ & $\begin{array}{l}\text { Smart cards } \\
>\text { Cost - prohibits use for single ride } \\
>\text { Unavailability to low-income customers }\end{array}$ \\
\hline
\end{tabular}

SCAT is continuously looking for ways to lower the operational costs of their fare collection systems. And, also interested in increasing revenue and customer convenience. With these goals in mind, SCAT can capitalize on the increased automation, security and data capabilities offered by new fare and data technologies that can be integrated into existing fare collection systems. These systems combine fare media, such as magnetic stripe cards or smart cards, with electronic communications systems, data processing computers, and data storage systems to more efficiently collect fares and may also increase revenue by increasing ridership. 
Table 14: Financial Advantage of Electronic Fare Media

\begin{tabular}{|l|l|l|}
\hline \multicolumn{2}{|c|}{ Increased Revenue } & \multicolumn{1}{|c|}{ Decreased Costs } \\
\hline $\begin{array}{l}\text { Shorter and more convenient fare } \\
\text { increased ridership. }\end{array}$ & $\begin{array}{l}\text { Use of electronic fare media decreases } \\
\text { cash/coin handling. }\end{array}$ \\
$\begin{array}{l}\text { Integration with other modes or } \\
\text { operators may enable more customer } \\
\text { discounts and loyalty schemes resulting } \\
\text { in increase ridership and revenue. }\end{array}$ & $\begin{array}{l}\text { (i.e., at fare box or fare gate) decreased } \\
\text { or eliminated. } \\
\text { Higher value ticket/fare sales } \\
\text { transactions, resulting in fewer } \\
\text { transactions. }\end{array}$ \\
\hline $\begin{array}{l}\text { Increased transaction data permits } \\
\text { equitable distribution of shared } \\
\text { revenues, and audit trail to protect } \\
\text { against employee theft. }\end{array}$ & $\begin{array}{l}\text { Automation of fare collection processes } \\
\text { decreases labor costs. }\end{array}$ \\
\hline $\begin{array}{l}\text { Increased customer information permits } \\
\text { optimization of fares, schedules, and } \\
\text { transit services. }\end{array}$ & $\begin{array}{l}\text { Use of products without mechanical or } \\
\text { moving parts (e.g. ticket transports) } \\
\text { increases equipment reliability, reducing } \\
\text { maintenance. }\end{array}$ \\
\hline $\begin{array}{l}\text { Increased media security decreases fraud } \\
\text { levels. }\end{array}$
\end{tabular}

Today, fare collection systems are being updated from traditional cash, coin, token, and magnetically-based systems employing labor intensive processes and limited data collection capabilities, to sophisticated smart card based systems. Smart cards have the potential to reduce costs through increased automation while enhancing customer convenience.

\section{Because of all the advantages of a Smart Card, it is strongly recommended that SCAT deploy Smart Card technology.}

Because SCAT is interested in the ability to offer innovative customer service provisions to their riders such as card balance protection and auto load features, the audit trail created by smart card systems provides this ability to track the value of each card in the system. This also permits SCAT to offer balance protection services to customers who register their cards. Balance protection services also require a card to be registered, tying the card number to either the customer's name or to a personal identification number issued to the customer.

The flexibility offered by the use of smart card systems, permits operators to more easily implement changes in fare policy by uploading fare changes and multiple fare structures electronically to the system payment and sales devices. Additionally, this flexibility allows operators to promote 
different products as well as incentives and loyalty discounts (for instance, 12 rides for 11, free transfers) based upon usage. For transaction processing systems, smart cards offer a benefit over magnetic stripe tickets in terms of security, flexibility and data capacity, but at a higher cost.

For SCAT to migrate from the current magnetically based system to a smart card system would require a redesign of some of their existing fare payment processes. Some of the changes may include:

$>$ Automating certain clearinghouse and settlement functions to a private sector partner.

$>$ Overlaying of the new, more expensive technology onto the existing fare system without making any of these changes may add costs that may be difficult to offset with anticipated benefits.

$>$ The major cost/benefits will be realized by taking the opportunity afforded by integrating the advanced technology to optimize fare payment and collection processes.

Smart cards, which are much more difficult to counterfeit than paper, coin, or magnetic stripe tickets, will help reduce incidents of fraud. Smart card security is achieved by combining the following three basic elements:

$>$ Encryption: the transformation of data that is only readable through the use of a secret key;

$>$ Authentication: the process of ensuring the message received is the message sent; and

$>$ Non-repudiation: guarantees that the message sender cannot deny having sent it.

In addition to enhanced security, maintenance costs with a smart card system should be less. Especially, since the current magnetic stripe system is not operating fully and jams frequently. This maintenance process is labor intensive and costly to SCAT. The use of contactless smart cards decreases the number of mechanical and moving parts required in the turnstiles, fareboxes and distribution devices. Additionally, eliminating or reducing the use of other system components such as bill acceptors and coin re-circulation units can lessen the wear and tear on the supporting infrastructure, resulting in lower maintenance costs.

\section{Technology Description}

The main components of systems using smart card based technology are:

$>$ A fare payment system - the infrastructure used to receive value from the fare payment media and/or check the validity of the media for the current transit trip

$>$ A fare distribution system - the infrastructure used for the distribution of the payment media, as well as the distribution of the value that is loaded onto the fare media.

$>$ Clearinghouse and back office processing systems - infrastructure used to capture and process transaction data generated by the fare payment and distribution systems. 
Within the last ten years, smart card developers and chip manufacturers have developed new card technology and faster chips. Smart cards have different processing capabilities than traditional payment systems. These capabilities include:

$>$ Memory only - simple memory cards store limited amounts of data in preprogrammed formats and offer little or no security.

$>$ Memory with security logic - security logic typically uses some form of access code (as large as 64 bytes) to secure card data.

$>$ Memory with microprocessor - microprocessor is capable of processing data, increased security, with the ability to implement cryptographic algorithms.

The following are non-exclusive examples of popular smart cards in use:

$>$ Contactless card

$>$ Hybrid card

$>$ Dual interface cards

$>$ Multi-Application cards

\section{Contactless Cards}

Electronic payment systems employing smart card technology have two types of communication interfaces. Contact cards require physical contact between the chip on the card and the corresponding contact in the card reader. Contactless cards use radio frequency to communicate with the card reader device and requires no contact between the card and reader. The reader activates the chip by electromagnetic signal as the reader passes the card. The card can be passive or active. Passive cards are powered by radio frequency generated from the reader. An active card is powered from a battery imbedded in the card.

\section{Hybrid Cards}

Within the industry, the term "hybrid card" is used to define either a card that contains both smart card and magnetic stripe elements or a card that contains two chips, one, which communicates through contact type interface, and one which communicates through the contactless interface. Applications using two different interfaces do not share operating systems or data. Since the two interfaces do not communicate with each other, a terminal is required to move data from one interface to the other, thereby limiting the flexibility and use of hybrid card technology.

\section{Dual Interface Cards}

Dual interface card technology is sometimes referred to as "combi-card" technology and provides the physical platform for multi-application card systems involving entities with different functional requirements. For example, transit operators prefer contactless cards for fare payment transaction speeds under 0.3 seconds. Financial institutions typically require a contact interface that provides the capability to process complex encryption processes associated with financial applications. Dual 
interface "combi-card" technology provides a single chip and the same memory that can be accessed through both contact and contactless card interfaces.

\section{Multi-Application Cards}

Multi-application systems can accommodate multiple fare types and fare structures including stored value electronic purses, stored rides, time-based passes as well as discounts and loyalty schemes. These capabilities allow for the development of multi-application card systems.

\section{State-of-the-Art}

Transit operators in several U.S. cities are planning to replace their current fare collection systems with smart card systems. A recent article in Card Technology Magazine stated, "By 2003, mass transit riders worldwide will use more than 115 million chip cards to pay transit fares. This number is up from last year's estimate of 15.1 million." Transit operators prefer contactless card technology to contact card technology because it allows passengers to speed through turnstiles at rates of 30 to 60 per minute. Contactless technology also provides added convenience by sparing cardholders the trouble of removing the cards from their wallets. This added convenience in turn alleviates congestion at turnstiles and minimizes long boarding queues.

In addition to faster throughput, smart card systems can be designed to capture more detailed transaction and revenue data than non smart card systems. The data can be used to evaluate route planning, peak travel times, ridership statistics and profiles, effectiveness of the distribution network, and enable more efficient revenue distribution among operators. Another incentive for integrating smart card technology is that transit operators want to decrease expenditures on collecting revenue, and lessen the associated security risks connected with collecting large amounts of cash and tokens.

\section{Challenges to SCAT Deployment}

Migrating from the current payment system (cash, ticket, token, and/or magnetically based system) to a smart card based system typically would require SCAT to redesign some of the existing fare payment processes. For example, changes in some of the payment system components - readers, turnstiles, fareboxes, and ticket vending machines - need to be done. This can be costly for SCAT depending on the amount of equipment to be installed. If a regional smart card that can work on Manatee County buses and fast food chains is to be issued, several agencies will need to be involved. This can pose some challenges since some of the agencies have never cooperated before with SCAT. Also, to successfully achieve the benefits, many of the institutional aspects of the revenue collection process must be integrated or at least coordinated. Combining card production, distribution, and marketing of several agencies can be complex, but it can produce significant cost savings. 


\subsection{Short Term NeedS}

Technologies identified in the previous chapter based on SCAT short-term needs are outlined below. This section outlines their proven capabilities, state-of-the-art, and challenges to SCAT deployment for each of the prioritized technologies.

\section{Automatic Passenger Counters}

As the name suggests, Automatic Passenger Counters (APC) are devices for counting passengers automatically as they board and as they alight buses at each stop along a route. Studies have suggested equipping 10 percent of the vehicles in the fleet. The benefits of APCs:

$>$ Reduced cost to collect ridership information

$>$ Increase in the amount and quality of the information gathered.

$>$ Reduce or eliminate the need for manual checkers.

$>$ Around 10 percent of the trips can be sampled in a given year which is a much greater number than any agency samples with manual checkers.

$>$ Automatic equipment is less likely to miscount passengers at busy stops.

\section{History}

APC systems have been in operation for about 20 years. APCs rely on location information to maximize their benefits. The first systems came into use when AVL systems were rare, so nearly all of the older systems needed their own location technology: probably either signpost and odometer, or dead-reckoning. Since computer technology was far less advanced, all of the first systems used removable media and manual downloading. These factors made the pioneering systems relatively expensive (between $\$ 4,000$ and $\$ 12,000$ per vehicle) to buy, install, operate, and maintain, both because of the need for some form of AVL, and because of the manual downloading required. The older storage media and downloading techniques also were less reliable and more prone to data loss.

\section{Technology Description}

APCs typically use one of two counting technologies, either treadle mats or infrared beams. Treadle mats, placed on the steps of the bus, register passengers as they step on a mat, and infrared beams (mounted either horizontally or vertically), directed across the path of boarding and alighting passengers, register riders when they break the beam. Typically, two mats or two beams are put in succession, so that a boarding passenger triggers them in a different order than does an alighting one, allowing the APC to distinguish between boardings and alightings. Other counting technologies are being developed, such as those employing computer imaging.

An electronic record is created at each bus stop, typically including the following information:

$>$ Stop location

$>$ Date and time of bus stopping 
$>$ Time of doors opening and closing

$>$ Number of passengers boarding; and number of passengers alighting

These records are grouped by trip, and usually held in storage on the vehicle for a time, until they are downloaded to a central facility for further processing and use. Location typically is determined using one of the technologies described in Section 2.1 - Automatic Vehicle Location Systems. Either the APC system is linked to an operational AVL system employed by the same agency, or the APC system has its own location equipment.

The means of storing APC data on board the bus varies. Older APC installations tend to depend on floppy disks or even cassette tapes. Newer systems make use of the cheaper, faster, and higher capacity computer memory chips. Similarly, older APC installations might rely on physically transferring the diskette or tape to transfer the data. Newer systems will either download the data once a day via short-range microwave link when the vehicle comes back to the garage or in real time over dedicated radio frequencies.

\section{State-of-the-Art}

An APC system procured now is frequently purchased as an add-on to an AVL system. Further, the storage media used has more capacity than it had several years ago, and the downloading is automatic. These factors can bring the cost of APCs down to around $\$ 1,000-\$ 1,200$ per bus (1). Since only a subset of the vehicles need to be equipped with APCs, it could cost as little as $\$ 6,000$ to equip ten percent of the SCAT fixed route fleet, or less than the cost of one human counter for a single year, the purchase of hand-held counters, and entering the manually collected data into a database. These economics make APCs a very attractive option.

\section{Challenges to SCAT Deployment}

In the past, the cost of APC units was a deterrent to procurement and installation. With the cost now in the neighborhood of $\$ 1,000$ to $\$ 1,200$ per bus if included in an AVL installation, this is less of an obstacle. The cost of an APC without an AVL system will be higher and may still be an impediment. Some agencies perceive that the accuracy of APCs is less than desired. SCAT may not feel they need APCs since registering fareboxes will give them ridership information. The vast amounts of data APCs produce may exceed SCAT's capabilities to use effectively. APCs eliminate the need for manual checkers, but SCAT may not be able to eliminate these positions or reassign the personnel to other duties.

Some of these impediments remain legitimate concerns. However, indications are that APCs are more accurate than manual counts. Additionally, registering fareboxes will not provide boardings and alightings by stop, information that SCAT could use in their planning and scheduling of bus routes. 


\section{ON-BOARD SAFETY COMPONENTS}

The FTA's Safety and Security Program goal is to achieve the highest practical level of safety and security for all modes of transit. In order to protect passengers, employees, revenues, and property, all transit systems are encouraged to develop and implement a proactive system security plan. FTA supports these efforts by developing guidelines, best practices, providing training and by conducting voluntary audits of individual agencies' security programs (9).

Security is a concern for many agencies and bus drivers, because there is little protection for the driver or his passengers along the route. A great feature of an AVL system is its ability to incorporate a silent alarm. The driver is provided with a switch in a discrete location and needs only to press it if he or she is in danger. Activating the switch initiates a number of activities. Central control is notified via the communication link that there is an emergency and that the police should be called. All communications to the bus is cut off, so the assailant is not made aware an alarm has been activated. Central control can hear everything occurring on the bus and this can further assess the situation or discount it as a false alarm.

Another important component of on-board safety features is closed circuit television (CCTV).

\section{State of the Art}

If silent alarms are included as part of the AVL package, a transmitter is activated on the bus, much like in stolen cars, greatly facilitating the police's efforts to locate the bus, especially if it is offroute.

The latest in CCTVs is an integrated digital video time laps/event recording CCTV system. It is able to monitor up to four cameras and provides a four-in-one solution, which combines intelligent digital video technology with motion detection, multiplexing with text insertion, plus remote access so you can view and analyze information in any way or time or location that the transit agency chooses (12).

Furthermore, proprietary image authentication ensures that images have not been tampered. Unlike analogue systems it eliminates the time-consuming task of searching videotape to find specific events. This digital video can instantly search through digital text. Also, it has the capability to easily navigate on-screen to select video reports and set alarm conditions, including motion detection and video signal loss.

\section{Challenges to SCAT Deployment}

The primary challenge to on-board safety components is the cost. Also, the communication system should be upgraded to include voice and data before these are deployed. 


\section{AdVANCEd COMmUNiCATION SYSTEMS}

Effective and efficient operation of SCAT relies on a system comprised of a good telecommunications infrastructure and vehicle-based communications technologies. The system will be used to transmit voice and data between vehicles and operations centers, and to transmit commands between operators and technologies (8).

The Sarasota County $800 \mathrm{Mg} \mathrm{Hz}$. two-way voice radio system used for fleet management and vehicle dispatching remains at the heart of SCAT transit operations. It is a Motorola Astro Digital 3.01MBE system, which is designed for voice only. Sarasota County policy is not to include voice and data on the same channel. There are no future plans for upgrading the current capacity of the system. Also, different geographic areas within the County have different capacities for example Englewood has no more capacity for additional voice channels. In summary, even though the capacity of the system is there the resources or the technology is not in place to implement additional voice or high speed data communications. Because there are no immediate plans on the horizon for expansion of current communication system and because other communication technologies are needed for implementing the new technologies such as the AVL system and shortrange data links for traffic signal priority it is recommended that SCAT get a separate (from the County's $800 \mathrm{MgHz}$. system) state of the art data communication system. Deployment of the suggested APTS technologies in this memorandum is a key, contributing factor to communications capacity constraints at SCAT. The most notable impact comes from AVL systems because they would regularly transmit location and schedule status information to dispatch centers. Technical and non-technical developments in the telecommunications industry are creating both opportunities and challenges for SCAT. Whereas decisions to deploy the previously described APTS fleet management technologies are more primarily based on benefits and costs to SCAT and its fleet system, other factors external to the technologies themselves influence the deployment of APTS communications systems and technologies. Four significant factors are:

$>$ The rapid technological advances in communications systems, most specifically the trend toward digital transmission;

$>$ The availability of radio spectrum/frequency;

$>$ The Federal Communications Commission's frequency refarming policy; and

$>$ The availability and use of services supplied by private firms.

Before examining the various APTS communications systems available to SCAT, these external factors are discussed. Following this discussion, the specific APTS communications systems and technologies are addressed. 


\section{Rapid Technological Advances}

The widely reported trend toward digital voice and data communications, and away from analog, continues in all parts of the telecommunications industry, especially in the mobile sector. Digital wireless communications systems have been proven to extract more capacity from existing bandwidth, including more efficient radio channel utilization through mixing of voice and data; to create new services and provide increased functionality; to improve privacy and security; and to reduce radio frequency interference.

However, the advantages of digital technology have not resulted in widespread replacement of analog radio systems commonly used in transit agencies. Often, transit agencies making major communication system upgrades are retaining their analog technology albeit with more sophisticated equipment that sometimes includes a digital messaging component. The Public Safety Wireless Advisory Committee (PSWAC), in its 1996 final report to the Federal Communications Commission ( $\mathrm{FCC}$ ) and the National Telecommunications and Information Administration (NTIA), suggested that digital technology is essential for data transmission. However, this has not yet proven enough to create wide-scale change in the transit industry.

Advances in channel access/loading technologies, such as new modulation and encoding techniques, digital and analog compression algorithms, multiplexing, and trunking are important developments that apply to the entire mobile telecommunications industry. While many of these improvements have focused on digital systems, some have also proven applicable to improving the capacity of analog radio systems.

Cellular digital packet data (CDPD) has become an important data communications technology for transit. It is used for transmitting data on cellular phone frequencies using bandwidth that is not used by voice calls. Some of the reasons CDPD is so popular for wireless data transmission include:

Relatively high data transfer rates (of up to $19.2 \mathrm{Kbps}$ ) can be supported by CDPD;

$>$ Internet Protocol multicast (one-to-many) service, meaning that a base station can broadcast a message to many recipients simultaneously; and

Utilizes 'unused' space on existing cellular networks - CDPD is also cost-effective for certain applications.

\section{Spectrum/Frequency Issues}

The availability of radio spectrum for use by transit agencies continues to be a significant issue. Advances in signal processing and other technologies, which make more efficient use of existing frequencies and make the use of ever higher radio frequencies feasible, have not proven to be a sufficient expansion of the radio spectrum. The FCC's reliance on allocating available spectrum 
through competitive auctions makes it difficult for transit operators and other public agencies to compete for available bandwidths. The lack of available spectrum is most severe in dense metropolitan areas.

There are issues surrounding the use of higher frequencies. In the early 1990s, the FCC began to aggressively open up markets for services in the 800 and $900 \mathrm{MHz}$ bands. Although many continue to successfully operate their lower band radio frequency systems, some transit agencies have moved into these higher bands for apparently higher performance. The lower radio bands do have certain characteristics that are not ideal in a crowded radio spectrum with increasing demand for data transmission.

However, systems based on these frequencies still work, and technology is improving their performance. Most transit systems still use them. An alternative to using dedicated spectrum for transit communications is to participate as a partner or customer in a shared communications system with a public agency, a public safety user, or a commercial customer. Some transit agencies are choosing this option. Another option is to operate in one of the three unlicensed FCC bands (that do not require approval from the Government).

\section{Frequency Refarming}

The FCC's June 1995 rules requiring frequency refarming could have a number of effects on transit agencies even though the FCC's rules are being implemented through equipment manufacturers (and do not apply directly to radio frequency system operators). For example, transit agencies might need to purchase technically more complex and potentially more expensive radio equipment. Existing equipment could become obsolete more quickly if the aftermarket supply of parts and service was mainly concerned with supporting more modern equipment and systems. Thus far, however, the impact of refarming on the transit industry appears to be minor, although that does not mean that future FCC actions might not have an impact. One solution being employed by several transit agencies that could help protect them from refarming is to purchase software programmable radio equipment when upgrading. Since a complete discussion of refarming and its potential impact on transit is beyond the scope of this report, readers are referred to a study that covered these issues in considerable detail.

\section{Data Communication Systems}

The deployment of an AVL system for SCAT network would result in the need for increased capacity to the communications systems. Mobile voice and data communication systems for SCAT would need to include the use of analog, digital, and CDPD. These communication systems are used for routine activities such as talking to dispatch, aligning transfers from one bus to another, or for emergency situations such as bus breakdowns. 


\section{Technology Description}

Mobile transit communications systems involve the broadcast of information over Radio Frequency (RF) waves from a transmitter to receiver. The technology and methods used to perform this function, which includes both voice and data transmissions, vary widely from traditional two-way radios to personal communication system (PCS) devices.

\section{State-of-the-Art}

As mentioned above in the description on Rapid Technological Advances, the widely reported trend toward digital communications has not affected transit as much as expected. In general, transit agencies have been able to address their RF capacity needs by selectively using the latest generation in telecommunications technology and services.

Agencies have upgraded their two-way voice systems to increase capacity, functionality, and/or incorporate data transmission. In some cases, this has been done working with an existing frequency allocation in a lower band (i.e. less than $800 \mathrm{MHz}$ ) and in other cases using the 800 and $900 \mathrm{MHz}$ bands.

\section{Challenges to SCAT Deployment}

As the telecommunications industry continues to grow and change rapidly in both the business and the personal communications markets, the importance of robust telecommunications for transit agencies increases as well. This fast-paced evolution makes it challenging for SCAT to maintain, enhance, and plan for their wireless communication needs. Representing such a small share of this multi-billion dollar per year industry, transit has not typically had a strong voice in its direction. While many of the emerging services could benefit transit, it is unclear whether transit agencies will take advantage of them.

\section{Bus Signal Priority}

Bus Signal Priority (BSP) is a strategy by which a particular set of vehicles is given preference at traffic signals, either anytime they arrive at the intersection or only under certain conditions (e.g., on-time status, amount of traffic at opposing approaches). Although a transit vehicle does not warrant the same urgency as emergency vehicles, which always have priority, there are benefits to giving a bus priority at a traffic signal under the right conditions. The overall goal should be maximizing the number of people per hour through the intersection, rather than maximizing the number of vehicles. Giving buses preference at traffic signals would help achieve that goal (8). 


\section{Technology Description}

To activate BSP for buses, a signal (via a sonic or optical pulse) is transmitted from the bus to the traffic signal controller. Depending upon the phase the traffic signal is in, the controller will either extend the current green phase or advance the timing of the next green phase. This allows the bus to pass through the intersection with minimum delay.

\section{State-of-the-Art}

Transit vehicles have been given priority at traffic signals for a long time. In the early systems, the bus transmitted a request directly to the traffic signal, and priority was given. The request was either automatic or, in some cases, totally at the discretion of the driver. There was no way to control the granting of priority, based on transit concerns such as the vehicle's on-time status or its occupancy level, without relying on the driver. However, if inductive loop detectors (available since the mid-1960s) were placed at the intersection, the granting of transit vehicle priority could be modified in response to traffic concerns, such as the number of cars waiting at the other approaches. Modern BSP systems take advantage of other APTS technologies, such as AVL and CAD. With AVL and CAD, a vehicle's on-time status is easily and quickly determined. Using wireless communications, this request can be transmitted directly from vehicle to traffic signal, or from vehicle to dispatch to traffic control to traffic signal. Further, if real-time APC data are used, then the request for priority also could be accepted or rejected based on the number of passengers on the bus.

\section{Challenges to SCAT Deployment}

There are challenges to implementing BSP, which almost always requires cooperation between the transit authority and the governmental agency in charge of traffic. This means coordinating two potentially different philosophies, one of which might hold to the principle of maximizing vehicle throughput rather than people throughput. Another issue is whether or not to grant priority to an approaching bus. If a bus is running early, it does not make sense to expedite its travel through the intersection. However, granting priority to every approaching bus would shorten route travel times, thereby allowing the agency to change schedules and perhaps, reduce the numbers of buses required to provide service. The challenge is to achieve this reduced running time without seriously impacting the flow of other traffic.

\section{AdVANCED Traveler INFORMATION SYSTEMS (ATIS)}

Traveler information systems fall under the following broad categories ( 8 ).

$>$ Pre-Trip Transit

$>$ In-Terminal/Wayside Transit Information Systems; and

$>$ In-Vehicle Transit Information Systems. 


\section{Pre-Trip Transit}

Pre-trip traveler information systems will help SCAT passengers make decisions about the choice of transportation mode, route, and departure time before they begin their trip. There are four main types of pre-trip information:

$>$ General Service Information

$>$ Itinerary Planning.

$>$ Real-Time Information,

$>$ Multimodal Traveler Information.

With General Service Information, travelers can find route, schedule, and fare information by phoning the transit center or by transit maps and schedules located on vehicles, by the wayside, or at transit centers. This is the traditional form of traveler information.

In Itinerary Planning, transit users request an itinerary based on such variables as least travel time, minimal walking distance, lowest cost, least number of transfers, modal preference (bus or rail), and paratransit. Itineraries are given that can include walking directions from the origin to the transit stop, from one stop to another en-route, and from the final transit stop to the final destination. This was discussed in detailed in Transit Operations Software section.

Real-Time Information is generated by AVL-equipped vehicles and can be accessed by travelers through kiosks, Web sites, and interactive voice response (IVR) telephone systems. There are two approaches to presenting transit users with real-time information. One is to display the actual location of transit vehicles en-route. The second approach is to provide the estimated arrival time for incoming vehicles at a selected stop or station. This requires supplementary software that uses the current location of buses together with current traffic conditions to calculate the expected time of arrival.

Multimodal Traveler Information Systems deliver traffic and transit information to the traveler. These systems combine real-time and static data from one or more transit services. Agencies have developed multimodal traveler information systems to promote transit and other commuting alternatives such as carpooling in order to reduce the number of trips by automobile in regions not in compliance with the air quality requirements of the Clean Air Act Amendments of 1990. Some agencies have developed public-private partnerships to provide traffic services. Most of these partnerships are in urban regions where transit controls a significant share of the commuter traveler information market. As with freeway Intelligent Transportation Systems, the availability of quality real-time information from the public sector drives the collaboration with the private sector in distributing traveler information. 
Recent improvements to pre-trip transit and multimodal traveler information systems fall into three general areas:

$>$ Interactive voice response (IVR) telephone information;

$>$ Kiosks

$>$ The Internet (Website Design)

Interactive voice response telephone information systems allow customers to call a single phone number and navigate a menu for needed information. Previously, transit customer service operations relied on agents to provide various types of information over the telephone. For many years, automated telephone information systems assisted agents in answering routine questions. These new systems eliminate the need for agent involvement in many information requests. This is a mid-term need for SCAT.

Kiosks are being deployed in some locations. Transportation agencies have placed kiosks at public sites to provide transit information to travelers who might not be aware of transit alternatives. Public-private partnerships are being formed to explore the commercial viability of kiosk networks. Advertising on the exteriors of kiosks is one approach. The earliest kiosks did not communicate in real time and sometimes resulted in outdated information. For the size of Sarasota County and because of the demographics of SCAT passengers, kiosks are not a cost effective option at this point in time.

The Internet offers an alternative to kiosks for SCAT for increasing public awareness of transit services and providing transit information. There are several advantages to using the Internet for transit information.

$>$ The Internet provides a more suitable browsing environment for itinerary planning.

$>$ Second, the Internet is also a cost effective alternative to kiosks, which have high capital, maintenance, and operating costs.

Third, the Internet provides transit users with information 24 hours a day, seven days a week. In contrast, some kiosks have restricted access, such as those located in shopping areas.

$>$ Additionally, there are normally only a few kiosks available in a transit service area.

\section{Challenges to SCAT Deployment}

Interactive voice response systems do not always have good voice recognition. However, there have been recent improvements in speech recognition technology. Another difficulty is that some systems incorporate automated distribution features for information that would be too timeconsuming to provide over the telephone. In these cases, information can be sent via fax or e-mail. 
The Internet is not always the most accessible means of providing transit information since many of SCAT passengers might not have access to the Internet. In all these cases, displaying the real-time position of the vehicle en route or estimating the time of vehicle arrival can be problematic. First, real-time estimates can be subject to revision. The accuracy of estimation techniques and the need for ongoing calibration will be important issues for SCAT as real-time information is deployed.

\section{In-Terminal/Wayside Transit Information Systems}

By providing estimated arrival times at stops and stations to waiting SCAT passengers, anxiety about when or whether the vehicle will arrive can be eliminated.

\section{Technology Description}

Agencies with AVL systems are able to provide real-time in-terminal or wayside transit information. In some cases the system provides what could be considered both pre-trip and en-route information. There are several communications devices that provide traveler information. The primary devices for in-terminal and wayside systems are:

$>$ Video monitors

$>$ Variable message signs (VMS)

Variable message signs may be supplemented with audio announcements of the displayed information. The display may include service announcements or advertising. It is recommended that SCAT looks into public-private partnerships for offsetting the cost by advertising on the displays. Real-time in-terminal and wayside information systems require a communications link to a central computer system that provides the information about upcoming arrivals. The need for a powerful and good communications infrastructure at widely distributed locations are an important economic issue for SCAT, because it has several large transit transfer stations and close to 3,000 bus stops.

\section{Video Monitors}

Video monitors are used often where a large amount of information needs to be displayed and where flexibility in using graphics, fonts, and color is needed. A video monitor providing real-time arrival updates would be less suited for SCAT hence it is not recommended.

\section{Challenges to SCAT Deployment}

The challenge to implementing video monitors or variable message signs remains the issue of getting information to the device. Wireline placement can be difficult and costly. Wireless transmission of information has not yet proven to be consistent enough to handle larger amounts of data. 


\section{In-Vehicle Transit Information Systems}

In-vehicle transit information systems provide useful en route information to SCAT passengers about their transit trips. As well, they comply with the Americans with Disabilities Act (ADA), which requires that vehicle stops at all train stations and key bus stops be announced. SCAT drivers cited these announcements as one of their main challenge. Automated annunciation systems relieve the vehicle operator of that responsibility by announcing stops, transfer possibilities, and points of interest automatically, based on the vehicle's location, route, and direction of travel. In some instances, this information is also provided to passengers via variable message signs placed at one or more locations in the bus. Although, primarily motivated by support for the disabled, it is also helpful for those unfamiliar with the route, when the bus is crowded, and when it is difficult to see outside the vehicle.

\section{Technology Description}

Automated announcements are made via the bus public address system. Visual messages are provided through VMS. Route specific software provides the information to be dispensed. The precise information to be announced and displayed at a particular time would be determined by SCAT's AVL system.

\section{State-of-the-Art}

Automated in-vehicle information has been installed by a few agencies. While these information systems need AVL, not all agencies with AVL have included them. Of those that have, more have installed annunciators than have installed VMS. However, incorporating advertising, as some agencies are contemplating, could help to defray the cost of the in-vehicle systems.

\section{Challenges to SCAT Deployment}

The primary challenge to in-vehicle transit information systems is the cost. This has resulted in few transit agencies deploying these systems.

\section{TRANSIT ACCESSIBILITY SYSTEMS}

This section is also included in portions of the ATIS section detailed above. The costs associated with this section are calculated in the ATIS spreadsheet. Americans With Disabilities Act (ADA) specifies accessibility guidelines for transit vehicles. This section outlines how technology can be used to comply with minimum guidelines and requirements for accessibility standards.

For mobility and accessibility it is recommended SCAT provide controls (wheel chair ramps) that are interlocked with the vehicle brakes, transmission. This ensures that the transit vehicle cannot be moved when the accessibility system is engaged. Also the fixed route service of SCAT should be

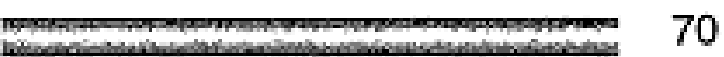


equipped with a recorded or digitized human speech messages (annunciators), to announce stops and provide other passenger information within the vehicle.

To make the fixed route service more appealing for passengers with disabilities, all fixed route transit vehicles should have an automatic stop request button adjacent to some seats. This can be used for requesting stops and which alerts the driver that a mobility aid user wishes to disembark. Such a system should provide auditory and visual indications that the request has been made. Variable message signs are suggested for destination and route signs. The signs should have both auditory and visual capabilities.

\subsection{MID-TERM NEEDS}

Technologies identified in the previous chapter based on SCAT mid-term needs are outlined below. This section outlines their proven capabilities, state-of-the-art, and challenges to SCAT deployment for each of the prioritized technologies.

\section{VeHicle COMPONENT MONITORING}

Vehicle component monitoring systems assist in the early detection of problems with vehicle components (e.g. engine, exhaust system) to avoid component failure while vehicle is in use. This can be part of the AVL package. The communication system, in addition to reporting vehicle location can report the condition of the vehicle. Many aspects of vehicle performance and condition are already monitored and displayed to the driver, and many more are available to a mechanic who needs simply to plug the engine into a diagnostic computer. These aspects, or some relevant subset, can be measured and reported to the dispatcher who can remove the transit vehicle from service before it breaks down or at least have a bus ready to replace it.

\section{State of the Art}

In addition to general location, the dispatcher also receives information about transit vehicle condition. There are three mechanical alarms, which may sound: Low Air (Brakes), Engine Temperature, or Oil Pressure. If any of these alarms sound, the dispatcher knows that there is a problem and can immediately send a replacement bus and a mechanic with information about the condition of the bus. This saves time and helps reduce deviations from schedule. This allows for problems to be addressed before they become serious. Also, this eliminates the need for gauges that drivers normally monitor. However, the commercial drivers' license requires that drivers monitor air pressure.

\section{Challenges to SCAT Deployment}

Cost is the most challenging aspect of implementing security features for SCAT vehicles. 


\section{TRANSPORTATION DEMAND MANAGEMENT}

Transportation Demand Management (TDM) is a term applied to a broad range of strategies that are intended to change traveler behavior for the purpose of reducing or reshaping use of the transportation system (8). The paramount objective of TDM strategies is to reduce the amount of automobile travel on the roadways by more efficiently utilizing existing transportation resources and infrastructure. TDM strategies employ ITS technologies to:

$>$ Facilitate and increase the use of public transportation, including carpooling, vanpooling, walking, bicycling, and telecommuting

$>$ Compress work weeks

$>$ Apply congestion pricing programs

$>$ Manage parking and apply demand pricing.

TDM strategies frequently combine innovative approaches and advanced technologies in order to create a more integrated approach to managing the various problems within a regional transportation system.

The following TDM strategies utilize ITS technologies:

\section{Dynamic Ridesharing}

Also called real-time ridesharing, is a form of carpooling that provides rides for single, one-way trips rather than for trips made on a regular basis. Dynamic ridesharing can be either a program organized and run by an official agency, or a system informally operated by participants. This latter setup is called "casual carpooling."

In organized dynamic ridesharing programs, individuals submit requests for a ride to an operations center (SCAT) or central database, either by telephone, e-mail, or direct input to a system residing on the Internet. A request may be made for any destination or time of day, but matches are more likely to be found for travel in peak periods and in principal commute directions. Requests for ride matches can be made well in advance or close to the time when the ride is desired. A return trip would be a separate trip request and could be matched with a different driver. The database of trips that have been offered by registered drivers is searched by the ride matching software to see if any match the approximate time and destination of the trip request. 


\section{Technology Description}

The ITS element in dynamic ridesharing is the automation of the trip request matching and arrangement process, which allows trips to be arranged on short notice. This can be done by either the traveler using the Internet or by a customer service representative at a transit agency call center. The technology involved is rideshare software and possibly the Internet.

\section{State-of-the-Art}

The FTA has funded several ridesharing activities. However, concerted efforts to develop organized programs generally have either been terminated (Bellevue, Washington; Sacramento, California; and Los Angeles, California) or never implemented (Ontario, California and Houston, Texas). Only the Seattle Smart Traveler remains in existence, and only in a limited manner. In contrast to the low utilization of organized dynamic ridesharing programs, casual carpooling has received heavy utilization in two locations. In Oakland, California, where drivers pick up passengers by the roadside in order to use the HOV lane to cross the San Francisco-Oakland Bay Bridge into San Francisco, and in Northern Virginia, where drivers pick up passengers in order to use the HOV lanes on the Shirley Memorial Highway into and out of the District of Columbia. Daily users at the two casual carpooling sites average in the thousands. In 1993, RIDES for Bay Area Commuters estimated 8,000 daily casual carpoolers crossed the Bay Bridge.

\section{Challenges to SCAT Deployment}

There are many potential reasons for low dynamic ridesharing. Possible reasons include a lack of awareness of the programs, a deficiency in the number of driver participants and offered rides, insufficient incentives to rideshare, a concern about sharing rides with strangers, the time factor to receive a match list and contact possible trip providers, and, in many instances, the need to obtain a match for a return trip. Some recent rideshare programs that have been installed on the Internet have the capability to overcome the time delay factor in obtaining a match list, but many of the other impediments described above remain. Also, the lack of HOV lanes in Sarasota County and other priorities are causes for the lack of fully successful; rideshare programs.

\section{Automated Service Coordination}

This can be defined as multiple transportation operators in a region that provide coordinated service with the assistance of APTS technologies (8). By coordinating the services of multiple transportation operators in a region, the connectivity of public transportation services can be greatly improved for persons who would have to travel on more than one transportation agency's vehicles. This will produce the opportunity for attracting more trips to public transportation. 


\section{Technology Description}

Several ITS technologies are employed to facilitate automated service coordination. The most prevalent technology applications are: central and remote scheduling and dispatching; automatic vehicle location; advanced communications (particularly data communications); and automated fare payment. For example, the coordinating agency may provide scheduling and dispatching services for other local service providers using an automated scheduling system. Likewise, the coordinating agency may outfit local service providers' vehicles with AVL equipment in order to monitor all vehicles within the region. Further, they may provide customers with an automated fare payment device that can be used seamlessly on all regional service providers.

\section{State-of-the-Art}

There are two significant trends in automated service coordination program deployment. First, more agencies are jointly procuring technologies in order to save resources. One example of this is the Greater Attleboro-Taunton Regional Transit Authority, which is jointly purchasing mobile data terminals with the Cape Cod Regional Transit Authority. Second, there is a growing trend toward implementing service coordination with technology, rather than developing a coordinated service without technology and adding it later. An example is the Lord Fairfax Planning District in Virginia, which is developing a coordinated service with technology. The Virtual Transit Enterprise (VTE) in South Carolina is another example of incorporating technology to facilitate information sharing and service coordination.

\section{Challenges to SCAT Deployment}

ITS technologies have the potential to greatly improve the coordination of transit services in terms of operational efficiency and customer service (1). However, there are several challenges to the implementation of its to facilitate coordination of service. The challenges are both institutional and technical.

There are two major institutional challenges. First, the issue of coordinating service has been discussed vigorously over the past 25 years. There are many reasons why coordinating service among public transit agencies and health and human service agencies is a challenge. These reasons include the fact that a large number of these agencies are not highly computerized, and since their respective scheduling may be done by hand, it is difficult to coordinate service manually. The advent of technology is just beginning to facilitate service integration and coordination. The procurement aspect of coordination, where multiple agencies in a region coordinate to purchase the same ITS equipment and software, can be very useful. Not only does this type of coordination reduce the per-unit cost of ITS items (and thus the cost to transit agencies), but it ensures that agencies can share information and potentially coordinate service much easier than if all involved agencies have different equipment and software. 
Second, due to the typical size of agencies that wish to coordinate, they often do not have personnel who have the technical expertise to procure and deploy ITS technologies. Or, if they do have the technical expertise, they do not have the time to spend on these activities. This lack of time or technical expertise can result in an ITS procurement or deployment taking longer to accomplish, or in ITS not being considered at all.

There are two major technical challenges. First, while data collection and management is routine in large transit agencies, it is often a challenge in smaller agencies that would be coordinating. This is often due to minimal labor and computer resources that are necessary to collect and manage data. Further, data used by automated tools (e.g., GIS) must be constantly updated and maintained, which requires resources that smaller agencies do not often have. Considering that ITS technologies can generate large quantities of data, this is an important issue. Second, the automation of certain functions within coordinating agencies may improve operations and customer service, but the automation of certain customer service related functions might actually confuse and alienate certain customers. For example, an automated reservations system that requires the customer to use a touch-tone keypad to enter information may be difficult for an elderly person or someone with specific disabilities to use.

\section{TRANSIT INTELLIGENT VEHICLE INITIATIVE}

Federal Transit Administration (FTA) ranks safety as the number one priority goal as approximately eight billion annual passenger trips rely on transit, thus making the transit IVI program a critical component of the FTA's overall agenda (10). A safer vehicle will minimize accident and incident rates, as well as their related costs. FTA is responsible for the transit element of the IVI program and works closely with the ITS Joint Program Office to define transit IVI research initiatives. The current focus of transit IVI is on bus and paratransit vehicles; rail vehicles will be considered in the future.

The first and highest priority candidates for bus IVI applications are crash scenarios that present the greatest severity and risk to human lives. Using safety as the guiding factor in deciding what IVI technologies should be considered, the FTA commissioned a report, FTA IVI Needs Assessment, to determine these needs. The results from this research show that the five most frequent crash types involving a bus in order are:

$>$ Lane changes and merges

$>$ Rear end collisions

$>$ Intersection collisions

$>$ Backing up collisions

$>$ Buses running into parked cars 
Altogether, five crash categories comprise approximately 87 percent of crashes involving buses within the United States between 1994 and 1996. Of these crashes, the most frequent type is lane changes which (36 percent of all crashes); rear end collisions (22 percent); and intersection collisions (18 percent). IVI technologies that address these crash types are the highest level priority for the FTA IVI Program.

The second level priority for transit IVI technologies are those that help reduce the accidents that carry a medium range of risk and severity. They include other crash types such as running into parked cars ( 9 percent) and backing up collisions ( 3 percent).

Finally, the transit IVI platform provides an opportunity for evaluation of other types of technologies that improve the efficiency of the fleet and provide even more levels of safety. For instance, these technologies might include:

Tight maneuvering/precise docking: Tight maneuvering/precise docking technologies, using precision control and automated guidance technologies, allow the driver to handle the bus more effectively in close quarters (terminals and tunnels). It also permits safer boarding and alighting.

Precision control and automated guidance: Longitudinal and lateral vehicle control for driver assistance on transit buses

Obstacle/pedestrian detection: Obstacle/pedestrian detection technologies will warn drivers of approaching activity in sufficient time to avoid an accident.

Fully automated overnight maintenance: Automation of bus movements through the service areas in bus maintenance garages is another potential IVI application that is of interest to transit operators.

\section{Technology Description}

The FTA has identified four transit applications as immediate areas for IVI investment. These four focus particularly on the safety of the driver (and indirectly both passengers and pedestrians) and the vehicle. Using systems that enable drivers to process information, make better decisions, and operate vehicles more safely are the strong points of the following four priorities.

Tight Maneuvering/Precise Docking - This application positions the bus very precisely relative to the curb or loading platform. The driver can maneuver the bus into the loading area and then turn it over to automation. Sensors continually determine the lateral distance to the curb, front and rear, and the longitudinal distance to the end of the bus loading area. The driver will be able to override the system at any time by operating brakes or steering, and will be expected to monitor the 
situation and take emergency action if necessary (for example, if a pedestrian steps in front of the bus). When the bus is properly docked, it will stop, open the doors and revert to manual control. Safer boarding and egress for the handicapped, the elderly and children, are important considerations in developing these systems.

Lane Change and Merge Collision Avoidance - These systems provide various levels of support for detecting and warning the driver of vehicles and objects in adjacent lanes (e.g., "blind spot" warning for early implementation). Later systems would introduce capabilities that will provide merge advice and/or warnings of vehicles in adjacent lanes whose position and relative velocity make the planned lane change unsafe. Those capabilities could include speed and steering control intervention for enhanced collision avoidance.

Forward Collision Avoidance - This feature senses the presence and speed of vehicles and objects in the vehicle's lane of travel and will provide warnings and limited control of the vehicle speed (coasting or downshifting) to minimize risk of collisions with vehicles and objects in front of the equipped vehicle.

Rear Impact Collision Mitigation - The two basic concepts proposed for this application are the following: transit bus-based systems to warn following driver(s) of potential collision (e.g., visual warning display on rear of bus); and impact injury and damage mitigation.

\section{State-of-the-Art}

There are few actual United States examples of currently operational IVI projects in transit. Most of the current work focuses on designing performance specifications and testing technologies in partnership with transit agencies, private corporations, and local universities. In 1997 in Houston, Texas, the first operational test of IVI was done to test collision avoidance technologies and demonstrate the effectiveness and safety of automated vehicles for transit. These test and performance specifications projects are related in more detail in the Application Examples section below.

\section{Challenges to SCAT Deployment}

In addition to research on the use of available technologies, there are some key non-technical issues currently under study by other U.S. DOT-funded partnerships. The National Highway Traffic Safety Administration (NHTSA) and Parsons Brinkerhoff are conducting a review of societal and institutional factors for IVI (1). The transportation community has raised concerns over the impacts of IVI services on society and potential barriers to deployment, including the general areas of product liability and the institutional challenges of enhancing the roadway infrastructure to better support intelligent vehicles. This study will seek to evaluate those deployment issues. A second 
project that has implications for IVI deployment is a benefits assessment of intelligent vehicles that will be conducted at the Volpe National Transportation Systems Center in Cambridge, Massachusetts, sponsored by the NHTSA and the U.S. DOT/Research and Special Programs Administration. This project will work on the development of proper methodologies and tools for estimating the effectiveness and potential benefits of IVI systems. It is important that any "lessons learned" from these projects be made available to the transit industry at large. As many previous high technology studies have indicated, the transit industry is reluctant to incorporate untried, untested technologies into its basic fleet operation. The very relevant concerns about cost and credibility require that transit be as informed as possible on all applications that might be useful in their operations, while best utilizing taxpayer resources across the transportation field.

\subsection{Costs for Recommended Projects}

- Based on the discussion in the previous section the following technologies are recommended for SCAT. Tables 15 through 22 tabulate costs for immediate, short-term and mid-term needs of SCAT.

-

$>$ GPS/DGPS AVL System in conjunction with a communication upgrade to voice and data

$>$ Electronic Fare Payment System

$>$ Smart Card Technology

$>$ Automatic Passenger Counters for $10 \%$ of the fleet

$>$ On Board Safety Components

- Silent Alarms as part of an upgrade to the AVL system

- CCTVs (at least one on each bus)

$>$ Bus Signal Priority

- For 100 of the busiest intersections

$>$ Advanced Traveler Information Systems

- Real time Information Systems through VMS and Annunciators on buses

- Itinerary Planning Systems as an upgrade to Trapeze and tie in with ATIS.

- Website

$>$ Vehicle Component Monitoring as part of an upgrade to the AVL system

$>$ Transit Accessibility Systems as part of an upgrade to the ATIS system

$>$ IVR - Telephone System as part of an upgrade to the ATIS system 
Table 15: Cost for Automatic Vehicle Location System

\begin{tabular}{|c|c|c|}
\hline System Description & Capital Investment ${ }^{1}$ & O\&M Annual Costs ${ }^{182}$ \\
\hline AVL-GPS for Vehicles & $\$ 228.00$ & $\$ 18.20$ \\
\hline GUI Interface & $\$ 100.00$ & $\$ 8.00$ \\
\hline Software and Integration & $\$ 880.00$ & $\$ 70.40$ \\
\hline Develop Database & $\$ 8.00$ & $\$ 0.60$ \\
\hline Servers $^{3}$ & $\$ 30.00$ & $\$ 2.40$ \\
\hline Testing and Acceptance & $\$ 8.0$ & - \\
\hline Communication High CDPD ${ }^{4}$ & $\$ 228.00$ & $\$ 148.20$ \\
\hline Training $^{5}$ & $\$ 74.10$ & - \\
\hline Engineering $^{6}$ & $\$ 342.34$ & - \\
\hline Total & $\$ 1,824.34$ & $\$ 229.64$ \\
\hline
\end{tabular}

Notes:

1. All costs are in $\$ 1000$

2. Operating and Maintenance costs are $8 \%$ of capital costs.

3. Assumes on server and one spare

4. Data communication infrastructure would need to be deployed for AVL implementation.

5. Training is assumed to be $5 \%$ of capital costs

6. Engineering includes design, deployment and support. Assumes $22 \%$ of capital costs.

Table 16: Cost for Electronic Fare Payment System

\begin{tabular}{|c|c|c|}
\hline System Description & Capital Investment' & O\&M Annual Costs ${ }^{182}$ \\
\hline On-board Ridership Sensor ${ }^{3}$ & $\$ 29.30$ & $\$ 2.30$ \\
\hline On-board Fare System ${ }^{3}$ & $\$ 23.40$ & $\$ 1.90$ \\
\hline COTS Software & $\$ 200.00$ & $\$ 16.00$ \\
\hline Customize EFP Software & $\$ 100.00$ & $\$ 8.00$ \\
\hline Develop Database & $\$ 8.00$ & $\$ 0.60$ \\
\hline Hardware at Center ${ }^{3}$ & $\$ 54.00$ & $\$ 4.30$ \\
\hline Testing and Acceptance & $\$ 8.0$ & - \\
\hline Communication High $\mathrm{CDPD}^{4}$ & - & $\$ 87.80$ \\
\hline Training $^{5}$ & $\$ 23.47$ & - \\
\hline Engineering ${ }^{6}$ & $\$ 108.44$ & - \\
\hline Total & $\$ 577.89$ & $\$ 122.33$ \\
\hline
\end{tabular}

Notes:

1. All costs are in $\$ 1000$

2. Operating and Maintenance costs are $8 \%$ of capital costs.

3. Deployed on all fixed route fleet.

4. Data communication infrastructure is anticipated to be installed during the AVL system deployment. These are just $O \& M$ costs.

5. Training is assumed to be $5 \%$ of capital costs

6. Engineering includes design, deployment and support. Assumes $22 \%$ of capital costs. 
Table 17: Cost for Automatic Passenger Counters

\begin{tabular}{|c|c|c|}
\hline System Description & Capital Investment & O\&M Annual Costs ${ }^{1 \& 2}$ \\
\hline On-board APC ${ }^{3}$ & $\$ 5.00$ & $\$ 0.40$ \\
\hline Software & $\$ 10.00$ & $\$ 0.80$ \\
\hline Develop Database & $\$ 8.00$ & $\$ 0.60$ \\
\hline Hardware at Center ${ }^{3}$ & $\$ 1.20$ & $\$ 4.30$ \\
\hline Testing and Acceptance & $\$ 5.0$ & - \\
\hline Communication Low CDPD & - & $\$ 1.30$ \\
\hline Training $^{5}$ & $\$ 1.46$ & - \\
\hline Engineering ${ }^{6}$ & $\$ 6.75$ & - \\
\hline Total & $\$ 35.95$ & $\$ 2.84$ \\
\hline
\end{tabular}

Notes:

1. All costs are in $\$ 1000$

2. Operating and Maintenance costs are $8 \%$ of capital costs.

3. Deployed on $10 \%$ of fixed route fleet.

4. Data communication infrastructure is anticipated to be installed during the AVL system deployment. These are just O\&M costs.

5. Training is assumed to be $5 \%$ of capital costs

6. Engineering includes design, deployment and support. Assumes $22 \%$ of capital costs.

Table 18: Costs for On-board Safety Features

\begin{tabular}{|l|c|c|}
\hline System Description & Capital Investment $^{1}$ & O\&M Annual Costs $^{1 \& 2}$ \\
\hline On-board Safety Sensor $^{3}$ & $\$ 9.00$ & $\$ 0.70$ \\
\hline On-board CCTV $^{3}$ & $\$ 225.00$ & $\$ 18.00$ \\
\hline COTS Software & $\$ 100.00$ & $\$ 8.00$ \\
\hline Develop Database & $\$ 8.00$ & $\$ 0.60$ \\
\hline Hardware at Facility & $\$ 4.10$ & $\$ 0.30$ \\
\hline Testing and Acceptance & $\$ 8.0$ & - \\
\hline Communication High CDPD & $\$ 135.00$ & $\$ 87.80$ \\
\hline Training $^{5}$ & $\$ 24.46$ & - \\
\hline Engineering $^{6}$ & $\$ 112.98$ & - \\
\hline Total $^{4}$ & $\$ \mathbf{6 0 2 . 0 8}$ & $\$ 114.72$ \\
\hline
\end{tabular}

Notes:

1. All costs are in $\$ 1000$

2. Operating and Maintenance costs are $8 \%$ of capital costs.

3. Deployed on all fixed route fleet.

4. Data communication infrastructure upgrade and O\&M costs.

5. Training is assumed to be $5 \%$ of capital costs

6. Engineering includes design, deployment and support. Assumes $22 \%$ of capital costs. 
Table 19: Cost for Bus Signal Priority

\begin{tabular}{|c|c|c|}
\hline System Description & Capital Investment' & O\&M Annual Costs ${ }^{182}$ \\
\hline On-board Processor ${ }^{3}$ & $\$ 29.30$ & $\$ 2.30$ \\
\hline Cell-based radio system ${ }^{3}$ & $\$ 14.90$ & $\$ 1.20$ \\
\hline Signal Software ${ }^{4}$ & $\$ 200.00$ & $\$ 16.00$ \\
\hline Signal Hardware ${ }^{4}$ & $\$ 200.00$ & $\$ 16.00$ \\
\hline Testing and Acceptance & $\$ 8.0$ & - \\
\hline Communication Low CDPD ${ }^{5}$ & - & $\$ 11.70$ \\
\hline Training $^{6}$ & $\$ 22.61$ & - \\
\hline Engineering $^{\top}$ & $\$ 104.44$ & - \\
\hline Total & $\$ 556.54$ & $\$ 43.70$ \\
\hline
\end{tabular}

Notes:

1. All costs are in $\$ 1000$

2. Operating and Maintenance costs are $8 \%$ of capital costs.

3. Deployed on all fixed route fleet.

4. Assumes at 100 intersections

5. Data communication infrastructure is anticipated to be installed during other projects. These are just O\&M costs.

6. Training is assumed to be $5 \%$ of capital costs

7. Engineering includes design, deployment and support. Assumes $22 \%$ of capital costs. 
Table 20: Cost for Advanced Traveler Information Systems (VMS and Annunciators)

\begin{tabular}{|c|c|c|}
\hline System Description & Capital Investment' & O\&M Annual Costs ${ }^{1 / 2}$ \\
\hline On-board Annunciators ${ }^{3}$ & $\$ 270.00$ & $\$ 21.60$ \\
\hline On-board VMS Small ${ }^{3}$ & $\$ 90,00$ & $\$ 7.20$ \\
\hline VMS Large (15 in County) ${ }^{4}$ & $\$ 60.00$ & $\$ 4.80$ \\
\hline VMS Small (100 in County) ${ }^{5}$ & $\$ 200.00$ & $\$ 16.00$ \\
\hline COTS Software ${ }^{6}$ & $\$ 200.00$ & $\$ 16.00$ \\
\hline Develop GUI ${ }^{7}$ & $\$ 100.00$ & $\$ 8.00$ \\
\hline Customize Software & $\$ 200.00$ & $\$ 16.00$ \\
\hline Develop Database for Vehicles & $\$ 8.00$ & $\$ 0.60$ \\
\hline Servers at Main Facility & $\$ 45.00$ & $\$ 3.60$ \\
\hline Testing and Acceptance & $\$ 8.00$ & - \\
\hline Communication High CDPD ${ }^{6}$ & $\$ 228.20$ & $\$ 148.20$ \\
\hline Training ${ }^{7}$ & $\$ 70.45$ & - \\
\hline Engineering $^{8}$ & $\$ 325.48$ & - \\
\hline Total & $\$ 1,734.48$ & $\$ 176.44$ \\
\hline
\end{tabular}

Notes:

1. All costs are in $\$ 1000$

2. Operating and Maintenance costs are $8 \%$ of capital costs.

3. Deployed on all fixed route fleet.

4. 4-Line Display

5. 2-Line Display

6. Data communication infrastructure would need to be deployed for ATIS implementation.

7. Training is assumed to be $5 \%$ of capital costs

8. Engineering includes design, deployment and support. Assumes $22 \%$ of capital costs.

Table 21: Cost for Advanced Traveler Information System (Website)

\begin{tabular}{|l|c|c|}
\hline System Description & Capital Investment & O\&M Annual Costs $^{182}$ \\
\hline Design of Website & $\$ 100.00$ & $\$ 8.00$ \\
\hline Customize Software & $\$ 100.00$ & $\$ 8.00$ \\
\hline Develop Database & $\$ 8.00$ & $\$ 0.60$ \\
\hline Testing and Acceptance & $\$ 8.0$ & - \\
\hline Training $^{3}$ & $\$ 10.80$ & - \\
\hline Engineering $^{4}$ & $\$ 49.90$ & - \\
\hline Total & $\mathbf{\$ 2 6 5 . 9 0}$ & $\$ \mathbf{8 . 6 4}$ \\
\hline
\end{tabular}

Notes:

1. All costs are in $\$ 1000$

2. Operating and Maintenance costs are $8 \%$ of capital costs.

3. Training is assumed to be $5 \%$ of capital costs

4. Engineering includes design, deployment and support. Assumes $22 \%$ of capital costs. 
Table 22: Cost for Advanced Traveler Information System (IVR)

\begin{tabular}{|l|c|c|}
\hline System Description & Capital Investment $^{\mathbf{1}}$ & O\&M Annual Costs $^{\mathbf{1 8 2}}$ \\
\hline COTS Software & $\$ 200.00$ & $\$ 16.00$ \\
\hline Develop IVR & $\$ 100.00$ & $\$ 8.00$ \\
\hline Develop Database & $\$ 8.00$ & $\$ 0.60$ \\
\hline Testing and Acceptance & $\$ 8.0$ & - \\
\hline Training $^{3}$ & $\$ 15.80$ & - \\
\hline Engineering $^{4}$ & $\$ 73.00$ & - \\
\hline Total & $\mathbf{\$ 3 8 9 . 0 0}$ & $\$ \mathbf{8 4 . 6 4}$ \\
\hline
\end{tabular}

Notes:

5. All costs are in $\$ 1000$

6. Operating and Maintenance costs are $8 \%$ of capital costs.

7. Training is assumed to be $5 \%$ of capital costs

8. Engineering includes design, deployment and support. Assumes $22 \%$ of capital costs.

\subsection{Characteristic Transit Agency Comments}

For confidentiality reasons, the transit agency and/or staff have not been mentioned in this report. The comments stated in this section were gathered via telephone interviews. Most transit agency staff have suggested to:

$>$ Do a competitive bid process

$>$ Back load payments

Language of contract should be carefully worded to indicate all expectations from vendor.

$>$ Huge chunk of payment $(20 \%)$ after delivery and acceptance. (This language should be in contract)

$>$ Terms of acceptance of product should be carefully outlined in contract

- The bids should be evaluated based both on costs and technical expertise

$>$ Training staff before system is installed is very important

$>$ Prepare dispatchers for the new system and get them on-board for expectations for system

\section{SAMPLE QUESTIONS to Transit AgenCIES}

1. What type of system do you have for your transit division?

2. Did you have any problems with installation?

3. How well is the system operating? Do you have any operating problems?

4. What if any are there current problems with the system?

5. What were your installation costs?

6. What are your capital costs?

7. What are your annual operating costs? 
8. What are your annual maintenance costs?

9. How much staff is required to operate the system?

10. How is the support from the vendor?

\section{AVL/CAD}

Trapeze@

$>$ It worked flawlessly. No problems. Up and running on time.

$>$ Trapeze doesn't handle paratransit very well but no program can really handle four transfer centers (this transit agency had a system that included 4 transfer centers in a small city with six zones).

$>$ Historically Trapeze support has been a weakness. Trapeze insists they have taken steps to correct that.

$>$ Installing AVL/GPS. Kiosks and dedicated telephone system (IVR Mentor Engineering) installed. Trapeze is going to integrate the different components into overall system. Trapeze is doing a lot of custom software for this particular transit agency.

$>$ Giro (Hastus) and Trapeze have bulk of the market share.

\section{Hastus ${ }^{8}$}

$>$ Transit agencies who have Hastus are very happy with it. Anticipate installation problems, but support is very good.

\section{Orbital@ (Hardware and Software)}

$>$ System works well, GPS tracks well. Orbital offered partnership to develop with this particular transit agency (since Orbital was just getting into AVL transit)

$>$ Get reports when buses are off-schedule/route. Easy to see. Had some bugs.

$>$ Communication was a problem. Only have one radio. One for data, one for voice would be better. When talking with just one, don't have data. Process from switching frequencies is weak link in their system. Could be fixed with more money. Wouldn't have problem with two separate radios.

$>$ Orbital software has module written by Teleride. Not same as current product, it is first version by Orbital. Very happy with system.

$>$ No major glitches. They are layering other systems on top. TSP will be installed soon.

$>$ Provides real time information.

$>$ Orbital collects a lot of data. Very happy with it.

$>$ Operating for three years but now is when benefit is really being seen. Data collection is biggest benefit of system.

$\checkmark$ System is incomplete. They put out an RFP. Orbital put up best proposal. They are now behind schedule on implementation. 
Orbital overestimated what they could do in proposal and how fast they could do it.

ASAS system: Automatic Sign Announcement System. Used through GPS to identify and call out station stops with audio and visual signs. Approx. $\$ 10-15000$ per bus. Requires a lot of up front work to establish routes and stops. Plotting longitude and latitude to program bus route to be announced. That's the biggest area needed. Need to put route profiles in and stops to be announced. Did this to help ADA community in addition to just passenger information. Systems allows visually or hearing impaired people to obtain information. Helpful to out of town visitors too. Hope for more open platforms, more common equipment so it can be expanded easily.

\section{Teleride(8)}

$>$ Scheduling in place by Teleride.

Since first to really install it, there were lots of bugs and changes.

$>$ Installation in 1994. Still have some problems but solutions are implemented. One problem is bus power fluctuation problems to cause equipment to lock up.

$>$ "Be cautious of Teleride. Conversations he has had not been pleasant. No personal experience though."

\section{Trimble}

$>$ Installed in 1991. Overall positive. Implementation was supposed to take 18 months, took $41 / 2$ years. But they were one of the first to do it. Had issues with Trimble on transit control head (needed to read data messages). Readout was not good. Needed to re-do which Trimble did. Generally reliable.

$>$ Benefits include on-time performance improvement. Improved by $40 \%$ in off-schedule right away. Went to mid $90 \%$ on-time.

$>$ Response time to security incidents is major improvement.

$>$ Know where bus is for emergencies for silent alarms.

$>$ Parameters are set up, once operator goes outside parameter, message can be sent to operator to remind them to get back on schedule. These functions, once done on street, now more efficient in dispatch center.

\section{Automatic Passenger Counters}

IN APC, the hardware is not as important as software. There are a number of issues with unbalanced loads and errors. Counters count operators getting on and off, people carrying babies, people riding through end of loop and so forth. Those are issues for software to handle, not hardware. Overhead optical is a newer option. Needs more than one censor to avoid double count. 
APC vendors measure accuracy by counting the people on and off. If that number is the same the system is said to be $100 \%$ accurate. However if 100 people board and 100 get off -yet the system says 10 people got on and 10 people got off - that is hardly $100 \%$ accurate.

\section{Urban Transportation Associates}

$>$ They have used it since 84 . System is accurate. The infrared beams do go out of alignment. Maintenance is important.

$>$ Accuracy is in the 90th percentile.

$>$ System does take a long time to process raw data to bring up to usable form.

$>$ Does not have user-friendly software, however they haven't upgraded since 1995. Since then there is new software available.

\section{INIT®}

$>$ Wanted bus and rail. Only bid for both was from INIT.

$>$ Seen some good, some bad. Bad is primarily due to miscommunication as a result of INIT's base being in Germany. There is nobody on-site to address issues.

$>$ Accuracy is very impressive $(96 \%$ or better accuracy ratings) but they have done no fullblown test. System works but not up and running fully yet. Very happy with the way INIT works.

$>$ INIT is competitively priced.

$>$ They talked with LA transit agency that had tested seven different firms. They found INIT to be best.

$>$ INIT uses IRIS overhead passive infrared sensor. Superior to all other types, apart from in certain light conditions it won't count right. Hard to predict errors, but errors are less overall.

\section{UTA®}

$>$ UTA uses side mounted active infrared. This is useful in single door buses, but not in double. Good system, but with a large load with people standing in front of sensor in a ${ }^{\text {"c }}$ crush load" of the bus, it won't work anymore. Therefore it may be best in small transit areas without crowded buses.

$>$ UTA had lowest price for a "turnkey." They also know requirements for US. Some foreignbased vendors do not understand the way US agencies want to use APC.

$>$ The fluctuations in power on US buses also caused problems for European companies. 


\section{Wardrop(3) and Microtronix@}

$>$ Wardrop does software. Microtronix does hardware. They use treadle mats. This system can't work with low floor buses because you need steps. In additional, the cost of adapting the wheelchair lifts is a concern.

$>$ Also, you can't take the system out and use on a new bus as it is designed for one bus and installed. This type is rarely used now.

\section{BUS ANNUNCIATORS}

DRI®

$>$ In addition to the "talking bus," they now have an add-on for AVL. Internet based system that can assimilate to phones. This system is available to public. Unlike traditional AVL, costly radios aren't needed. Radios can also hit a bandwidth limit, but this system cannot. Used in King County. System includes ability to set reminders when a bus is near and you can follow each bus and see arrival times online.

> Said they were connected to GPS. Very few maintenance problems. Drivers love it, no need to make ADA announcements. Works very well no problems.

$>$ Has been beneficial. Drivers are not nearly as distracted because of announcement, compliance virtually $100 \%$. Made their jobs easier. No problems with installation and have operated for seven years with no significant problems.

$>$ Biggest problem is getting drivers to use the system. Every bus automated, very few drivers use it because they claim it's disrupting and people don't want to hear it. May be related to size of system as bigger cities might have had announcements on buses before but this is a new concept. System is very reliable, few maintenance problems. When used the system does the job very well. Any new buses will have the system built in.

$>$ System is currently on 585 buses. It is ADA compliant and very effective for visitors. Overall it is a very functional system. Haven't had many problems other than maintenance that are mostly minor issues. Plan to add to the rest of the fleet soon to make all buses ADA compliant. In current system, drivers must put route in which forces drivers to use the system. In beginning some drivers didn't want to use but now most use it.

\section{Bus Signal Priority}

\section{Opticom®}

Opticom equipped 100 buses. Will use 25-30 for the test. See the outcome and then decide if they are going to expand the technology in the future. 10 intersections for the test. $3 \mathrm{M}$ response has not been the greatest. $3 \mathrm{M}$ was preempting signals instead of giving priority. Test is costing $\$ 40,000$ just for software changes and signal timing changes. Info System software.

$>$ Under construction. 110 intersections, both buses and emergency vehicle. They just have emitters and each intersection is programmed with controlled software. $\$ 2.8$ million 
anticipated costs for 110 intersections. Approximately 160 buses will be equipped. Local representative in Northwest is very responsive. Some problems have come up with phase selectors but they have been able to work it all out with the help of $3 \mathrm{M}$. 


\subsection{PEER SYSTEM EXPERIENCES}

The following examples of peer-system experiences were chosen based on the needed APTS technologies in table 11. These examples are meant to give SCAT an idea of how various APTS technologies are being implemented in different counties in the United States. They were derived from FTA publications, conversations with transit agencies and the publication (8).

\section{AVL in COLTS (County of Lakawanna Transit System)}

AVL technology is not merely limited to large agencies. COLTS (County of Lakawanna Transit System, a 32 bus system location in Scranton, Wilkes-Barre), which is similar in size to SCAT, has had an AutoTrac GPS-based system in operation since October 1994. They recently implemented an AVL system designed by AutoTrac, Inc. The "Fleetservice" system includes differential GPS, next-stop enunciation, on-time schedule monitoring, multiple mapping stations controlled by an area network, and a replay feature. The agency reports a sizeable increase in on-time performance; while the enunciators help with ADA compliance, and the AVL assists record keeping. The 32vehicle system was installed in only 9 months.

\section{AVL in Denver and Baltimore}

The Regional Transportation District (RTD) has had an operational AVL system on all of its 900 buses since the end of 1995. Although RTD is a much larger transit system than SCAT, because the AVL system can be applied to each bus, it can assist SCAT in the same ways on a smaller scale. AVL data are used to post real-time departure information on signs at the two downtown Mall stations. The system, which cost about $\$ 11$ million, includes an extensive CAD system. RTD feels that the AVL system gives them better control of the fleet, while freeing a number of on-street supervisors for other important duties. Schedule adherence has improved since the installation of AVL. Disabled buses can be located and serviced much more quickly. Also, one fewer person is necessary at the downtown Mall stations where many of their routes terminate. The agency also believes that AVL greatly heightens passenger safety. Police are now much more willing and able to respond to emergencies on buses, because the bus can now be located to within a few feet. Prior to the implementation of AVL, it could take a long time to locate the bus if it were off-route. In one situation, AVL greatly assisted RTD and the police in re-uniting a mother with her child, which she had left behind on a bus (8).

The Maryland Mass Transit Administration (MTA) has taken a phased approach to implementing its AVL system. The agency has purchased a DGPS system from Orbital along with a new radio system at an estimated cost of $\$ 15,000$ per bus, including the radio and related base station equipment. Among the agency's 868-vehicle fleet, 380 are AVL-equipped. The agency plans to equip the rest of the fleet by including AVL on all new vehicles it purchases. In December 1999, the agency was due to accept 65 new AVL-equipped vehicles at a cost of $\$ 8$ million. AVL data will 
be used in a real-time passenger information system that is under development. Current plans are for pre-trip information to be available over the phone (and perhaps later, the Internet) and for more limited en-route information at wayside electronic signs. When the system is fully on-line, MTA expects service provision to be more efficient by reducing the number of buses needed, while maintaining the current level of service. Although these savings are not expected until the fourth to sixth year of operation MTA expects AVL to save $\$ 2$ to 3 million per year by purchasing, operating and maintaining fewer vehicles. MTA also expects customers to notice improved service reliability, which they hope will result in increased ridership. Based on these expectations, AVL systems not only save transit agencies money, but could also improve ridership, which could be very beneficial for SCAT (8).

\section{Real-Time Traffic Information in San Francisco}

NextBus Information Systems Inc., a San Francisco Bay area company started three years ago, provides real-time traffic information to passengers. Utilizing NextBus on 20 buses, DART First State (Rehoboth Beach, Delaware) experienced a ridership increase of about 12 percent. The Fairfax CUE (City of Fairfax, Virginia) also uses NextBus to provide arrival times on the Internet and on electronic boards at major bus stops. The city paid $\$ 13,333$ for a global positioning unit per bus. Based on the success of the system, Arlington County is preparing to install the system on a Metrobus route. In Glendale, Calif., the NextBus system is used for detection as part of a BSP system. Since SCAT already has a functioning website, this system would be convenient for SCAT riders as they would be able to access timing information from the website. As can be seen increased passenger information convenience can lead to increased ridership.

\section{ATIS in Orange County, New York City and Miami}

The California DOT (Caltrans) and the FHWA are implementing a comprehensive traveler information system in Orange County, with two main components: Transit Probe and Travel TIP. The Transit Probe project is a $\$ 3$ million multi-jurisdictional transit demonstration project that will integrate transit and traffic management with ATIS to benefit transit agency operations and foster partnerships with traffic management agencies. It will provide the public transit rider with realtime transit information from which better-informed travel plans can be made. Transit Probe calls for GPS-equipped fixed-route buses traveling on their routes within Orange County to act as probes, and provide highly accurate bus location, speed and time data to a central dispatcher. SCAT would be able to implement this program by using any buses they have that are already equipped with GPS. Information such as arterial street and freeway traffic flow, incident data and transit information will be derived from GPS data. The general public will access the information via strategically located kiosks throughout Orange County. This program will allow SCAT the opportunity to communicate better with their passengers, by providing them with up to date transit information, and on-site customer service. They will also be able to use a trip itinerary feature at the kiosks to find the best transit route to their destination (8). 
TRANSCOM is jointly funded and operated by a consortium of highway and transit agencies throughout the greater New York City region. The consortium provides a focal point for the collection, fusion and distribution of real-time traveler information. Much of TRANSCOM's early efforts focused on creating a regional system architecture to provide all the participating agencies with timely access to important information. A recent TRANSCOM initiative is the Service Area Traveler Information Network (SATIN) project. To make traveler information more accessible to the general public, 20 information kiosks are being deployed in various public locations to provide information on traffic, roadway routing, service areas, transit schedules, weather, emergency services, tourism information, and park and ride conditions. Real-time traffic information is collected by TRANSCOM from the various operating agencies. SATIN kiosks provide access to information from all the transit agencies in the region relating to schedules, fares and reported delays. Golden Screens Interactive Technologies are providing the kiosks and the information distribution system. The overall development cost for the initial 20-kiosk system is roughly $\$ 1.3$ million, with the cost divided between TRANSCOM and Golden Screens under a public-private partnership arrangement. Golden Screens plans to access private sector financing to expand the kiosk network, using the initial kiosks to demonstrate the economic viability based on advertising revenues. Information displayed on the kiosk screen includes an advertising banner, a critical ingredient in Golden Screen's business case. Installation and one year of operations and maintenance support for each additional kiosk will cost between $\$ 20,000$ and $\$ 30,000$. Site selection criteria include pedestrian traffic of at least one million persons per year. A trip itinerary planning capability is in the process of being added. There is also interest in presenting more detailed real-time transit information, but the individual transit agencies must develop the capabilities to provide such information to TRANSCOM. Golden Screens is proposing to use the Internet for presenting transit information.

Tri-Rail operates 28 trips a day over a 72-mile corridor from Palm Beach to Miami, with 18 stations. Tri-Rail also operates shuttle buses for feeder service to and from several stations. Since the trips are relatively infrequent (roughly one per hour in each direction), many transit users arriving at the station already know the scheduled arrival time of the train they are planning to take. The difficulty for Tri-Rail is that it operates on only a single track shared with both Amtrak and freight services. Tri-Rail trains are sometimes shunted to a siding, disrupting the scheduled arrival times. Tri-Rail implemented the TrainTrac train/bus operation tracking and passenger information system during 1997 to provide transit users with station arrival times. TrainTrac was developed by Geofocus and provides on-train and in-bus computers using GPS receivers to monitor location and speed. TrainTrac frequently sends this information to the central dispatch system using $900 \mathrm{MHz}$ radio frequency communications. TrainTrac uses the Environmental Systems Research Institute, Inc. (ESRI) GIS platform to estimate station arrival times. Transit users access this information before they arrive at the station by calling a toll free number. Customer service agents use the GIS-based application to address questions. An Interactive Voice Response (IVR) system addresses the more 
routine questions about train or bus arrival time status. Transit users at the station view train arrival information on electronic message boards (light emitting diode displays with fully variable characters) installed on station platforms. Message boards display scrolling text messages (with an accompanying multi-lingual audio version) indicating the estimated arrival time for the next train, interspersed with public information. Future plans include new distribution channels and a Web site version. There is also the potential for distributing the message board displays through an alphanumeric pager service. This system is a great way for passengers, especially the visually impaired passengers, to access transit arrival information. It can be especially beneficial in the transportation-disadvantaged division of SCAT (8).1

\section{APC's in St Louis, LA County and Oregon}

APC is currently a short-term need for SCAT. It often comes packaged in with some other larger AVL systems, so a separate vendor may not be needed. In terms of APC technology, INIT is a frequently used vendor, although its European base of operations causes some problems. The BiState Development Agency (BSDA) of St. Louis, MO acquired APC for nine buses, one rail. Accuracy is very impressive $-96 \%$ or better accuracy ratings in initial testing. LA County Metro Transit Authority tested a variety of systems and found INIT to be the most reliable, while also being competitively priced. INIT uses IRIS overhead passive infrared sensor. Superior to all other types, apart from in certain light conditions it won't count right. Hard to predict errors, but errors are less overall.

UTA, the one US-based vendor, uses side mounted active infrared. This is useful in single door buses, but not in double. Good system, but with a large load with people standing in front of sensor in a "Crush load" of the bus, it won't work as effectively. UTA had lowest price for a "turnkey" system.

Microtronix also does APC hardware. They use treadle mats that can't work with low floor buses because you need steps. In additional, the cost of adapting the wheelchair lifts is a concern. Also, you can't take the system out and use on a new bus as it is designed for one bus and installed.

In APC, the hardware is not as important as software. There are a number of issues with unbalanced loads and errors. Counters count operators getting on and off, people carrying babies, people riding through end of loop and so forth. Those are issues for software to handle, not hardware. Wardrop, a widely used software vendor, is currently undergoing a demonstration project with the LAMTA.

Lane Transit District (LTD) in Eugene, Oregon, has been operating an MVT Automatic Passenger Counting system since 1989. The on-board APC equipment uses treadle switches. Under the contract awarded in November 1997, MVT will supply new equipment and upgrades for recently 
acquired buses. This system upgrade will eventually expand the number of APC-equipped buses to 22.

A CUTR study of 1998 revealed approximately 93 percent of the transit systems with APC experience are satisfied with the system's overall reliability and passenger information. A vast majority achieved accuracy levels of 90 percent and above, regardless of the APC counting technology employed.

\section{APCs in Portland}

Tri-Met's system became operational in 1982 and cost $\$ 4,500$ per APC. Location was determined by combining time with knowledge of schedule and layover points. Plans call for expanding the number of APCs to 20 percent of the fleet (currently on 80 of Tri-Met's 635 buses). Today, the new counters are much cheaper, costing only about $\$ 1,000$ per bus. The APC system has been linked to Tri-Met's AVL system, which provides more accurate location information than did the old method. Finally, there also have been advances in retrieving the data from the bus. Now, they are transmitted along with the AVL data over the reserved radio frequencies, although the data are still not used in real-time. Formerly, data was retrieved by special units, which collected the data automatically from each APC-equipped bus via an infrared link when the bus returned to the garage. Tri-Met states that the APCs provide easier and quicker access to passenger data and are less expensive than manual counting. Although APC is not an immediate need for SCAT, it is very useful in providing transit information, also with improved technology, and reduced costs it is now easily accessible to transit agencies (8).

\section{Traffic Signal Prioritization in Montgomery County and Seattle}

Traffic signal priority treatment for Ride-On buses is a key transit component of the Montgomery County, Maryland TMC. The Ride-On transit system includes 3,000 miles of roadways and 200 miles of critical traffic links. Unlike some signal priority schemes that involve direct communications between a bus' MDT and the traffic controller, the Montgomery County TMC receives location and on-time status information from vehicles, processes it and sends directions to the signal controller that: 1) priority is not necessary because the signal is already in or about to change to a green phase; 2) grant priority by extending the green phase, or; 3) deny priority based on a combination of signal phasing, vehicle schedule adherence, impact on traffic in the vicinity or known special events. The TMC has the capability to deny all priority requests based on traffic incidents such as special events, weather conditions, etc. When implemented, the County is considering integrating APC data into the signal priority algorithm so that an extended green cycle would only be granted if the transit vehicle were carrying a minimum load.

The Washington State DOT uses King County Metro's AVL data to implement traffic signal priority treatment. In addition to using bus location information to help determine when to grant priority, 
the agency uses the buses as probes to determine the effect of priority on traffic flow. Because the signal priority arrangement is so new, the agency is planning to hire a staff person to coordinate with local transit service providers to develop protocols, procedures and standards for signal priority. A primary concern of the Washington State DOT is the impact signal priority might have on the regular traffic flow (8).

\section{CAD Systems in Milwaukee}

The Milwaukee Department of Public Works' Transit Division has been operating a CAD system since 1992, when it began installation of a GPS AVL system on its entire vehicle fleet of buses and service vehicles. The CAD software performs schedule adherence, route adherence, manual schedule restoration and covert emergency messaging/microphone activation. This would be very useful in SCAT paratransit division because it would make sending messages in cases of emergency easier. A significant improvement in the system's original capabilities was a software upgrade that included route termini as time points, and allowing the CAD system and dispatchers to monitor layovers and departures. The schedule adherence component signals both drivers and dispatchers when a bus is running two minutes ahead or three minutes behind schedule. In the majority of instances, the information provided on the transit control head is sufficient to get the driver back on schedule (8).

\section{Transfer Connection Protection in Chicago}

In January 1999, the Regional Transportation Authority (RTA) began Phase I of a study to define functional requirements and specifications for a transfer connection protection system for all Chicago regional transit providers. Participating agencies include the Chicago Transit Authority (CTA-city transit bus and rail), Pace (suburban transit bus), Metra (commuter rail) and the Illinois Department of Transportation. The CTA and Pace are investigating transfer connection protection systems as components of their transit management systems. The RTA would like to determine the feasibility of using these developments as the foundation for creating inter-agency protection of transfer connections, including the Metra commuter rail service. The potential benefits of the RTA's transfer connection protection project include reducing transfer wait time for riders and improving the consistency of inter-carrier connections. The actual implementation of transfer connection protection by RTA is contingent upon implementation of AVL and necessary support systems at CTA, Pace and Metra (8).

\section{GIS in Portland and Corpus Christi}

An extensive survey and data collection program was recently undertaken in the Portland metropolitan district to obtain source data for a sophisticated travel demand modeling effort. By applying demographic data to a GIS representation of the land, residences and existing transportation systems, the Portland, Oregon Metropolitan Service District (Metro) is better able to recommend and help coordinate land use and transportation planning. 
A very specialized form of GIS is being evaluated in Corpus Christi, Texas for scheduling paratransit pick-ups. This system, called Autonomous Dial-A-Ride Transit (ADART), is not what one usually thinks of as GIS because there is no visible map from which a user makes decisions. In this case, the map is internal and the computer system itself makes the decisions. With the assistance of GIS, the network of computers in the vehicles selects the vehicle that can most efficiently handle each trip request and displays driving directions to each pick-up location to the selected vehicle's operator. This system can be applied to SCAT's paratransit division. It would increase efficiency, since the computer will make decisions based on individual trip-requests (8).

\section{Smart Card Fare Integration in Seattle and San Francisco}

Seattle's Central Puget Sound Regional Fare Coordination Project's contract was awarded in February 2000. It is estimated that approximately 500,000 to 1 million commuters (out of 1.5 million) will use the planned dual-interface cards on buses, electric trolleys, commuter rail trains and ferry terminals at full deployment. The beta-test is scheduled for mid-2001 and full system deployment is scheduled for early 2002. The scope of the project is based upon corporate and university campus programs participating. Planned deployment includes 2,300 card readers (fare transaction processors), 40 automatic re-value kiosks and 22 customer service terminals. The contractor will be responsible for providing additional card re-value methods under a 10-year service contract.

San Francisco's TransLink Project is in the demonstration phase. Phase I includes the issue of 20,000 cards. Full use of approximately 750,000 cards was expected in October 2001. TransLink has the potential to affect 1.5 million transit users in the Bay Area that utilize multiple modes including buses, light rail vehicles, the Bay Area Rapid Transit (BART) metro system, commuter rail and some ferries. The plan is to eventually deploy 550 add-value machines and 4,000 proximity card readers, and to have 400 point-of-sale locations, 50 operator pass sales offices and 500 handheld card readers for fare inspection. The current plan is to utilize the dual-interface card technology (8).

\section{TMCs in Houston and Phoenix}

TMC's for SCAT use are recommended to be operational within five to ten years. Although the application of TMC in Huston was done on a large scale, they can also be applied successfully on a smaller scale. Houston TranStar is a joint project of the City of Houston, the Metropolitan Transit Authority of Harris County, the Texas Department of Transportation and Harris County. These agencies recognized the importance of developing a multi-modal, cross-jurisdictional facility to effectively manage growing traffic congestion in this rapidly expanding region. Operated out of a 52,000 square-foot facility that was officially opened in April 1996, TranStar was designed to integrate all of the metropolitan Houston's transportation-related agencies at a single site. TranStar is responsible for the planning, design, operations and maintenance of transportation operations 
and emergency management operations within the Greater Houston Area. The service area encompasses 5,436 square miles with a population of four million. Metro bus dispatchers and Metro police use their fleet management consoles alongside the traffic operations staff. This setup provides Metro staff with direct visual access to the wall-mounted displays mapping traffic speeds and incidents, and monitors showing closed-circuit television feeds from 90 locations. Metro staff is able to use this real-time information to assist in managing its fleet, in addition to using data from the future AVL system it is planning. This breadth of information is augmented by the ability to communicate directly with traffic operations staff. TranStar staff anticipates that having Metro dispatchers relay incident reports from bus drivers throughout the transit service area, adding over 1,000 human sensors to the traffic surveillance system, will enhance overall incident detection. Incident response affecting all modes of transportation should be improved in the process. TranStar collects its traffic condition data primarily via tag readers mounted along freeways that pick up signals from the approximately 200,000 electronic tag-equipped vehicles (the tags are typically installed in vehicles for use at a number of automatic toll facilities throughout the area). As part of the USDOT Priority Corridor funding, TranStar is currently studying the possibility of installing tag readers on major arterials to calculate traffic condition information on surface streets as well as highways. As of October 1997, about five miles of the Hempstead Highway, a surface arterial running parallel to US 290 , was instrumented. This test will determine the feasibility of using electronic tag data in the stop-and-go environment of signalized surface streets as input to traffic speed calculations. If the test is successful, this information would augment vehicle location information that will be available when Metro implements their AVL system. Although MetroLift's para-transit operations center is not located at the TMC, TranStar is exploring the possibility of installing a communications link that would provide the para-transit operator with travel time and incident information (8).

Although the AZTech MMDI has not resulted in a physically joined transit and traffic operations center, it has created and extended the infrastructure to carry out many of the same functions of a joint TMC. Through the AZTech traffic information server and the telecommunications backbone that connects it with the various TMCs across the region, Phoenix Transit has access to traffic condition information from around the Phoenix area. The agency has its own AZTech workstation in its bus dispatch center that it can use to monitor traffic conditions that might affect operations. Its bus dispatch consoles can also be switched over to the AZTech system, if necessary. Available information includes traffic speed, incidents and video from numerous cameras. Phoenix Transit is using this information on a limited basis since it still needs training from the AZTech project team. With such training, transit dispatchers will be capable of being more proactive in using traffic information such as incidents and road closures to operate the bus system efficiently. The on-going development of AZTech's Roadway Closure and Restriction System (RCRS) will enable increased coordination between traffic and transit managers. The RCRS is a wide-area network that links most of the region's traffic operation centers and Phoenix Transit through highspeed wireline 
communications. The system will increasingly provide detailed traffic data on arterial streets on which public transit operates. The RCRS network will provide Phoenix Transit with more closed circuit television (CCTV) camera images for use in monitoring specific incidents. It is also designed to distribute information about incidents/accidents, road closures, lane restrictions and road maintenance ( 8 ).

\section{Automated Ridematching in Redmond/Seattle}

The Greater Redmond Transportation Management Association (GRTMA) has instituted an automated ridematching service for carpools and vanpools on the Internet that can also be used by individuals seeking a single ride. It is an employer-and map-based system. Anyone in King, Snohomish, Pierce, Kitsap and Island counties can register for the program. Individuals register themselves, providing an e-mail address, password and their home address or a nearby intersection. A map appears with the location indicated for verification by the registrant. The registrant's trip schedule is entered and the user has the ability to indicate preferences such as whether they wish to drive or ride, ride with smokers or non-smokers, or ride with employees of specific companies (only for employees of GRTMA member companies). A map showing the requestor's location and the location of potential matches are displayed on the screen together with their names and methods of contacting them. E-mails can be automatically sent to any of the persons on the list. Individuals can change their information at any time or remove themselves from the system if they have found satisfactory ridesharing arrangements, moved, changed jobs, etc. Every three months, e-mails are automatically sent to all registrants asking for their continued interest in participation. Non-respondents are automatically removed along with those responding in the negative. The system was essentially designed by the end users (company employees) who indicated the features they wanted in a rideshare program. Map Objects is the GIS. The database is accessed by SQL Server. Cost to date has been $\$ 278,000$. GRTMA owns the system and has licensed Puget Sound Systems Group to sell the system to other agencies. It is anticipated that the purchase price will be about $\$ 50,000$ to $\$ 100,000$. With the system residing on the Internet, the GRTMA has no involvement in day-to-day operations and virtually no system maintenance is required. A GRTMA staff person spends a small amount of time monitoring the Web site. The host computer (a PC server with a Windows NT operating system) is located at City of Redmond offices. GRTMA gets a system-generated report on utilization once a week. GRTMA is looking to add features such as bus schedules and fares (8). 


\subsection{APTS RECOMMENDATIONS FOR SCAT}

Based on the review of technologies and an assessment of challenges to SCAT deployment the following technologies are recommended for SCAT:

Immediate Needs (1-2 Years)

$>$ GPS/DGPS AVL System

$>$ Communication upgrade to voice and data in conjunction with the AVL System

$>$ Electronic Fare Payment System

$>$ Smart Card Technology

\section{Short-term Needs (1-5 Years)}

$>$ Automatic Passenger Counters for $10 \%$ of the fleet

$>$ On Board Safety Components

- Silent Alarms as part of an upgrade to the AVL system

- CCTVs (at least one on each bus)

$>$ Bus Signal Priority

- For 100 of the busiest intersections

$>$ Advanced Traveler Information Systems

- Real time Information Systems through VMS and Annunciators on buses

- Itinerary Planning Systems as an upgrade to Trapeze and tie in with ATIS.

- Website

$>$ Another communication system upgrade with ATIS and Safety Components project.

\section{Mid-term Needs (5-10 Years):}

$>$ Vehicle Component Monitoring as part of an upgrade to the AVL system

Transit Accessibility Systems as part of an upgrade to the ATIS system

$>$ IVR - Telephone System as part of an upgrade to the ATIS system

Even though the following technologies were outlined as possibilities in the Needs Assessment Memorandum, they are not recommended for deployment by SCAT. Transportation Demand Management technologies require multiple agency coordination and agreements with many service providers. Because of the intricate nature of deploying both TDM and Transit IVI technologies Countywide, and because of the current ridership trends, the following technologies might not be a cost effective option for SCAT to implement. 
Transportation Demand Management

- Automated Service Coordination

- Parking Management

$>$ Transit Intelligent Vehicle Initiative

Costs and staffing requirements were calculated for immediate and short-term needs projects only. Since technology is changing rapidly and costs fluctuate greatly, planning level costs for mid-term needs will not accurately reflect what the situation might be ten years from today. Table 23 summarizes costs for immediate and short-term needs projects. For detailed costs spreadsheet refer to Appendix A.

Table 23: Summary of Costs

\begin{tabular}{|l|c|c|}
\hline Technology & Capital Investment ${ }^{1}$ & O\&M Annual Costs $^{1}$ \\
\hline Immediate Needs & $\$ 1,824.34$ & $\$ 229.60$ \\
\hline AVL System & $\$ 577.89$ & $\$ 122.33$ \\
\hline EFP System & - & $\$ 380.00$ \\
\hline Staffing ${ }^{2}$ & $\mathbf{2 , 4 0 2 . 2 3}$ & $\$ 731.97$ \\
\hline Total & & \\
\hline Short-term Needs & $\$ 35.95$ & $\$ 2.84$ \\
\hline APCs & $\$ 602.08$ & $\$ 43.70$ \\
\hline On-board Safety Features & $\$ 556.54$ & $\$ 176.44$ \\
\hline Bus Signal Priority & $\$ 1,734.48$ & $\$ 8.64$ \\
\hline ATIS - VMS and Annunciators & $\$ 265.90$ & $\$ 8.64$ \\
\hline ATIS - Website & $\$ 389.00$ & $\$ 640.00$ \\
\hline ATIS - IVR & - & $\$ 994.98$ \\
\hline Staffing & $\$ 3,583.95$ & \\
\hline Total & & \\
\hline
\end{tabular}

Notes:

1. All costs are in $\$ 1000$

2. Recommended one manager at $\$ 120,000 /$ year (loaded rate), one assistant at $\$ 80,000 /$ year (loaded rate), one electronic repair technician at $\$ 50,000$ /year (loaded rate), one dispatcher with strong computer skills at $\$ 50,000 /$ year (loaded rate) and one planner to analyze data at $\$ 80,000 /$ year (loaded rate) for the SCAT Transit ITS Program.

3. Recommended one manager at $\$ 120,000 /$ year (loaded rate), two assistants at $\$ 80,000 /$ year (loaded rate), two electronic repair technicians at $\$ 50,000 /$ year (loaded rate), two dispatchers with strong computer skills at $\$ 50,000 /$ year (loaded rate) and two planners to analyze data at $\$ 80,000 /$ year (loaded rate) for the SCAT Transit ITS Program. 


\section{REFERENCES}

1. Federal Transit Administration website, Transit Intelligent Transportation Systems, http://www.fta.dot.gov/research/fleet/its/its.htm\#Documents. November 2001

2. Strategic Plan for Intelligent Vehicle-Highway Systems in the United States Report No: IVHS-AMER 92-3 Prepared by IVHS AMERICA May 20, 1992

3. Center for Urban Transportation (CUTR). "Sarasota Transportation Enhancement Plan (STEP)." Final Report. December 1999.

4. SCAT Website. http://www.co.sarasota.fl.us/public works scat/scat.asp January 2002.

5. Information provided via hardcopy via mail by the Transit Administrative Manager of SCAT in March 2002.

6. Information provided during Interview with SCAT in October 2001

7. Jaffe Engineering Website. http://www.jeng.com/florida/Default.htm January 2002

8. Federal Transit Administration website, Transit Intelligent Transportation Systems, http://www.fta.dot.gov/research/fleet/its/its.htm\#Documents. November 2001

9. US Department of Transportation Intelligent Transportation Systems website. http://www.itsdocs.fhwa.dot.gov//JPODOCS/REPTS_TE//13583.pdf, May 2002

10. Federal Transit Administration's office of safety and security website. http://transitsafety.volpe.dot.gov/Security/Security.asp, May 2002

11. http://www.access-board.gov/transit/html/vguide.htm 


\section{APPENDIX A (COST SPREADSHEETS)}


TABLE A.1 Automatic Vehicle Location (AVL) System for SCAT Note - costs are shown in thousands of dollars

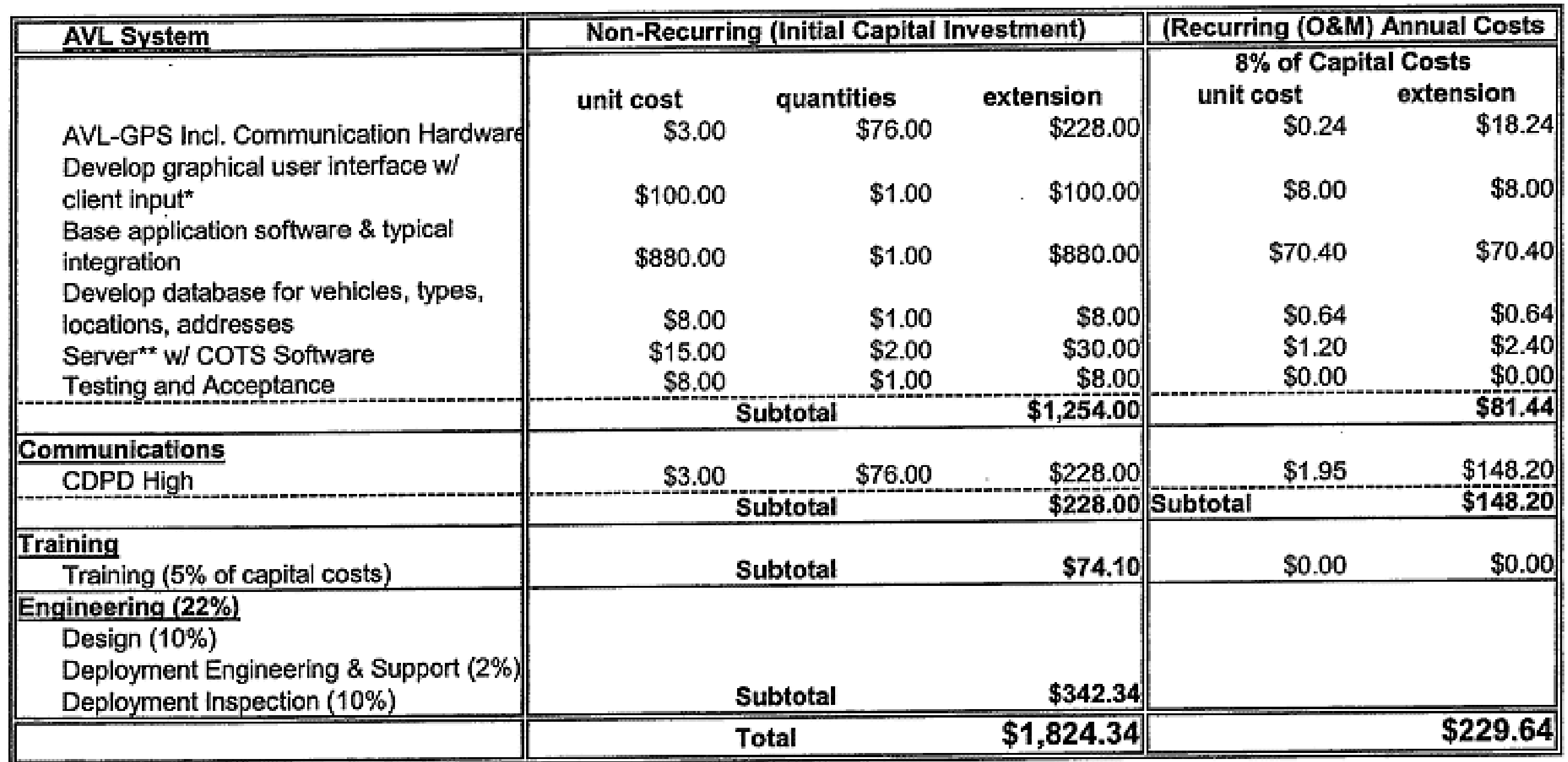

\section{Notes:}

"assume one server, one spare

this may change during the design phase 
TABLE A.2 Electronic Fare Payment (EFP) System for SCAT Note - costs are shown in thousands of dollars

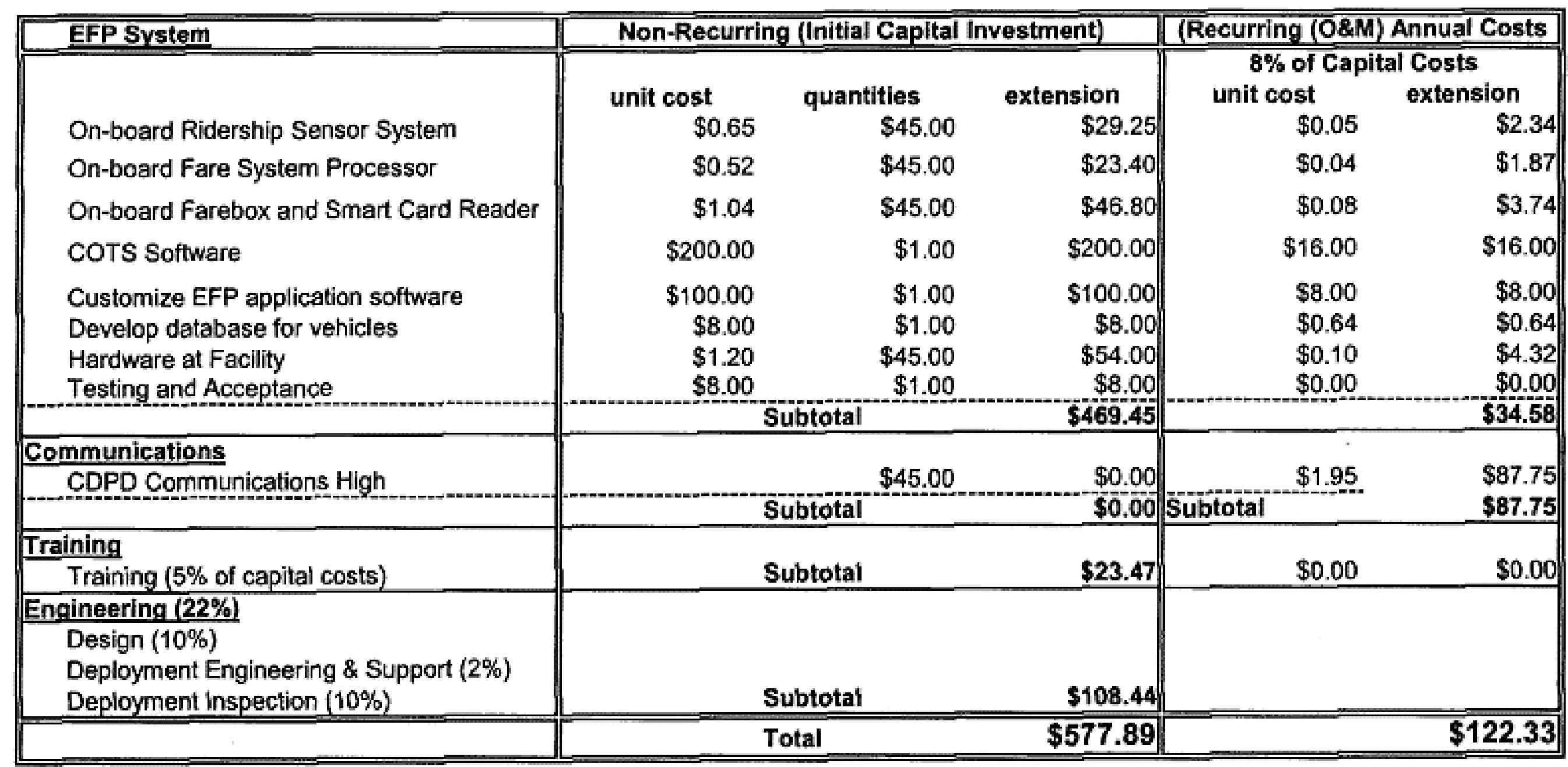


TABLE A.3 Automatic Passenger Counters (APCs) for SCAT Note - costs are shown in thousands of dollars

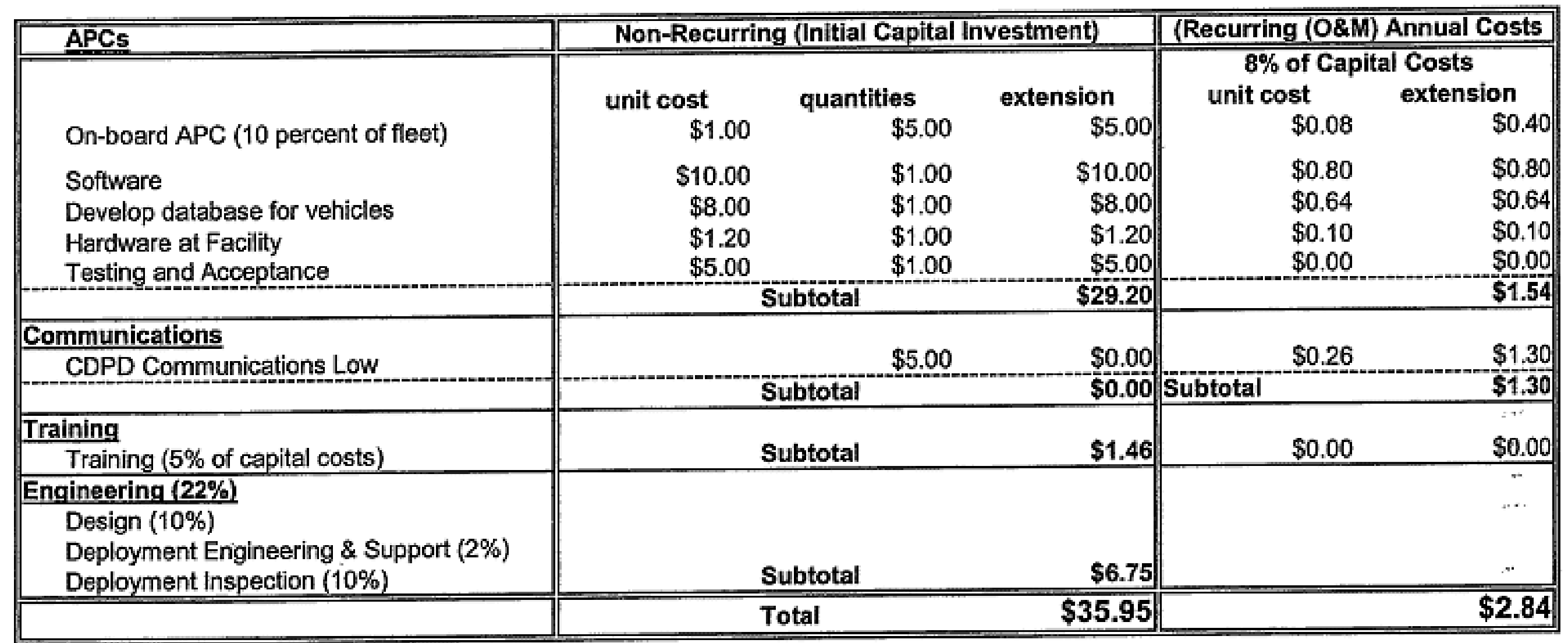


TABLE A.4 On-board Safety Features for SCAT

Note - costs are shown in thousands of dollars

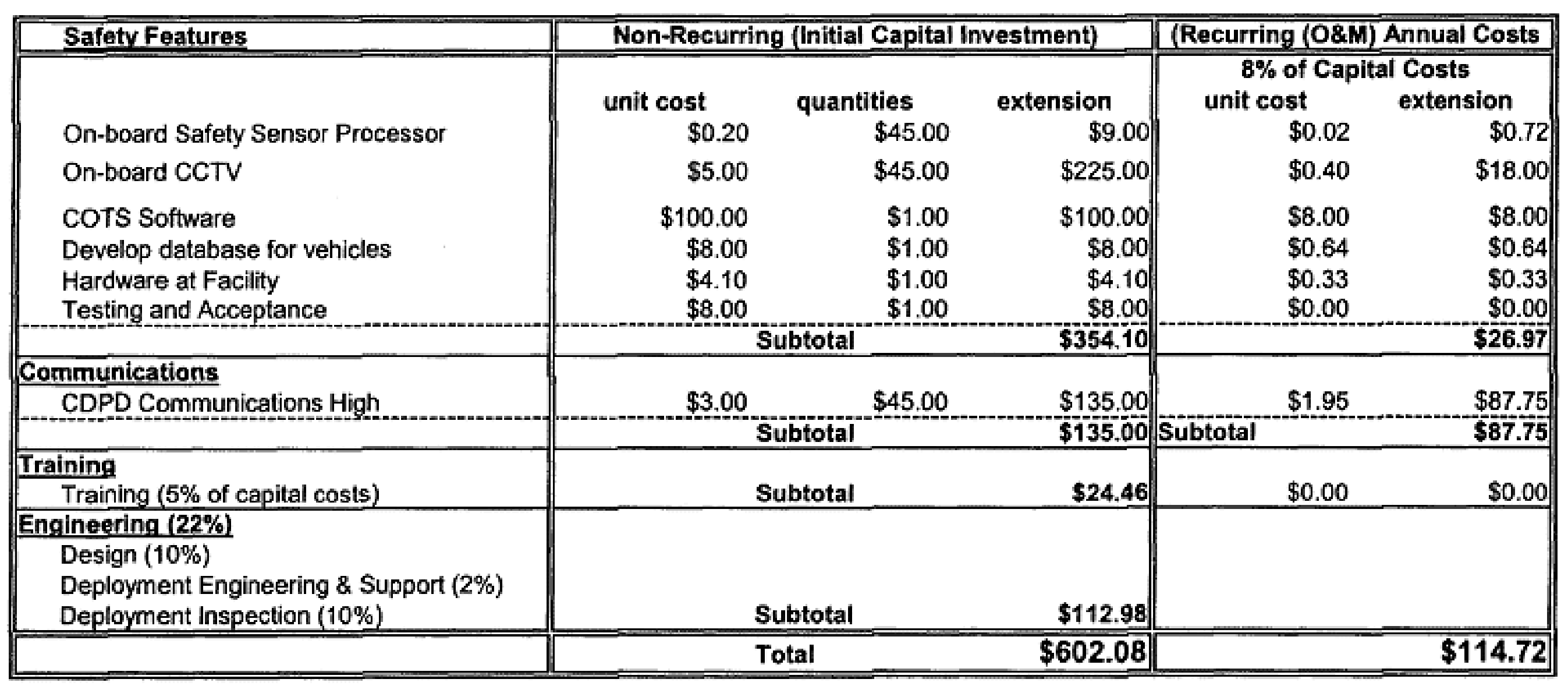


TABLE A.5 Bus Signal Priority (BSP) for SCAT

Note - costs are shown in thousands of dollars

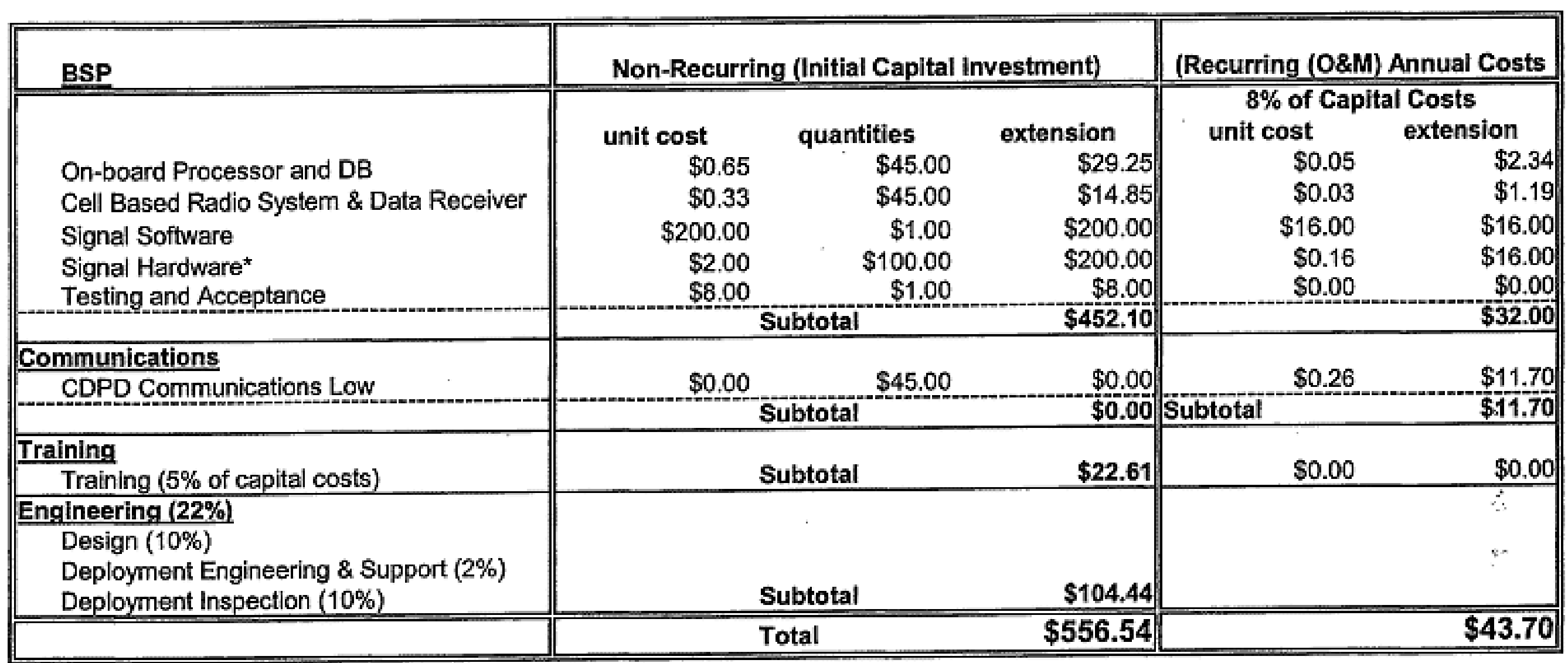

Notes:

* assumes 100 intersections 
TABLE A.6 Advanced Traveler Information Systems (VMS and Annunciators) Note - costs are shown in thousands of dollars

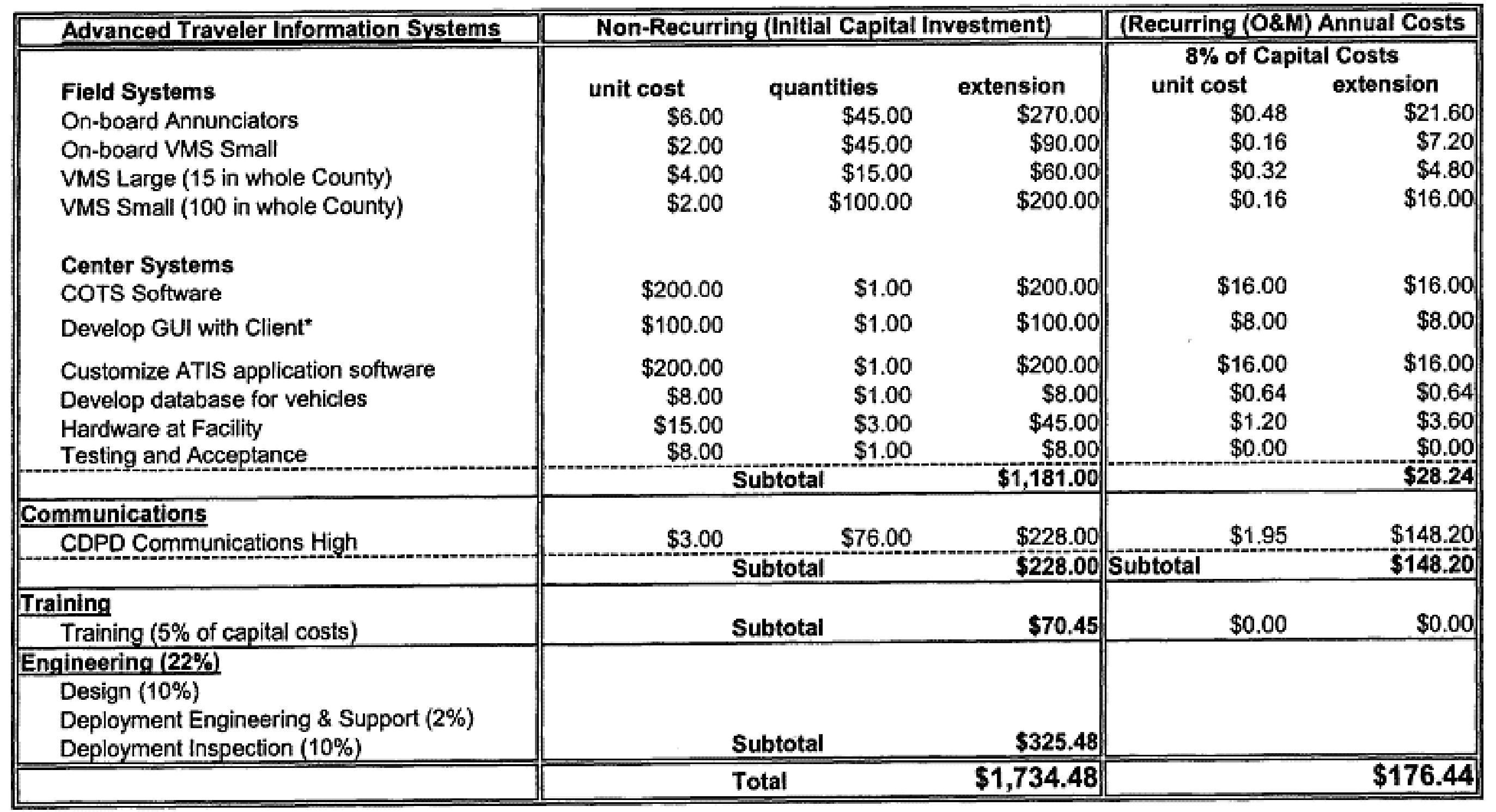

Notes:

* assumes GUI to run on workstation installed under other projects 
TABLE A.7 Advanced Traveler Information Systems (Website)

Note - costs are shown in thousands of dollars

\begin{tabular}{|c|c|c|c|c|c|}
\hline Website & \multicolumn{3}{|c|}{ Non-Recurring (Initial Capital Investment) } & \multicolumn{2}{|c|}{\begin{tabular}{|c|} 
(Recurring (O\&M) Annual Costs \\
$\mathbf{8 \%}$ of Capital Costs
\end{tabular}} \\
\hline $\begin{array}{l}\text { Website } \\
\text { Design of Website }\end{array}$ & $\begin{array}{l}\text { unit cost } \\
\qquad \$ 100.00\end{array}$ & $\begin{array}{l}\text { quantities } \\
\$ 1.00\end{array}$ & $\begin{array}{r}\text { extension } \\
\$ 100.00\end{array}$ & $\begin{array}{c}\text { unit cost } \\
\$ 8.00\end{array}$ & $\begin{array}{l}\text { extension } \\
\$ 8.00\end{array}$ \\
\hline $\begin{array}{l}\text { Customize software for website } \\
\text { Develop database for vehicles } \\
\text { Testing and Acceptance }\end{array}$ & $\begin{array}{r}\$ 100.00 \\
\$ 8.00 \\
\$ 8.00 \\
\end{array}$ & $\begin{array}{r}\$ 1.00 \\
\$ 1.00 \\
\$ 1.00 \\
\end{array}$ & $\begin{array}{r}\$ 100.00 \\
\$ 8.00 \\
\$ 8.00\end{array}$ & $\begin{array}{l}\$ 8.00 \\
\$ 0.64 \\
\$ 0.00\end{array}$ & $\begin{array}{l}\$ 8.00 \\
\$ 0.64 \\
\$ 0.00\end{array}$ \\
\hline & & Subtotal & $\$ 216.00$ & & $\$ 8.64$ \\
\hline $\begin{array}{l}\frac{\text { Communications }}{\text { CDPD Communications High }} \\
\text {. }\end{array}$ & & & $\$ 0.00$ & & $\$ 0.00$ \\
\hline & & Subtotal & $\$ 0.00$ & Subtotal & $\$ 0.00$ \\
\hline $\begin{array}{l}\text { Training } \\
\text { Training ( } 5 \% \text { of capital costs) }\end{array}$ & & Subtotal & $\$ 10.80$ & $\$ 0.00$ & $\$ 0.00$ \\
\hline $\begin{array}{l}\text { Engineering (22\%) } \\
\text { Design (10\%) } \\
\text { Deployment Engineering \& Support (2\%) } \\
\text { Deployment Inspection (10\%) } \\
\end{array}$ & & Subtotal & $\$ 49.90$ & & \\
\hline & & Total & $\$ 265.90$ & & $\$ 8.64$ \\
\hline
\end{tabular}


TABLE A.8 Advanced Traveler Information Systems (IVR)

Note - costs are shown in thousands of dollars

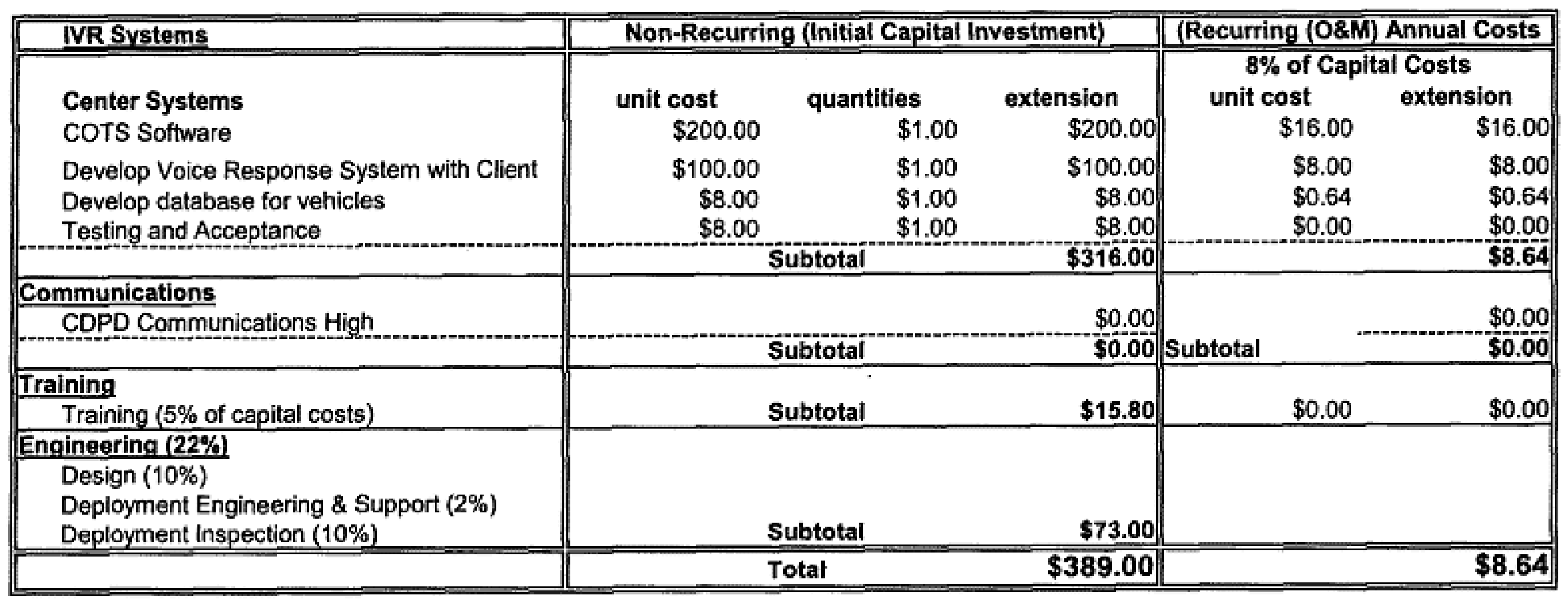

